WSRC-TR-94-0425

Publication Date: Sept. 1994

\title{
HYDROLOGIC BUDGET FOR A/M AREA, SAVANNAH RIVER SITE (U)
}

\author{
R.A. Hiergesell \\ J.S Haselow \\ D.G. Jackson \\ L. Ehrke
}

Westinghouse Savannah River Company

Savannah River Site

Aiken, SC 29808 


\section{DISCLAIMER}

This report was prepared as an account of work sponsored by an agency of the United States Government. Neither the United States Government nor any agency thereof, nor any of their employees, make any warranty, express or implied, or assumes any legal liability or responsibility for the accuracy, completeness, or usefulness of any information, apparatus, product, or process disclosed, or represents that its use would not infringe privately owned rights. Reference herein to any specific commercial product, process, or service by trade name, trademark, manufacturer, or otherwise does not necessarily constitute or imply its endorsement, recommendation, or favoring by the United States Government or any agency thereof. The views and opinions of authors expressed herein do not necessarily state or reflect those of the United States Government or any agency thereof. 


\section{DISCLAIMER}

Portions of this document may be illegible in electronic image products. Images are produced from the best available original document. 


\section{CONTENTS}

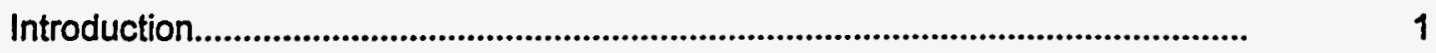

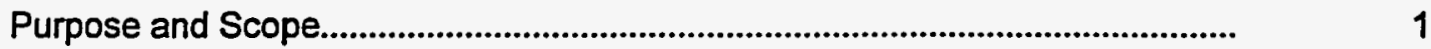

Hydrogeologic Setting.................................................................................................

Hydrostratigraphy..................................................................................... 1

General flow system characteristics...........................................................

Recharge...................................................................................................... 4

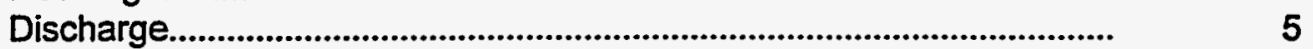

Numerical Model............................................................................................................

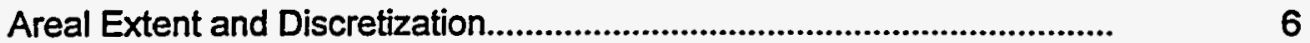

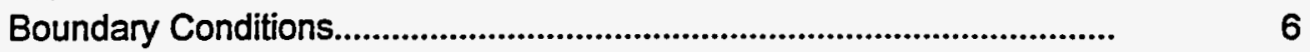

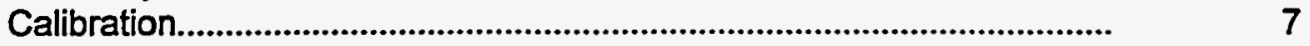

Hydrologic Budget.....................................................................................................

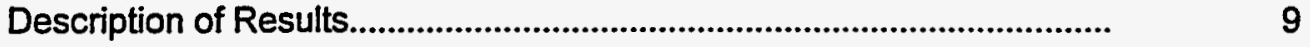

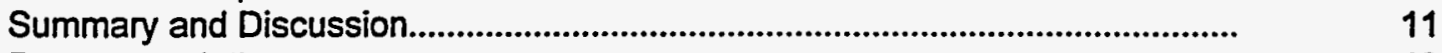

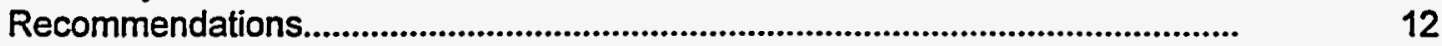

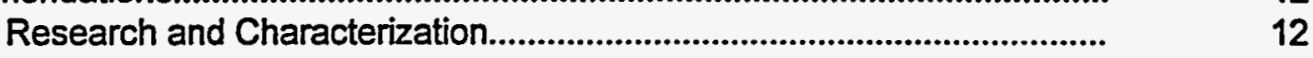

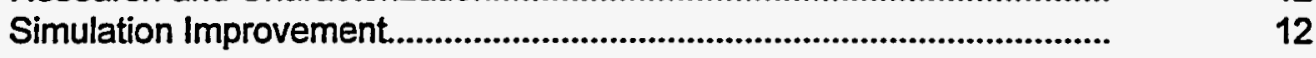

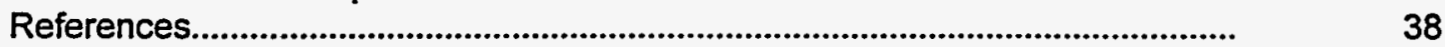

Appendix A. 
Figure 1.

Figure 2.

General conceptual model of hydrogeologic system...

Figure 3.

Figure 4.

Hydrostratigraphic units beneath AMM Area..

Hydrogeologic cross-section illustrating regional groundwater flow. $\quad 16$

Figure 5.

Water table configuration map..

Upper Lost Lake Aquifer Zone potentiometric map........................ 17

Lower Lost Lake Aquifer Zone potentiometric map......................... 18

Figure 6.

Figure 7.

Figure 8.

Figure 9.

Crouch Branch Aquifer potentiometric map...

Model grid mesh, Layer 1........................................................... 20

Model grid mesh, Layers 2-4..................................................... 21

Figure 10.

Correlation chart of model layers and hydrostratigraphic units...

Figure 11.

Recharge rates applied to uppermost layer in model grid.

Figure 12.

Model boundary conditions for Layer 1 .

Model boundary conditions for Layer 2 .. 


\section{INTRODUCTION}

In this investigation different components of the hydrologic budget for the groundwater flow system beneath the AMM Area were quantified. To accomplish this a regional groundwater flow model, previously calibrated to the groundwater flow system beneath the A/M Area, was used to generate flux terms which could then be used to quantify specific components of the hydrologic budget. The groundwater flow model utilized was developed by Intera, Inc. for the Environmental Restoration Department (Intera, 1993). The groundwater code MODFLOW (McDonald and Harbaugh, 1988) was utilized by Intera (1993) for the A/M Area regional groundwater model.

Sub-zones within the constructed model were defined in terms of groups of model nodes using the U.S. Geological Survey code ZONEBUDGET (Harbaugh, 1990). Cellby-cell flux terms generated by the groundwater model for each node were used as input to calculate the hydrologic budgets for each of the defined sub-zones. Results were tabulated both as actual groundwater fluxes and as normalized quantities to allow easy comparison of flux magnitudes for different sub-zones. In the process of defining sub-zones and calculating the flux magnitude for different components of the hydrologic flow system, the adequacy of the groundwater flow model in describing the actual flow system was better determined. In effect, quantification of flux terms from the groundwater model functioned as a "calibration tool" in that specific changes to the groundwater model which would enhance its calibration were identified and are described in this report.

\section{PURPOSE AND SCOPE}

The primary purpose of this investigation is to quantify the hydrologic budget terms in greater detail than was presented by Intera (1993). Secondary purposes of the investigation include providing a general assessment of the adequacy of representation of the natural flow system within the groundwater model and providing suggestions for calibration improvement and research needs that could enhance any future refinements of the A/M Area regional groundwater flow model.

The scope of this investigation was limited to the use of the existing groundwater flow model and ZONEBUDGET, to quantify the different components of the hydrologic budget for the AMM Area. As a result, the hydrologic budget terms reflect the conceptual model of the groundwater flow system as it is represented in this model. This conceptualization includes four layers and the distribution of hydraulic parameters that resulted from calibration of the model.

\section{HYDROGEOLOGIC SETTING}

\section{Hydrostratigraphy}

Several attempts have been made to define terminology to describe the hydrostratigraphic units at SRS. The nomenclature utilized in this report is that presented in Lewis and Aadland (WSRC-TR-92-355) and which appears in the 
generalized conceptual model in Figure 1. A detailed description of hydrostratigraphy of the AVM Areas is presented in that report and only a summary is provided herein.

SRS is located within the Southeastern Coastal Plain Hydrogeologic Province. Sediments of this province were deposited in environments ranging from fluvial deltaic to shallow marine and, in general, layers tend to thin in the direction of the ancestral coastline to the northwest. Beneath the AM Area, the hydrostratigraphic units are part of the Floridan-Midville Aquifer System. Individual units occurring beneath the A/M Area are, from shallowest to deepest, the Steed Pond Aquifer Unit, the Crouch Branch Confining Unit, the Crouch Branch Aquifer, the McQueen Branch Confining Unit, and the McQueen Branch Aquifer. Significant subdivisions of the Steed Pond Aquifer Unit and the Crouch Branch Confining Unit occur beneath the AM Areas and are illustrated in Figure 1. These include the division of the Steed Pond Aquifer into upper and lower aquifer units, the "M-Area" aquifer and the "Lost Lake" aquifer by the "green clay" confining zone. In the underlying Crouch Branch unit, the aquitard is separated into an "upper clay" and a "lower clay" by the transmissive "middle sand" zone. One significant subdivision is not indicated in Figure 1, the division of the Lost Lake aquifer zone into "upper" and "lower" subzones by a competent confining layer throughout much of the A/M Areas. This division of the Lost Lake aquifer zone into upper and lower sub-zones has significance in the model setup in that each is represented as a separate layer in the model. A pattern of thinning and eventual pinchout of confining units is present in the hydrostratigraphic units beneath the AM Areas. Several of the confining units pinch out at the northern portion of the AMM Areas, or just to the north of them. Where this happens, the aquifer units coalesce into single aquifers, as shown on Figure 1.

A summary of the hydrostratigraphic units beneath the A/M Areas, along with their stratigraphic and common names is presented in Figure 2. Detailed descriptions of the hydraulic characteristics of each of these units are presented in both Intera (1993) and in Lewis and Aadland (1992). These reports present the results of the various aquifer and laboratory tests that have been conducted to determine hydraulic conductivity in each of the units in numerous other investigations. A summary of these discussions is presented below.

The M-Area aquifer zone consists of sands and silty sands and forms the unit in which the upper surface of the saturated zone, or water table, occurs. It does not exist in a large portion of the study area, located to the south and extreme west, and is thickest in the northern part of the study area. In areas where the aquifer doesn't exist, it has either been eroded away by streams or else the water table drops off below the base of the hydrostratigraphic zone. The thickness of the $\mathrm{M}$-Area aquifer zone ranges from 0 to 55 $\mathrm{m}$. Hydraulic conductivity values from three multiple-well aquifer tests yielded hydraulic conductivity values that ranged from $2.4 \mathrm{E}-06$ to $4.5 \mathrm{E}-05 \mathrm{~m} / \mathrm{s}$. Results of 8 slug tests exhibited a range from $3.5 \mathrm{E}-08$ to $8.2 \mathrm{E}-05 \mathrm{~m} / \mathrm{s}$, but may reflect a bias toward lower permeabilities because rotary mud drilling was used to install the wells.

The Green Clay confining zone, which separates the M-Area aquifer zone from the Lost Lake aquifer zone, consists of sandy clay and clay. The thickness of this zone ranges from $0.6-8.5 \mathrm{~m}(2-28 \mathrm{ft}$.) in the A/M Areas and it likely pinches out in the subsurface just to the north of the area. Vertical hydraulic conductivity measurements for this clayey zone are from laboratory measurements conducted on core samples retrieved during 
well installations. In core material taken from the P-30 cluster well, measurements indicate that vertical hydraulic conductivity is on the order of $8 \mathrm{E}-10 \mathrm{~m} / \mathrm{s}$ (Bledsoe, 1988). This is comparable to lab measurements made on core material taken from the Green Clay at other parts of the SRS.

The "upper" and "lower" Lost Lake aquifer zones of the Steed Pond Aquifer consist of fine to coarse, moderately to well sorted, quartzitic sand. Thickness of both units, combined, ranges from $14-25 \mathrm{~m}$ ( 46 to $83 \mathrm{ft}$ ) beneath the A/M Areas. The upper and lower zones are separated throughout much of the $A / M$ area by a medial clay layer. At recovery well RWM-12, (northern part of the A/M area) this clay zone is approximately 2.4-3 $\mathrm{m}$ (8-10 ft.) thick and forms a competent hydraulic seal. Estimates of hydraulic parameters have been made for each zone separately. Pumping tests in the "upper" zone conducted at the Silverton Road Waste site indicate a range of hydraulic conductivities of $7.1 \mathrm{E}-5$ to $3.8 \mathrm{E}-4 \mathrm{~m} / \mathrm{s}$ (Geraghty \& Miller, 1987). Four specific capacity tests conducted in the upper zone yielded values of $1.35 \mathrm{E}-5$ to $7.51 \mathrm{E}-4 \mathrm{~m} / \mathrm{s}$ for hydraulic conductivity (Sirrine, 1987). For the "lower" zone, analyses from multiple-well tests at different localities in the A/M Area have yielded hydraulic conductivity values that fall within the range from $7.1 \mathrm{E}-5$ to $3.8 \mathrm{E}-4 \mathrm{~m} / \mathrm{s}$ and storativities within the range of $7.4 \mathrm{E}-5$ to $1.7 \mathrm{E}-4 \mathrm{~m} / \mathrm{s}$.

The Crouch Branch Confining Unit is subdivided into an "upper" and "lower" clay by a medial sand unit referred to as the "middle sand". The combined thickness of all three tunits range from 5.2-21.3 m ( 17 to $70 \mathrm{ft}$.) beneath the A/M Areas. Results of slug tests reported in Sirrine (1991) indicate the hydraulic conductivity of the "middle sand" ranges from $4.7 \mathrm{E}-6$ to $2.8 \mathrm{E}-4 \mathrm{~m} / \mathrm{s}$. Laboratory measurements of vertical hydraulic conductivity for the "lower" clay are reported to average $1.9 \mathrm{E}-9 \mathrm{~m} / \mathrm{s}$ (Bledsoe, 1988) while an average vertical hydraulic conductivity of the "upper clay" is reported as $3.4 \mathrm{E}-8 \mathrm{~m} / \mathrm{s}$ (Lewis and Aadland, 1992).

The Crouch Branch Aquifer is the lowest unit penetrated by monitor wells in the A/M Areas, and is the principle water producing aquifer beneath SRS. The thickness of this unit ranges from $46-55 \mathrm{~m}$ (152 to $180 \mathrm{ft}$.) beneath the AMM Areas and consists of poorly to well sorted, medium to coarse sand. One aquifer test described in Siple (1967) reports a transmissivity of $1.29 \mathrm{E}-2 \mathrm{~m}^{2} / \mathrm{d}$ and storativity of $3 \mathrm{E}-4$. Another aquifer test reported by Geraghty \& Miller (1987) reported a transmissivity of $3.5 \mathrm{E}-3 \mathrm{~m}^{2} / \mathrm{d}$ and storativity of $4.2 E-4$.

\section{General Flow System Characteristics}

The sequence of hydrostratigraphic layers beneath the A/M Area acts as a complex multi-aquifer groundwater system with vertical leakage occurring between layers. The uppermost aquifer is unconfined while deeper aquifers are semi-confined or confined. Deep dissection of the land surface by streams has cut into the upper hydrostratigraphic units of the groundwater flow system. Consequently, portions of the uppermost aquifer units can be isolated, horizontally, from the same aquifer units in other nearby areas. This incision of surface streams into the hydrostratigraphic units plays a major role in determining the groundwater flow patterns. 
A conceptual view of regional groundwater flow is shown in Figure 3. The basic premise of groundwater flow is that groundwater moves from areas of higher hydraulic

head to areas of lower hydraulic head. The hydraulic head at any given point within the groundwater system is indicated by the water level measured in a well that is open, or screened, to the system at that point.

In the uppermost aquifer, the water table elevation is a measure of the hydraulic head. Consequently, horizontal groundwater flow is in the direction from the high water table areas to the areas of low water table elevations. In general, the configuration of the water table mimics the surface topography, but in a subdued fashion. High water table areas correspond to the areas between perennial streams and low water table areas correspond to the areas along the perennial streams. Areas of higher hydraulic head elevations are areas where there is net groundwater recharge and the lower hydraulic head elevations are areas where there is net groundwater discharge.

Hydraulic head varies vertically within the groundwater flow system, hence vertical movement of groundwater also occurs. In recharge areas (areas of high hydraulic head) hydraulic head decreases with increasing depth and thus the vertical component of groundwater flow is downward. In discharge areas (areas of low hydraulic head) hydraulic head increases with increasing depth and thus the vertical component of flow is upward. Recharge areas within the study area are located primarily below the AM Area facilities and along the tributaries to Tims Branch which have outfalls at their heads. Discharge areas are located along Upper Three Runs Creek, Tims Branch, and Turner Branch located to the south and east, Hollow Creek and an unnamed creek to the north and west, and along the low, swampy, area which forms the Savannah River floodplain, southwest of the AM Area. In the shallower aquifers most of the water that recharges the groundwater system is eventually discharged to surface streams and wetlands, however, the deeper Crouch Branch Aquifer is more isolated, hydrologically, and thus is less influenced by vertical flow. In this aquifer groundwater flow is more predominantly horizontal.

The pattern of horizontal groundwater movement can be seen in Figures 4-7 which depict the configuration of the water table (M-Area Aquifer), and potentiometric surfaces for "upper" Lost Lake aquifer zone, "lower" Lost Lake aquifer zone, and the Crouch Branch Aquifers, respectively. Horizontal groundwater movement is perpendicular to the contour lines in these figures and in the direction of decreasing hydraulic head. The pattern is consistent with the concept of groundwater moving from recharge areas toward discharge areas, i.e. from areas of higher hydraulic head to areas of lower hydraulic head. The configuration of the water table and deeper potentiometric surfaces to the north and east of the AM Areas are not well known because there is practically no hydraulic head information to the north and east due, in part, to the fact that the site boundary occurs just north of the A/M Area.

\section{Recharge}

Recharge to the groundwater flow system occurs through the infiltration of precipitation into the soil and the eventual migration of some of this water through the vadose zone downward to the saturated zone. Since rainfall frequently occurs at rates that exceed the capacity of the soil to accept it, a large proportion runs off laterally to surface 
drainageways, and some is evaporated back into the atmosphere. Of that precipitation entering the soil zone, some is absorbed through plant roots and transpired back into the atmosphere. The water infiltrating the soil and not being transpired to the atmosphere moves downward through the vadose zone and eventually recharges the aquifer. The average annual precipitation, as measured in the AM areas, from 1952 to 1992 was $1.23 \mathrm{~m} / \mathrm{yr}$ (48.56 inches/yr). At the SRS, the amount of water eventually becoming available for groundwater recharge has been estimated at $1 / 3$ of the annual precipitation amount. This proportion is only a generalization and actual recharge will vary spatially and temporally based upon soil texture and slope, vegetative cover, antecedent soil moisture conditions, rainfall intensity and duration, as well as modifications made to the land surface by man (i.e. paving of parking lots and roads, etc).

In the AM Area some recharge to the water table also occurs along the surface drainageways having outfalls at their heads. At the outfalls process water is discharged continuously and thus the entire drainage reach loses water to the subsurface between the outfall point and the naturally occurring point of effluence on the stream. There are two such outfalls located on the southern side of the AMM Areas at the head of gullies which lead to Tims Branch. These are the A-1 and A-14 Outfalls. Water levels in the vicinity of the A-1 Outfall appear to confirm this source of recharge.

\section{Discharge}

Discharge from the groundwater system occurs through seepage of groundwater to streams and wetlands and from the pumping of wells. In the study area discharge occurs along Upper Three Runs Creek, Tims Branch, Turners Branch, and in the wetlands associated with these surface drainageways and in the wetlands located to the west of the AMM Areas.

Discharge from the groundwater system also occurs from the pumping of wells. There are two types of high capacity wells existing within the study area: production wells which are used for water supply, and recovery wells which are used to capture contaminated water for remediation purposes. In this study area there are 7 production wells which were installed at different times between 1951 and 1980 and which are screened in the deepest aquifer unit, the Crouch Branch Aquifer. The recovery wells were installed starting in the mid-1980's and continuing through the present.

\section{NUMERICAL MODEL}

The mathematical model implemented by Intera to simulate groundwater flow in the region beneath and surrounding the AMM Area is the U.S.G.S. code MODFLOW (McDonald and Harbaugh, 1988). This model is a finite-difference code and is probably the code most widely used for simulation of groundwater flow. MODFLOW can simulate confined and/or unconfined hydrogeologic settings and has a series of modules which allow it to simulate areal recharge, stream-aquifer interaction, well sources or sinks, evapotranspiration, drains, as well as head-dependent and constant head boundary conditions. The code can be set up to conduct steady-state simulations or to step through time in discrete time-steps. In the investigation by Intera, Inc. an initial steady- 
state simulation was conducted to establish calibrated initial model parameter values. The steady-state model was calibrated to hydraulic head data from 1985 . Selection of this time as the steady-state for the groundwater flow system corresponds to that time just prior to when the recovery well program was initiated. After this a transient simulation was conducted in which historical records of precipitation and pumping records from recovery wells were honored and the matching of simulated water levels with historical variations and trends of water level at specific wells was attempted.

\section{Areal Extent and Discretization}

The area simulated covers an area of approximately $8.13 \mathrm{E} 07 \mathrm{~m}^{2}$ and has the dimensions of $7.63 E 03 \mathrm{~m}$ by $1.07 E 04 \mathrm{~m}$. Within the horizontal plane each model layer is discretized using a 72 by 82 array of nodes, or 5904 nodes per layer. A variable nodal grid spacing was utilized to provide a greater degree of refinement in certain parts of the model domain. Horizontal dimensions of the cells surrounding each node vary from 76.2 $\mathrm{m}(250 \mathrm{ft}$ ) on a side, in the northeastern quadrant of the model area, to $304.8 \mathrm{~m}$ (1000 $f t)$ on a side.

MODFLOW allows the designation of inactive areas with in the model domain. The area south of Upper Three Runs Creek has been designated as an inactive zone in each of the 4 model layers and hydraulic heads are not calculated in this area. Although the model layers exist in this region, the area is of little interest because it is hydraulically isolated from the region of interest beneath the AM Areas. Additionally, in model Layer 1 (uppermost layer) an extensive area in the southern extent and an area along the western edge of the model domain are designated as inactive. The M-Area aquifer zone has been either been eroded away in these areas or the water table drops below the base of the zone, hence the inactive status in the model is justified. The model area and grid mesh for Layer 1 is illustrated in Figure 8, while the more extensive mesh for Layers $2-4$ is illustrated in Figure 9.

The groundwater flow system in the region around the A/M Area is composed of several aquifer and confining zones which have been previously described. Because of this, the groundwater flow model requires vertical discretization as well as horizontal discretization. Vertical discretization refers to the representation of the aquifer zones as discrete layers within the model, the thicknesses of these zones, and how that thickness varies laterally within each zone. This model is separated into 4 layers, corresponding to the M-Area aquifer zone, the upper Lost Lake aquifer zone, the lower Lost Lake aquifer zone, and the Crouch Branch aquifer, from shallowest to deepest. A generalized conceptual model of the hydrostratigraphic zones and how they correspond to the 4 model layers is shown in Fig. 10.

\section{Boundary Conditions}

The groundwater flow model attempts to duplicate natural flow conditions by imposing several types of boundary conditions. These are specified-flux, specified (constant) head, and head-dependent flux boundaries. The upper boundary of the model domain is a constant flux boundary, with the flux set equal to the amount of recharge reaching the groundwater flow system. In the steady state model, three different recharge rates were applied, ranging from $6.96 \mathrm{E}-04$ to $1.25 \mathrm{E}-04 \mathrm{~m} / \mathrm{day}(2.28 \mathrm{E}-03-4.11 \mathrm{E}-03 \mathrm{ft} / \mathrm{day})$. The 
areal distribution of these recharge rates over the model grid are shown in Fig. 11. MODFLOW allows this flux to be applied to the uppermost active layer at each node position.

Perimeter nodes of the model domain, by default, are no-flux boundaries, which are specified flux boundaries with flux $=0$ unless reassigned as a head dependent or constant head. The lower boundary of the model domain (bottom of Layer 4) is a constant flux boundary, where flux $=0$.

Boundary nodes in Layer 1 along the northern boundary, and the northern 16 nodes along the eastern edge of the domain are set as head-dependent flux boundaries. This is done using the GHB (General Head Boundary) Module in MODFLOW. All other perimeter nodes of Layer 1 are no-flux boundaries. There are 10 internal nodes within Layer 1 which are also given boundary status using the GHB Module. These correspond with the occurrence of Tims Branch in the area located approximately between the points where the outfall tributaries enter the main channel. The location of boundary nodes are shown in Fig. 12.

In Layer 2, head-dependent flux boundaries occur along parts of all four edges, and the locations of these are shown in Fig 13. The perimeter nodes are no-flux boundaries at all other locations. In the area of the domain immediately north of the "inactive area" the perimeter nodes are also set as head-dependent flux boundaries. This area corresponds to the occurrence of Upper Three Runs (UTR) Creek. Two other tributaries of UTR Creek are also set up as head-dependent flux boundaries, these being the lower reaches of Tims Branch and Turner Branch. Again, this is accomplished using the GHB Module. A curious feature of the Intera, Inc. model is the use of the GHB nodes for internal streams instead of the River Module option of MODFLOW which is more appropriate for simulation these hydrologic settings. The method of flux calculation is slightly different in each of these modules, but it only impacts the model results in areas where streams lose water to the aquifer, such as in Layer 1 below the outfalls.

Perimeter nodes in Layer 3 are primarily no-flux boundaries, except for portions of the northern and western edges which are set up as head-dependent flux boundaries. The extent of these boundaries are shown in Fig. 14.

In Layer 4, the deepest layer of the model, perimeter nodes are either no-flux or constant head type boundaries. The area along the southern edge of the domain and the area just north of the inactive area is a no-flux boundary, as is the westem half of the northern edge. The remaining perimeter nodes are designated as constant heads, and have been set equal to the hydraulic head of the Crouch Branch Aquifer at the location of each node. There are 7 extraction wells designated at different nodes in this model layer, these corresponding to location of water supply wells finished in this formation. The location of boundary types and of well nodes is illustrated in Fig. 15.

\section{Calibration}

The process of model calibration involves the matching of simulated hydraulic heads with field measurements of hydraulic heads by making iterative adjustments to input hydraulic parameters. This process was conducted in both the steady-state and 
transient simulations by Intera, inc. to achieve final calibration. The initial hydraulic parameter assignments were taken from an earlier groundwater flow model of the AM Area since that model had previously been calibrated. Additional adjustments were made to these parameter values because the new model is structurally different than the previous one. These differences relate primarily to grid refinement and to implementation of unconfined conditions model Layer 1 and an unconfined/confined formulation in model Layer 2. Following the initial steady-state calibration a transient calibration was performed by making additional adjustments to hydraulic parameters so that measured water level fluctuations and trends at specific wells could be better matched.

Hydraulic head data from wells throughout the A/M Area function as the primary target for calibration simulations. The quarterly measurements from the second quarter of 1985 were selected as the calibration targets for the steady-state calibration. A method of calculating the Mean Absolute Error (MAE) and the Root Mean Square Error (RMS) for residuals between modeled and measured hydraulic heads was conducted to allow recognition of input parameter adjustments that enhanced the calibration. It is stated in the report that discharge estimates to Upper Three Runs Creek were used as "a secondary calibration or performance measure", but this is nothing more than a verification that model results are in the "ballpark".

\section{HYDROLOGIC BUDGET}

Quantifying the hydrologic budget for a groundwater flow system involves describing the components of groundwater flow which correspond to recharge, discharge, inter-layer flow, and lateral inflow and outflow of the area of interest. In the natural setting, groundwater recharge and discharge fluxes vary temporally depending on variations in the timing and intensity of precipitation and the ability of the aquifers to store water. For the purposes of gaining an understanding of the groundwater flow system dynamics, the hydrologic budget can be estimated using "average" recharge conditions, meaning that a constant rate of recharge from precipitation is assumed. For hydrologic budgets calculated in this way, the groundwater flow system is assumed to be in the equilibrium, or steady-state condition, and net inflow is equal to net outflow. In this study, a steadystate hydrologic budget is quantified.

The results of the calibrated steady-state groundwater flow model developed by Intera, inc. was used to provide the flow terms needed to calculate the individual components of the hydrologic budget. The simulation flux terms calculated at each node were saved and utilized as input to the ZONEBUDGET code. One additional hydrologic budget term not previously identified is quantified in this investigation, outflow to wells in model Layer 4. Water supply pumping from this layer has been conducted relatively continuously for many years at the wellfields near the AMM Areas such that the groundwater flow system is regarded to be in a new equilibrium with pumping.

The basic strategy with ZONEBUDGET was to define sub-zones within the model domain which correspond to the components of the hydrologic budget. Since boundary conditions were established within the model to correspond to these components, ZONEBUDGET sub-zones were established to correspond to GHB or Constant Head 
(CH) node designations along the perimeter of the model domain. Also, the interior stream reaches of model Layers 1 and 2 that were simulated as GHB boundary nodes were subdivided into separate zones to allow for an assessment of model calibration in the vicinity of each of these sub-reaches.

The zone definition scheme resulted in establishment of 19 separate zones within all 4 layers. These zones are illustrated in Figs. 16-18, and are descibed below, layer by layer. Each layer is shown as a 72 by 82 array of numbers, with each number representing a node. The number at each node location represents the Zone Number of the sub-zone to which it is assigned. All nodes represented with a "9", for example in Fig. 16, represent ZONEBUDGET Zone 9.

Layer 1 is subdivided into 4 separate sub-zones. All Layer 1 nodes are assigned as Zone 1 unless they are reassigned with a different sub-zone number. Zone 9 is assigned to the perimeter nodes along the northern edge of the model layer, and these correspond to the nodes designated as GHB (or head-dependent) boundary nodes within model Layer 1. Zone 10 is located along the northern part of the eastern edge of the model domain, also corresponding to GHB node designations. Zone 8 is located in the interior of the layer and corresponds to those nodes simulated as "river nodes" using the GHB module. A large number of Layer 1 nodes are designated as "inactive" nodes within the groundwater model because of the limited extent of the water table, and consequently the model does not generate flux terms at those nodes. These inactive areas have no impact on ZONEBUDGET calculations, even though a Zone Number is assigned to nodes within those areas.

Layer 2 is subdivided into 8 separate sub-zones, as shown in Figure 17. All Layer 2 nodes are assigned as Zone 2 unless they are re-assigned with a different Zone Number. Zones 12,13,14, and 15 correspond to the GHB (or head-dependent) boundary nodes designated in model Layer 2 . These are located along the eastern, northern, western, and southwest edges of the model domain, respectively. Interior streams in this layer are designated as head dependent boundaries in the GHB module. Zone Numbers 5, 6, and 7 were assigned to Upper Three Runs Creek, Tims Branch, and Turner Branch, respectively.

Layer 3 is subdivided into 3 separate sub-zones, as shown in Figure 18. All Layer 3 nodes are assigned as Zone 3 unless they are re-assigned with a different Zone Number. Zones 16 and 17 are designated along the northern and western edges of the model domain and correspond to those nodes designated as GHB (or head-dependent) boundary nodes within model Layer 3.

Layer 4 is subdivided into 4 separate sub-zones, as shown in Figure 19. All Layer 4 nodes have been assigned as Zone 4 unless they are re-assigned with a different Zone Number. Zones 18, 19, and 20 correspond to those nodes designated as Constant Head boundary nodes in model Layer 4.

\section{Description of Results}

Utilizing the MODFLOW output file, ZONEBUDGET calculated the flux terms for each of the 19 zones described above. These results are presented in the individual Zone 
Summary sheets provided in APPENDIX A. The summary sheets identify the IN flux and OUT flux terms for each sub-zone. Flux terms are itemized for the following components: Constant Heads, Wells, Recharge, Head Dependent Boundaries, and any other sub-zones which potentially could exchange flux with the sub-zone of interest. All flux terms are expressed in units of $\mathrm{ft}^{3} / \mathrm{day}$.

To more easily visualize the magnitude of flow components relative to one another the flux terms have been normalized. This is expressed in two ways, first as a percentage of the total input or total output term for that sub-zone and, secondly, as a percentage of the total areal recharge entering the model area $\left(2,888,499 \mathrm{ft}^{3} /\right.$ day). Any term can be used to normalize the individual flux terms, however, it is more relevant to use a term that has hydrologic significance, hence the use of the total recharge quantity. These two terms are listed in the columns to the right of the Flux term on the ZONEBUDGET summary sheets for each sub-zone, which are found in Appendix $A$.

A schematic diagram presented in Figure 20 shows the groundwater fiux terms, in $\mathrm{ft}^{3} /$ day, between layers and between each layer and its boundaries and internal streams. A similar diagram is shown in Figure 21 which shows the same flux terms as a percentage of the total recharge term, as described above. All fluxes and normalized fluxes shown in these diagrams are based upon the values found in the individual Zone summaries.

The use of flux terms normalized to total areal recharge allows some generalizations regarding the relative magnitudes of flux terms. These are as follows:

Two thirds of total areal recharge occurs in Layer 2, one third occurs in Layer 1 . This distribution is related to the proportion of surface area of each layer within which the water table occurs. An amount almost equal to Layer 1 recharge leaks downward from Layer 1 to Layer 2 . This implies that groundwater movement within this zone is predominantly downward and that lateral inflow and outflow are relatively small components of the Layer 1 hydrologic budget. Layer 1 recharge occurs in an area away from the major streams of the study area, Upper Three Runs Creek and its tributaries.

The two largest non-recharge components of the hydrologic budget are leakage terms associated with Layer 2. These are vertical downward leakage from Layer 2 to Layer 3 and discharge to surface streams, respectively. Discharge to surface streams in model Layer 2 occurs in the areas where the major streams have incised model Layer 2, and thus where water table conditions exist in Layer 2 . The fact that the largest groundwater flux terms occur as outflow from Layer 2 is not surprising since Layer 2 receives $2 / 3$ of the total areal recharge and an amount almost equal to Layer 1 recharge from vertical downward leakage from Layer 1 . The general pattern of groundwater movement in Layer 2, therefore, is laterally to discharge zones along UTR Creek and its tributaries and downward to Layer 3.

Vertical downward leakage from Layer 2 to Layer 3 occurs in the area beneath the topographic uplands and away from the streams. Generally, this area is located beneath active Layer 1 cells. A flux equal to two thirds of the vertical downward leakage from Layer 2 to Layer 3 discharges upward, from Layer 3 to Layer 2, in the vicinity of UTR and the lower reaches of its tributaries. This upward flux beneath the surface streams is 
verified by the Zone 5 and Zone 15 flux summaries which indicate that inflow occurs to these zones from Layer 3.

Half of the amount leaking downward from Layer 2 to 3 leaks downward from Layer 3 to Layer 4. Again, this leakage occurs in the area beneath the topographic uplands, where Layer 1 cells are active. A flux equal to approximately 80 percent of leakage from layer three to Layer 4 flows vertically upward from Layer 4 to Layer 3 in the vicinity of UTR and the lower reaches of its tributaries. Although the fluxes summarized in this report accurately reflect the groundwater model results, the fact that groundwater flux entering Layer 4 from above is somewhat higher than was expected indicates that additional finetuning in model calibration would be beneficial.

\section{SUMMARY AND DISCUSSION}

In this investigation, the hydrologic budget of the AM Areas has been quantified. To accomplish this the most recent and up-to-date groundwater flow model of the area was used to generate flux terms which could then be utilized by the U.S.G.S code ZONEBUDGET to calculate fluxes for meaningful sub-zones of the groundwater flow model. Nineteen sub-zones were defined to correspond to groundwater inflow and outflow, leakage between hydrostratigraphic layers, and discharge to specific stream reaches. In particular, the subdivision of stream reaches allows for a more detailed analysis of the hydrologic budget, and eventually, should facilitate improvement in model calibration in the vicinity of these streams.

Results of the hydrologic budget analysis indicate that the groundwater flow patterns beneath the AMM Areas conform to the general concept of regional flow. In this conceptualization there is a relatively large component of vertical downward flow in the areas of higher hydraulic head, those areas between the main drainageways, and a relatively large component of vertical upward flow in the discharge areas along the more deeply incised streams. Between these areas the movement of groundwater is predominantly in the horizontal direction in the direction toward the discharge areas.

Quantification of the flux terms for the nineteen sub-zones has allowed a more detailed breakdown of the hydrologic budget than has been reported elsewhere. The specific groundwater flux terms are listed in the tables in Appendix A and shown schematically for each of the four model layers in Figures 22-25.

A detailed look at the hydrologic budget terms can serve to identify portions of the groundwater flow model which can be better calibrated. Previous model calibration efforts focused on matching simulated water levels with water levels observed in wells in the recharge areas of the model domain and less attention was given to matching simulated groundwater discharges along streams with stream baseflow gain measurements. Although the calibration appears to be adequate in areas where wells exist, some improvement can be realized in the areas along UTR Creek and the lower reaches of the tributaries to UTR Creek where it appears that the model underestimates the groundwater discharge these drainageways. Additionally, groundwater flux across the Crouch Branch Confining Unit, in both the upward and downward directions, 
appears to be overestimated by the model. Any future refinements to model calibration should address these discrepancies.

\section{RECOMMENDATIONS}

\section{Research and Characterization}

Improvement in the understanding of the groundwater flow system beneath the AM Areas can be realized by continuing a parallel path approach: continue with efforts in characterization of the groundwater flow system, including research into processes which are not well understood, and improvement of numerical simulations of the subsurface, incorporating results of the former as they become available. The following recommendations are possible approaches for consideration in each of these paths:

- Continue aquifer testing to obtain estimates of hydraulic parameters.

- Measure streamflows to characterize baseflow gains associated with specific stream reaches, including Tims Branch, Turner Branch and possibly Hollow Creek, north of SRS.

- Attempt to obtain water level and potentiometric information in the area of greatest uncertainty, north and east of AM Areas. Consider installation of new wells.

- Continue research to refine estimates of spatial and temporal variation in recharge.

- Quantification of evapotranspiration from wetland areas along streams and to the west of the AMM Areas.

\section{Modeling, Steady-State Simulation Improvement}

- Recalibrate steady-state model using constant fluxes at stream nodes along Tims Branch and Turner Branch that are consistent with baseflow gain measurements from along these stream reaches.

- Make adjustments to model parameters to increase groundwater discharge to UTR Creek and make it consistent with long-term baseflow gain data from stream gauging stations.

- Make adjustments to model parameters to decrease vertical leakage across the Crouch Branch Confining Unit. Such an adjustment would likely increase groundwater discharge to UTR Creek, as mentioned in previous item.

- Convert existing GHB model nodes to RIVER nodes along drainageways to represent stream reaches in a more appropriate way. (GHB nodes have inappropriately been used). 
- Designate additional RIVER nodes along the upper reaches of those drainageways having outfalls at their heads. This mechanism would allow a proper accounting of seepage to the water table (recharge) along these reaches.

- Adjust areal recharge to reflect a more reasonable spatial distribution, ie, no recharge. over stream nodes, less recharge to nodes with steep soil slopes, no recharge to nodes under parking lots, etc.

- Invoke the EVT package to simulate evapotranspiration losses from wetlands. 


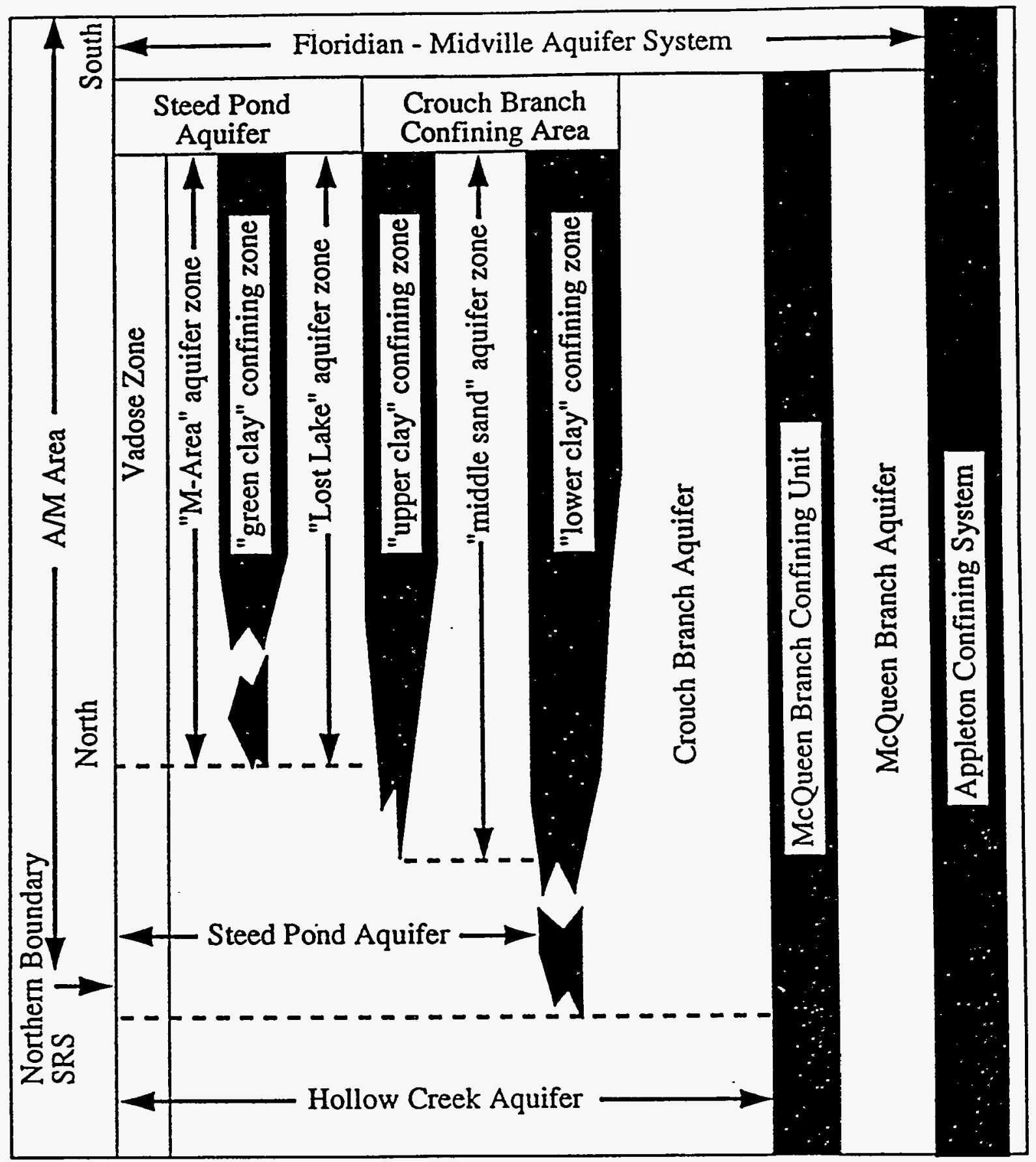

93X2756.03.AIL

Fig. 1 General conceptual model of hydrogeologic system 


\begin{tabular}{|c|c|c|}
\hline $\begin{array}{l}\text { phodrostratigrapho } \\
\text { pont }\end{array}$ & Strat graphic Unit & Gommonusagem \\
\hline M-Area Aquifer Zone & $\begin{array}{l}\text { McBean Member of } \\
\text { Santee Formation }\end{array}$ & McBean \\
\hline Green Clay Confining Zone & $\begin{array}{l}\text { Caw Caw Member of Santee } \\
\text { Formation }\end{array}$ & Green Clay \\
\hline Upper Lost Lake Aquifer Zone & Congaree Formation & Upper Congaree \\
\hline Unspecified & $\begin{array}{l}\text { Clay zone of the Fourmile } \\
\text { Member of the Fishbume } \\
\text { Formation }\end{array}$ & Lower Congaree \\
\hline Lower Lost Lake Aquifer Zone & $\begin{array}{l}\text { Fourmile Member of } \\
\text { Fishbume Formation }\end{array}$ & Lower Congaree \\
\hline $\begin{array}{l}\text { Upper Clay Conf. Zone } \\
\text { Middle Sand Aq. Zone } \\
\text { Lower Clay Conf. Zone }\end{array}$ & Ellenton Formation & Ellenton \\
\hline Crouch Branch Aquifer & $\begin{array}{l}\text { Steel Creek Member of the } \\
\text { Peedee Formation and Black } \\
\text { Creek Formation }\end{array}$ & Tuscaloosa \\
\hline $\begin{array}{l}\text { McQueen Branch Confining } \\
\text { Zone }\end{array}$ & Black Creek Formation & Tuscaloosa \\
\hline
\end{tabular}

Figure 2 Hydrostratigraphic Units beneath AM Area 


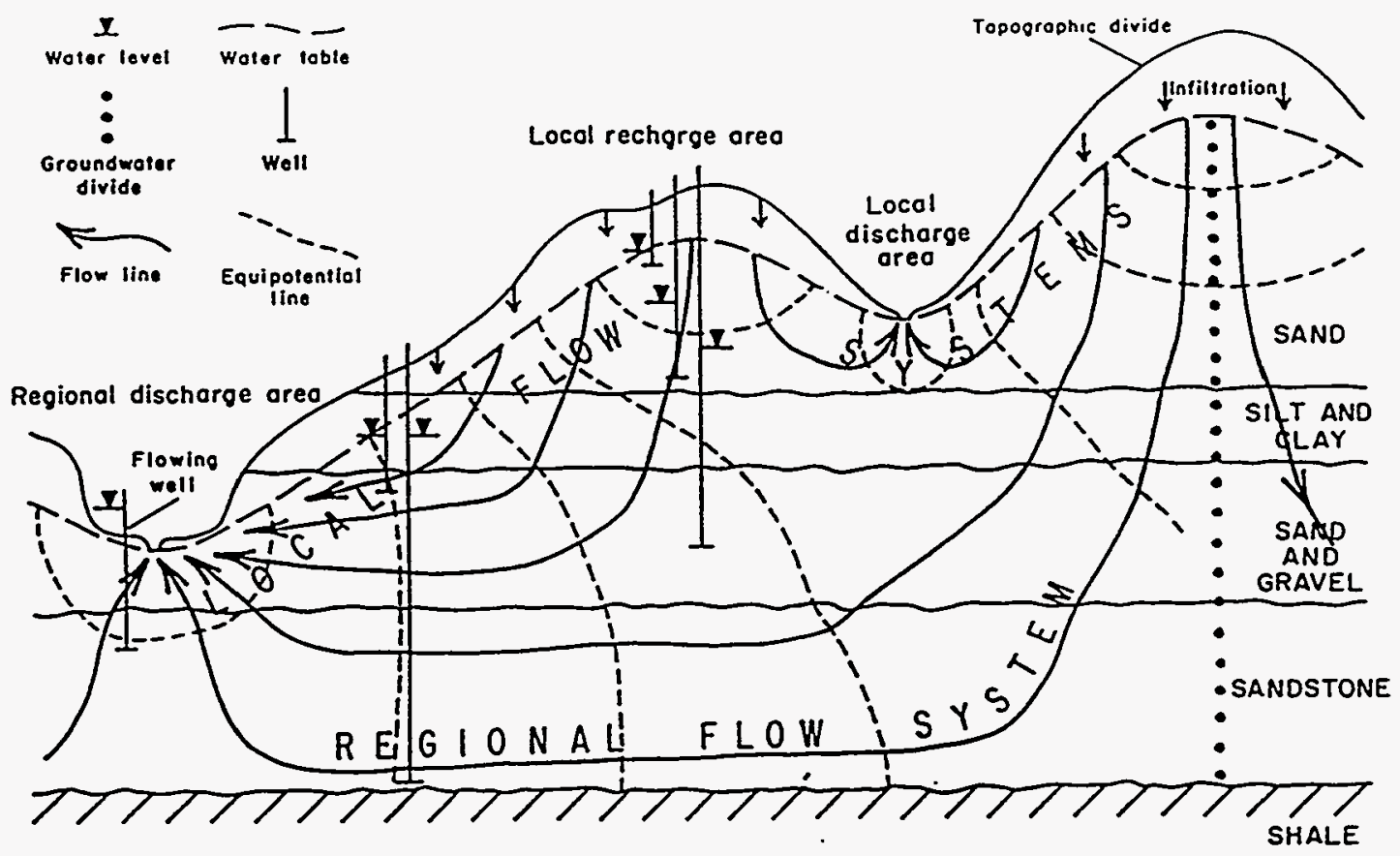

Fig. 3 Hydrogeologic cross-section illustrating regional groundwater flow

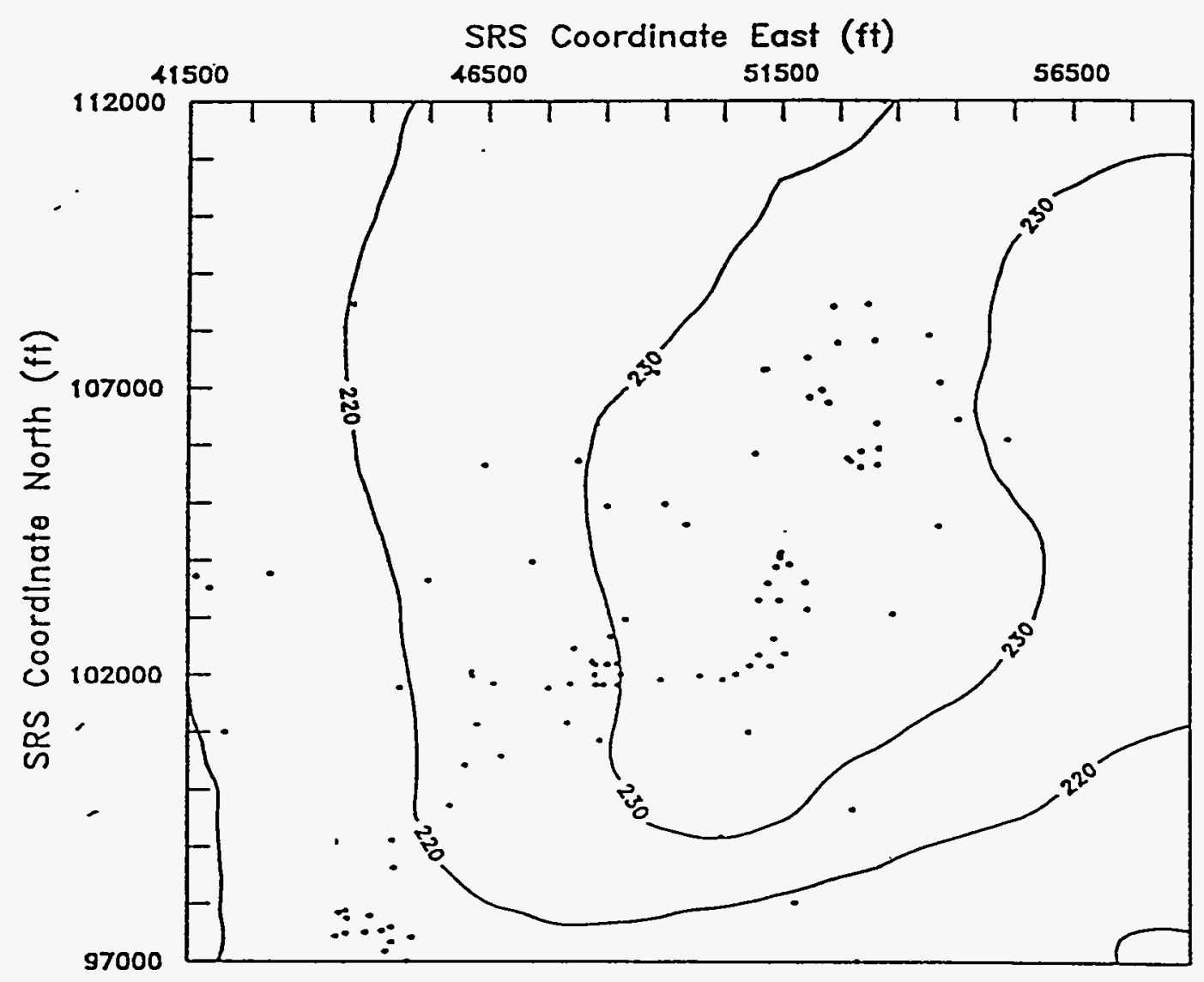

Fig. 4 Water table configuration map (ft. above m.s.l.) 


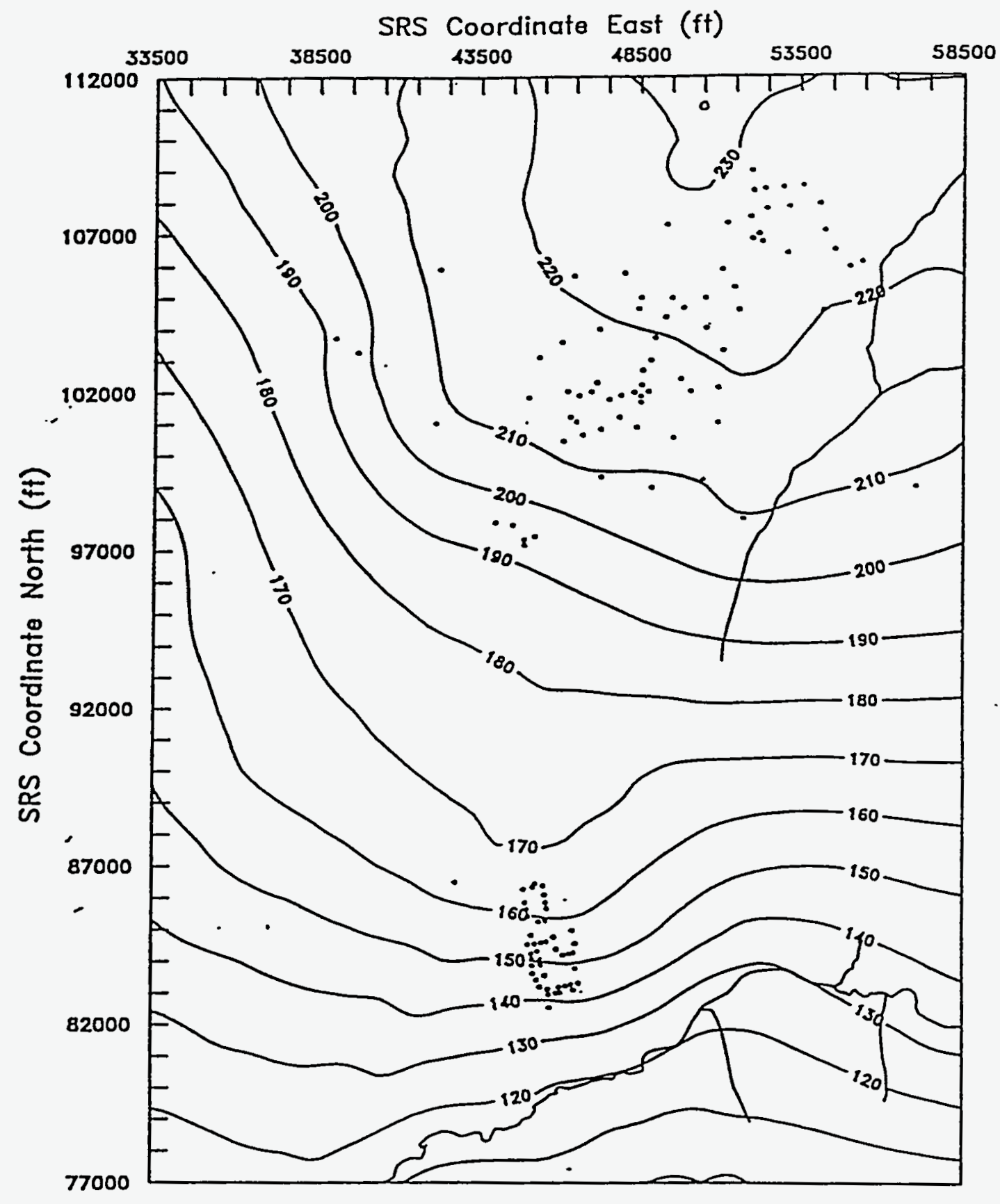

Fig. 5 Upper Lost Lake Aquifer Zone potentiometric map (ft. above msl) 


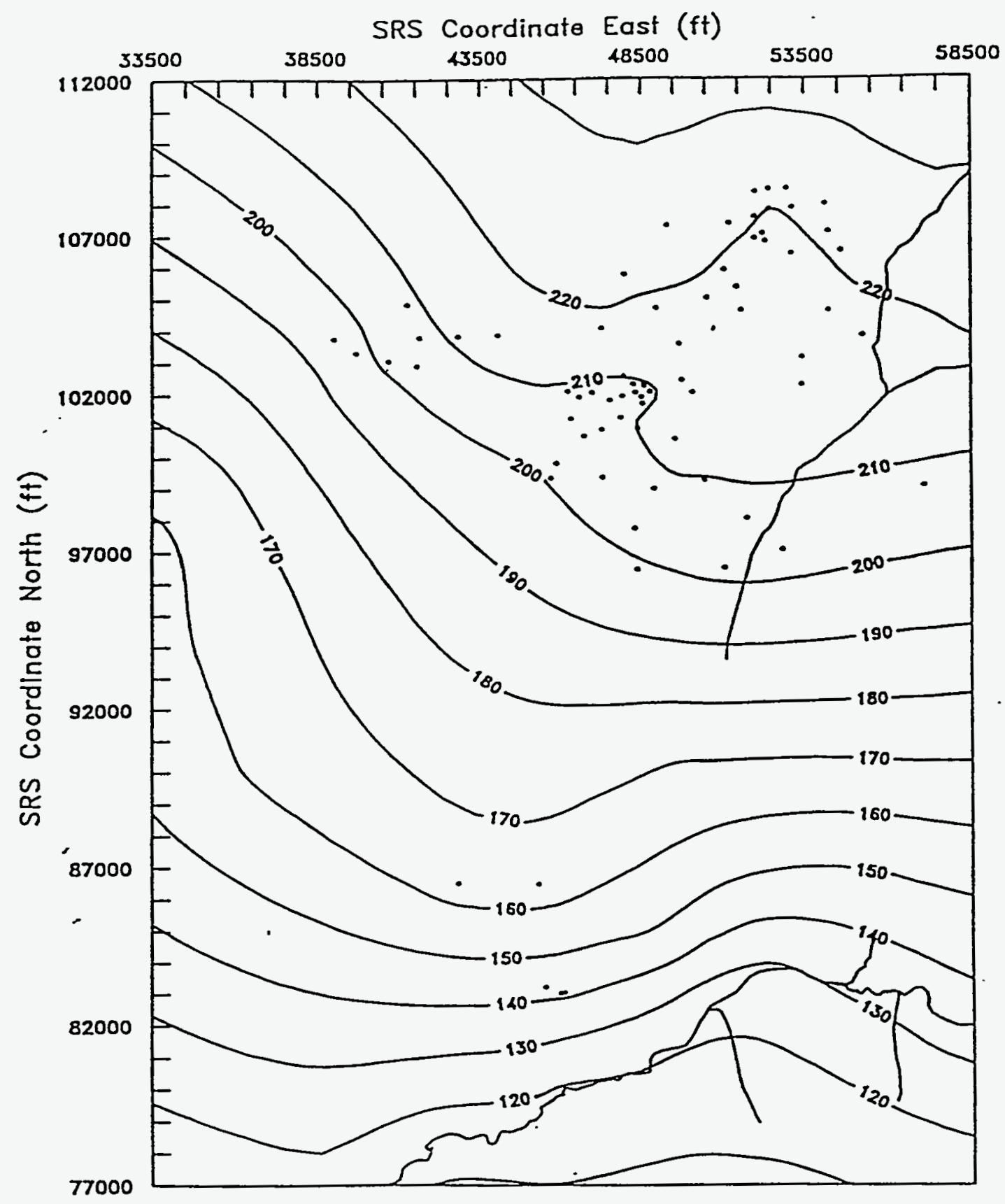

Fig. 6 Lower Lost Lake Aquifer Zone potentiometric map (ft. above msl) 


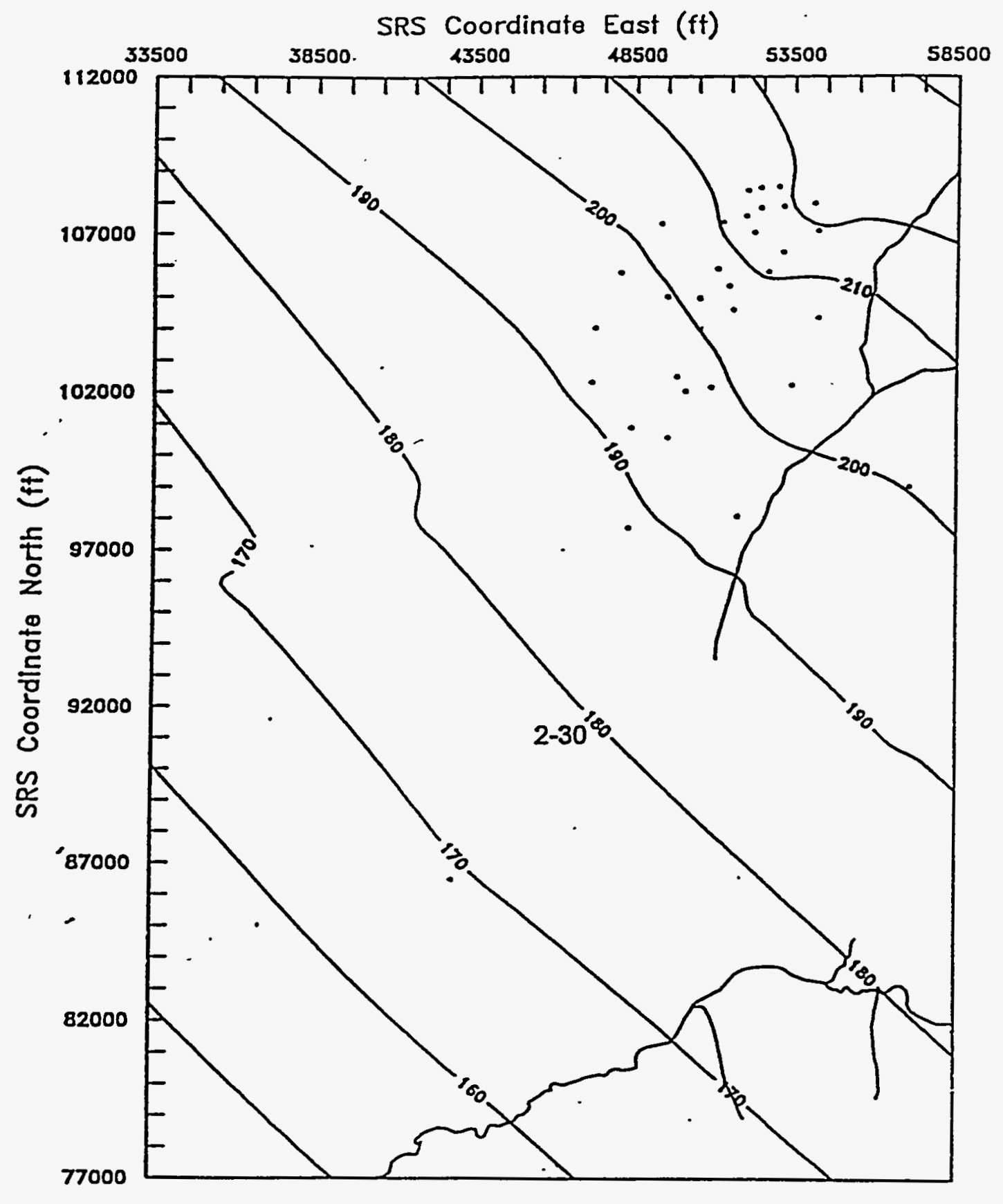

Fig. 7 Crouch Branch Aquifer potentiometric map (ft. above msi) 


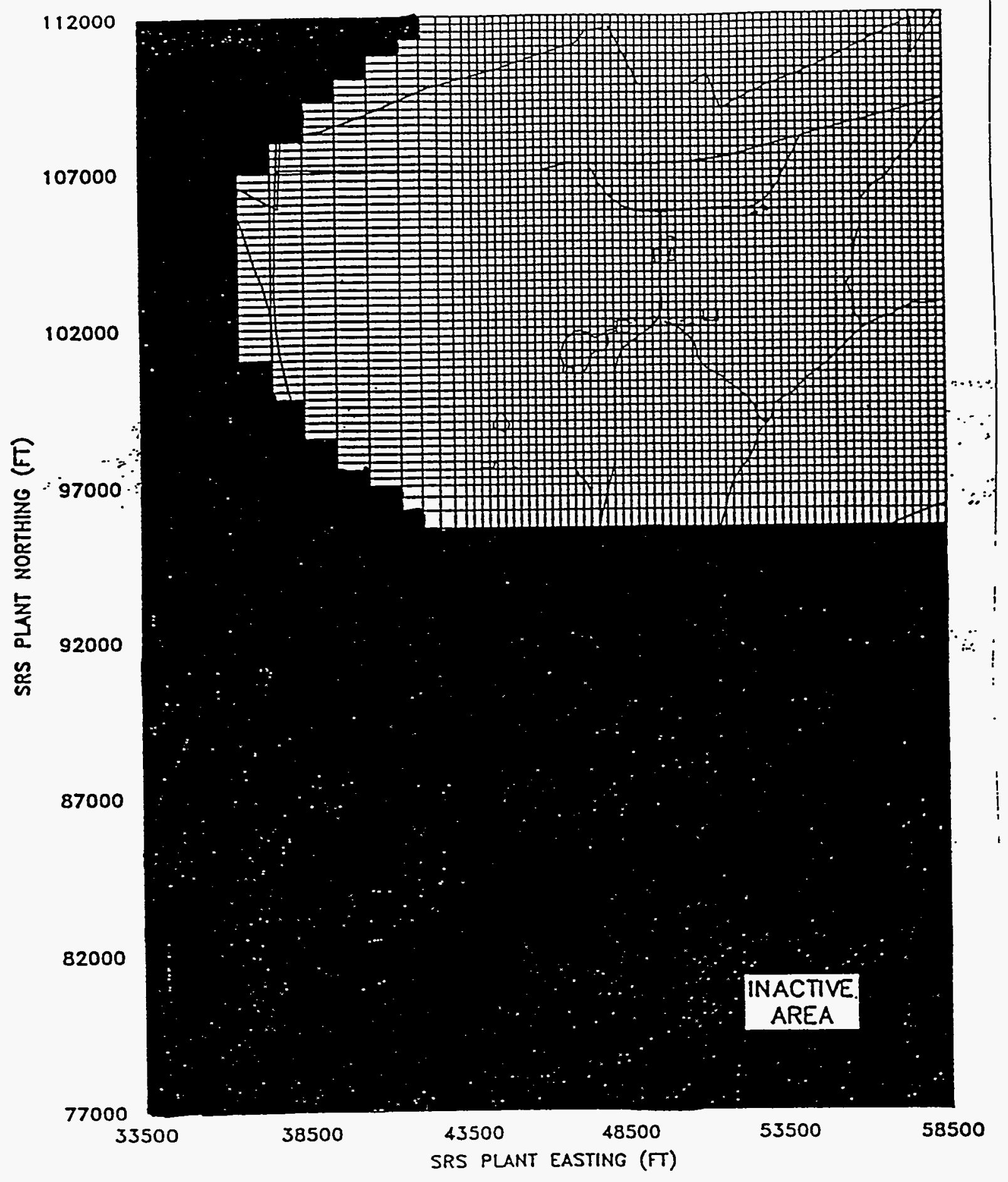

Fig. 8 Model grid mesh, Layer 1 


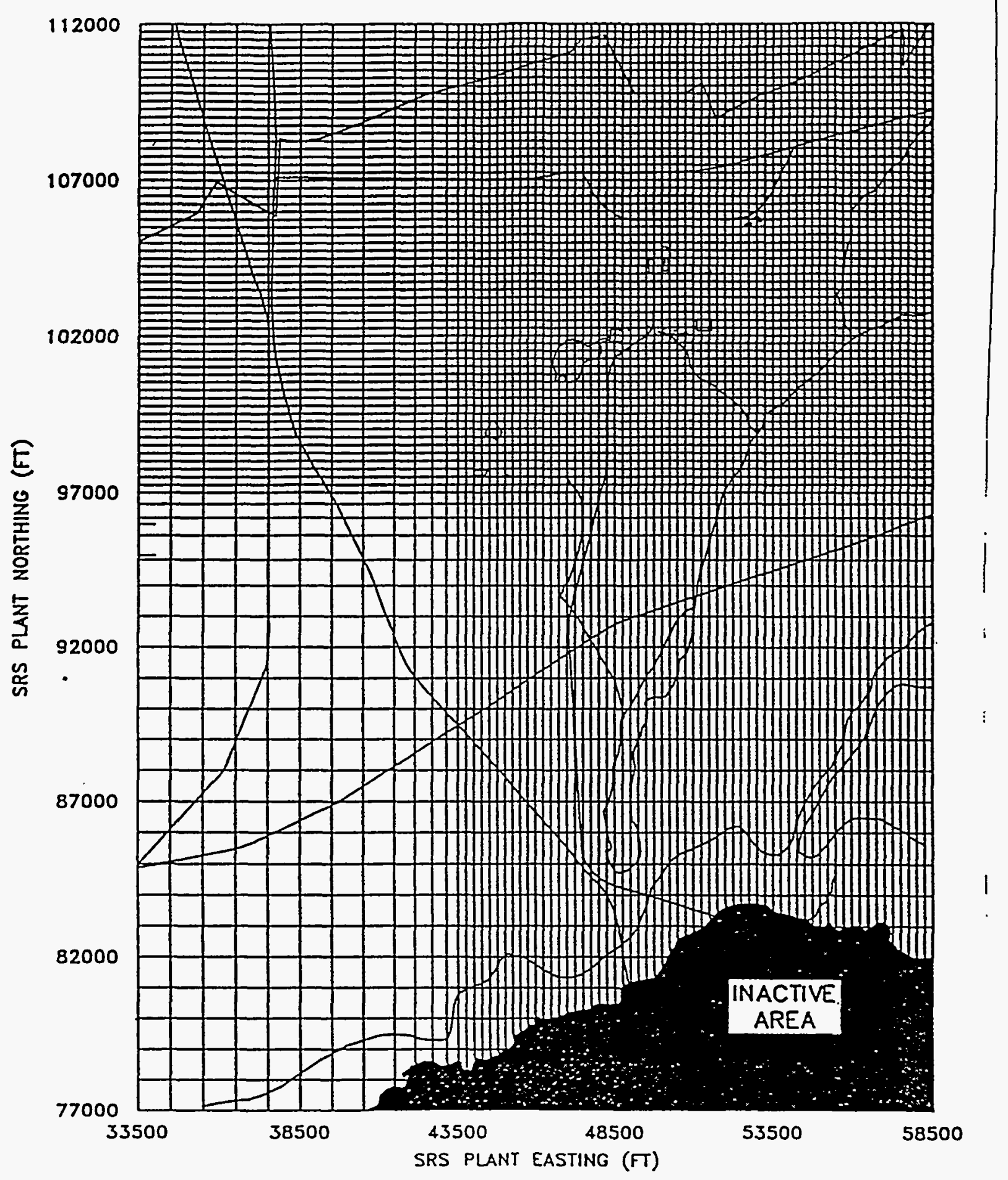

Fig. 9 Model grid mesh, Layers 2-4 


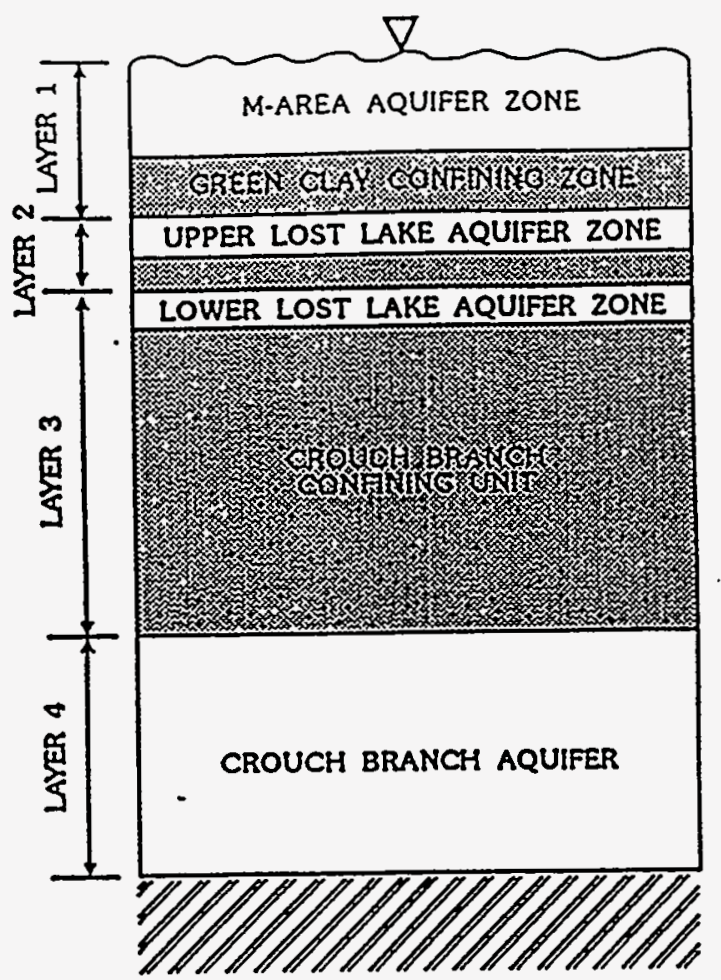

Fig. 10 Correlation chart of model layers and hydrostratigraphic units 
111111911111111111111111111111191111122222222222222222222222222222222222

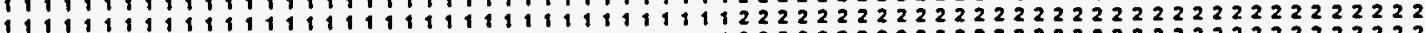

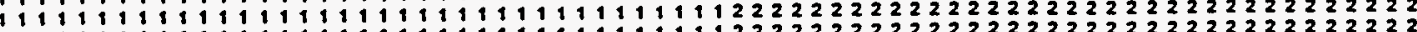
111111111111111111111111111111111122222222222222222222222222222222222

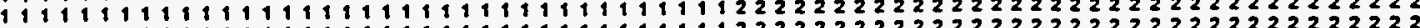

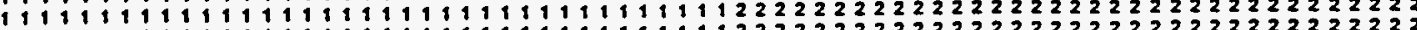

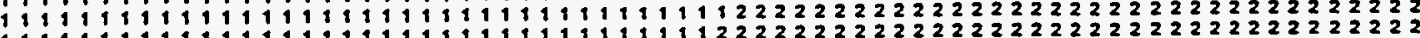

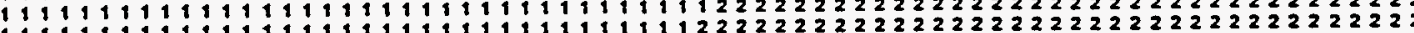

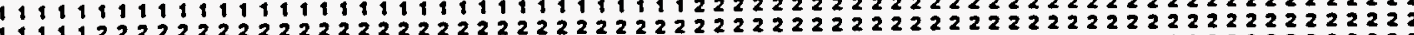

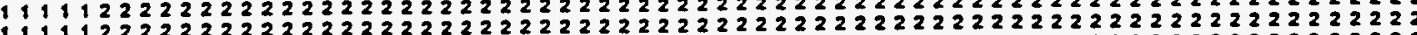

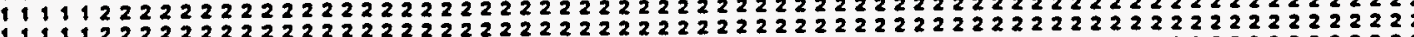

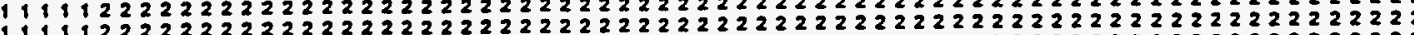

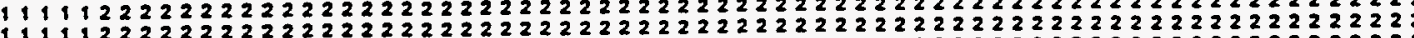

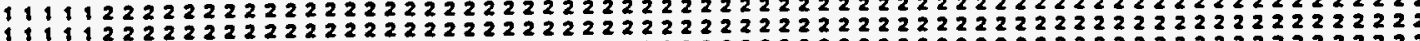

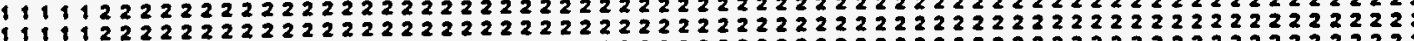

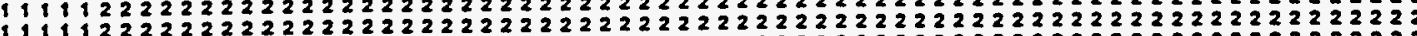

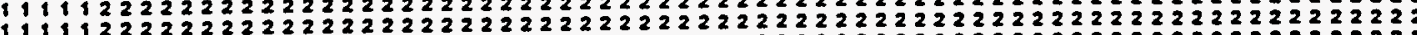

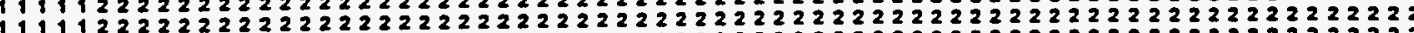

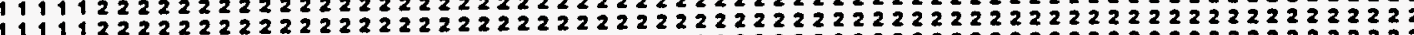

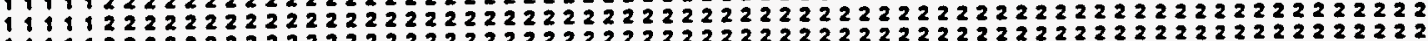

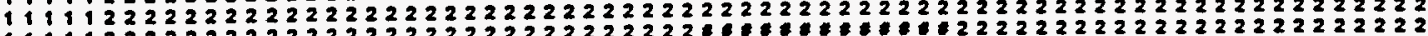

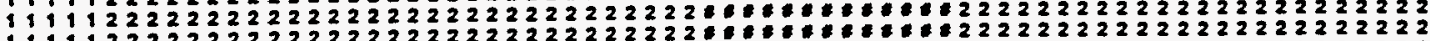

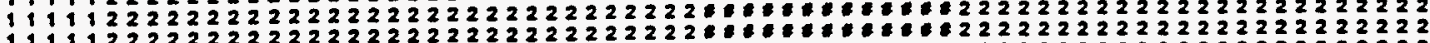

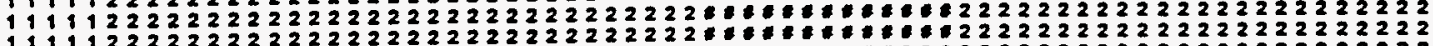

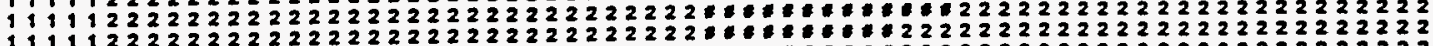

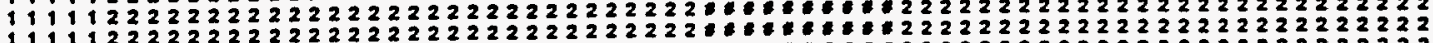

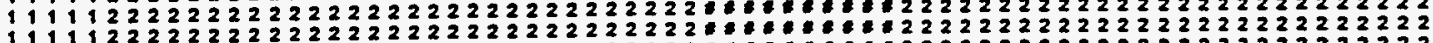

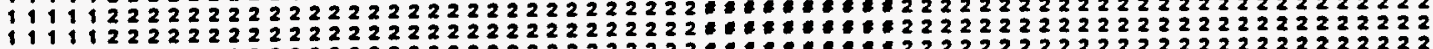

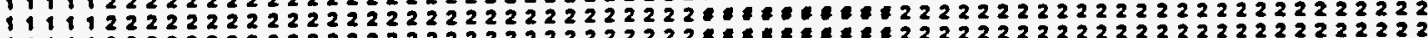

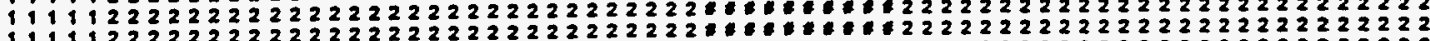

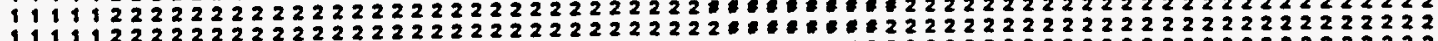

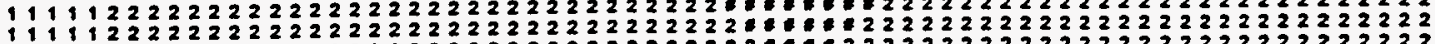

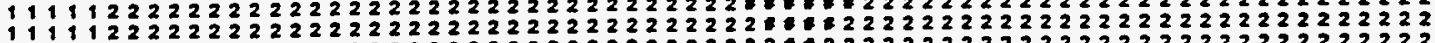

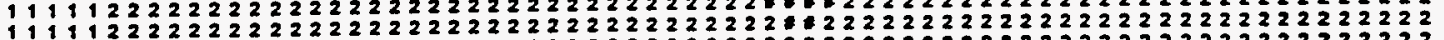

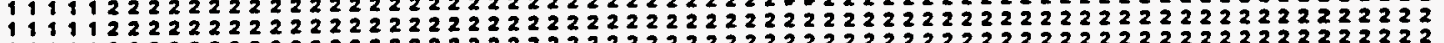

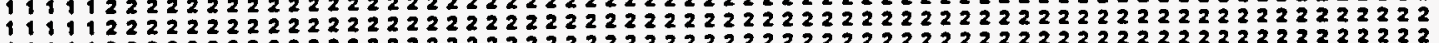

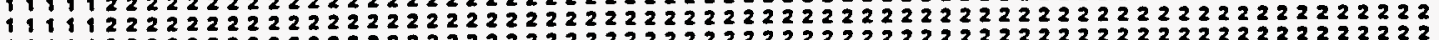

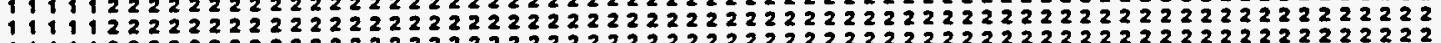

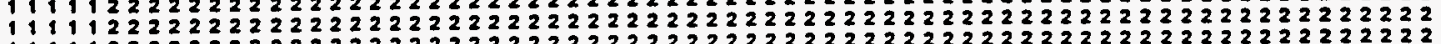

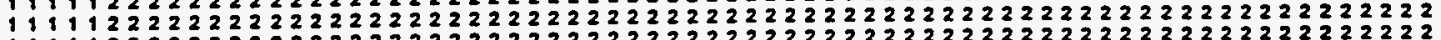

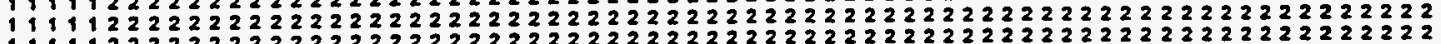

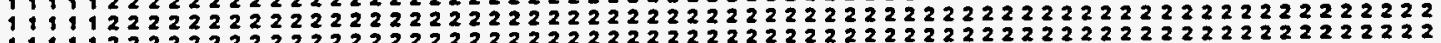

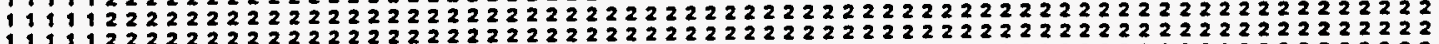

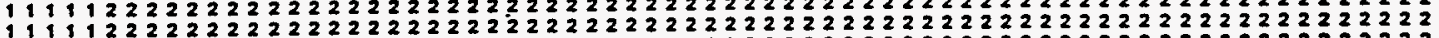

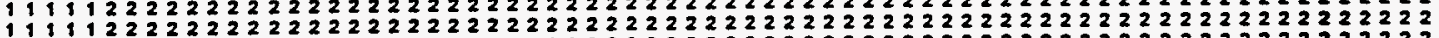

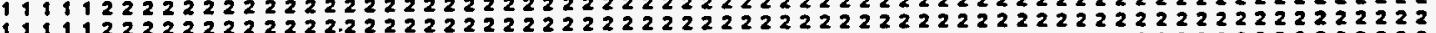

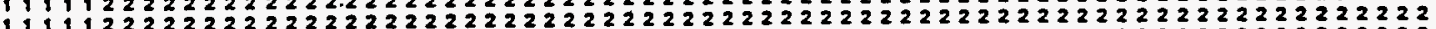

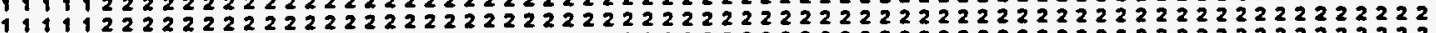

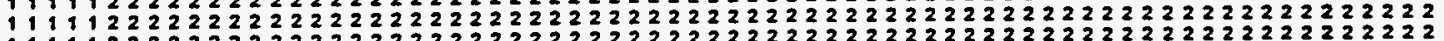

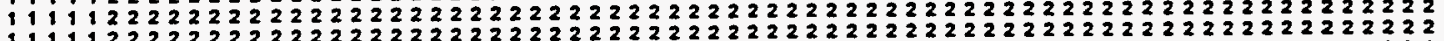

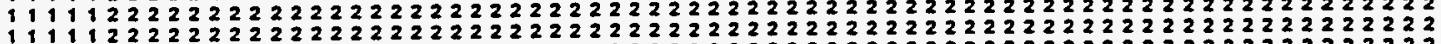

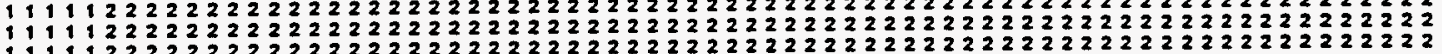

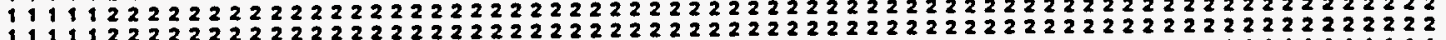

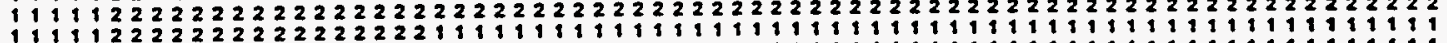

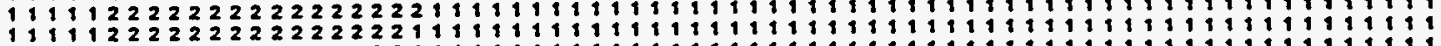

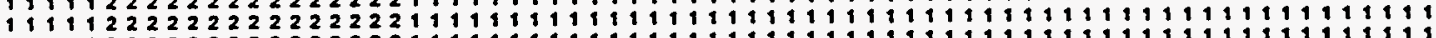

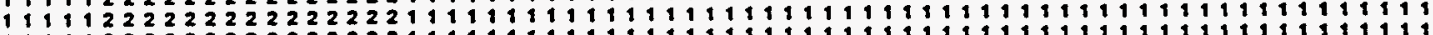

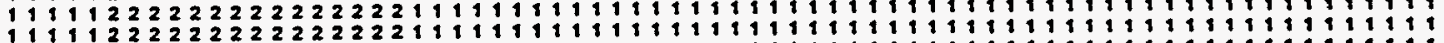

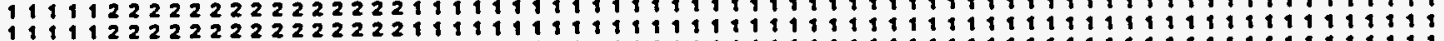

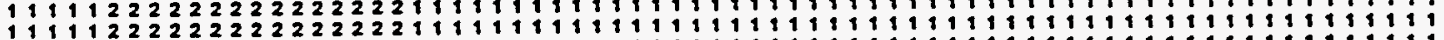

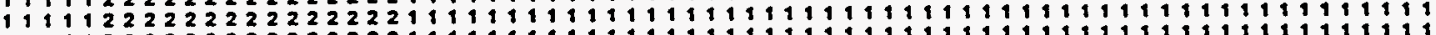

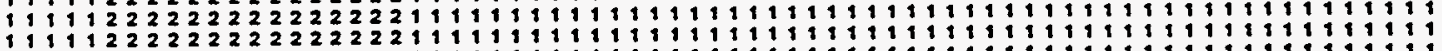

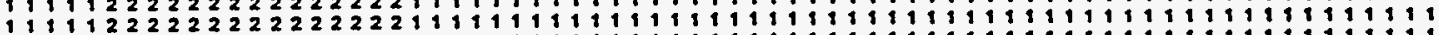

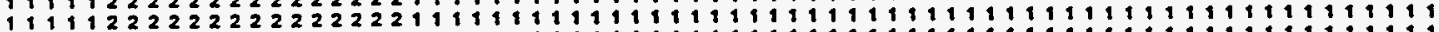

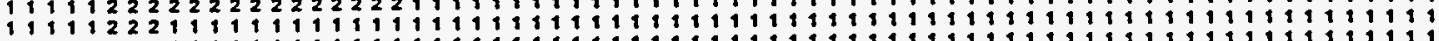

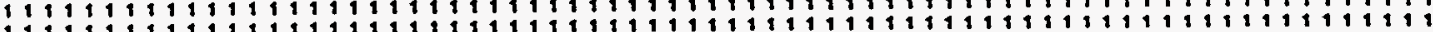

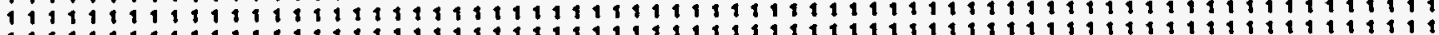

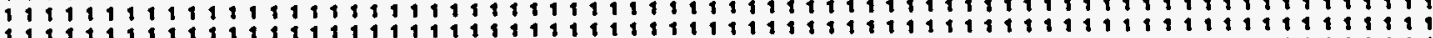

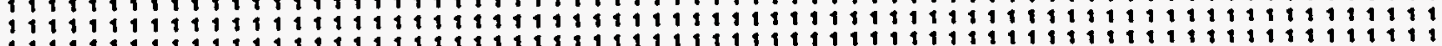

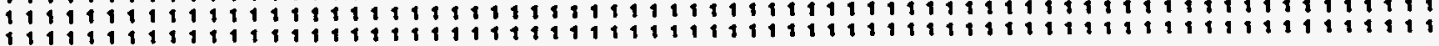

\section{LEGEND}

$1=9.74 \mathrm{E}-04 \mathrm{~m} /$ day $(3.194 \mathrm{E}-03 \mathrm{ft} /$ day $)$
$2=1.25 \mathrm{E}-03 \mathrm{~m} /$ day $(4.107 \mathrm{E}-03 \mathrm{ft} /$ day $)$
$\#=6.96 \mathrm{E}-04 \mathrm{~m} /$ day $(2.282 \mathrm{E}-03 \mathrm{ft} /$ day $)$

Fig. 11 Recharge Rates Applied to Uppermost Layer of Model Grid 


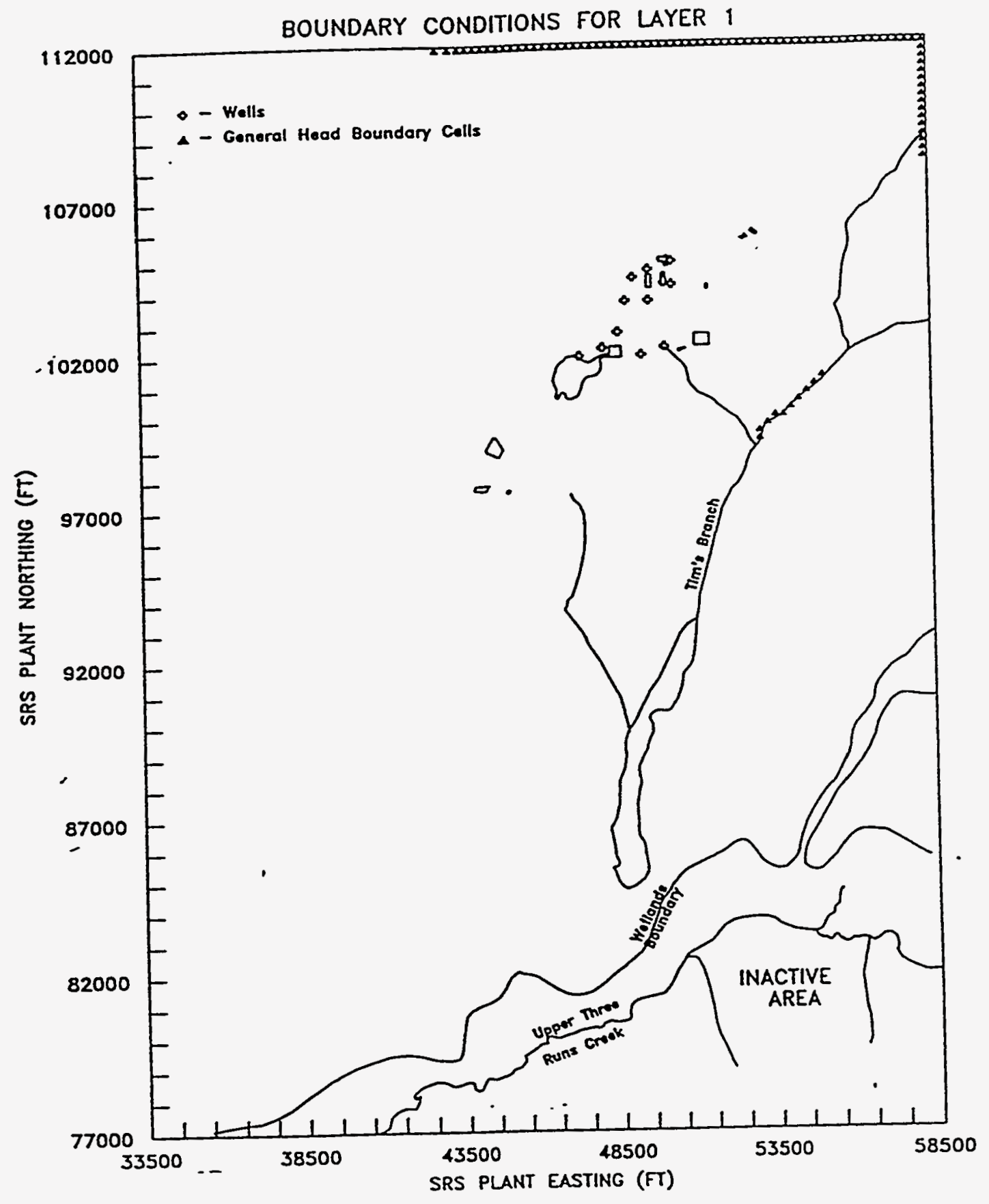

Fig. 12 Model boundary condition for Layer 1 


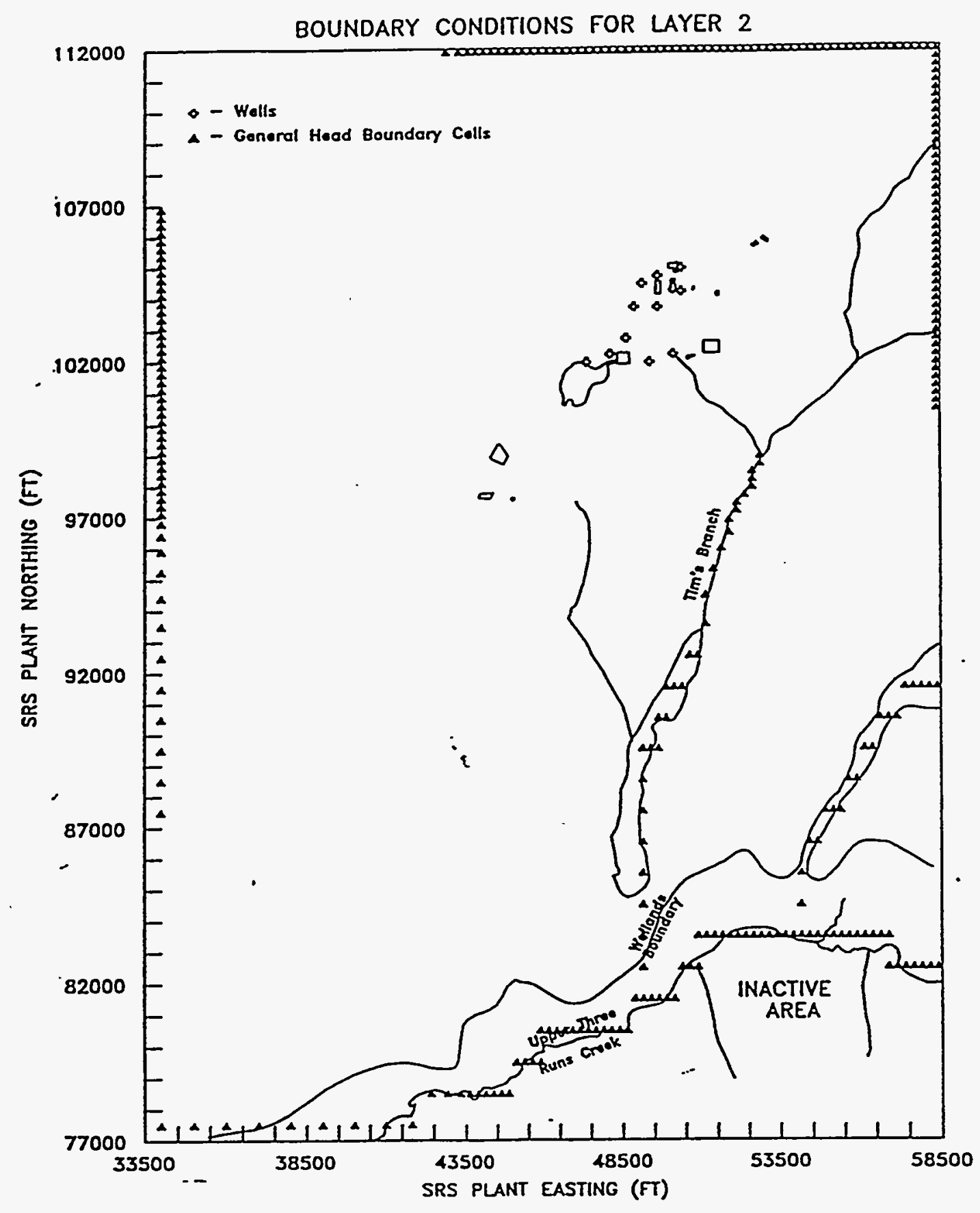

Fig. 13 Model boundary condition for Layer 2 


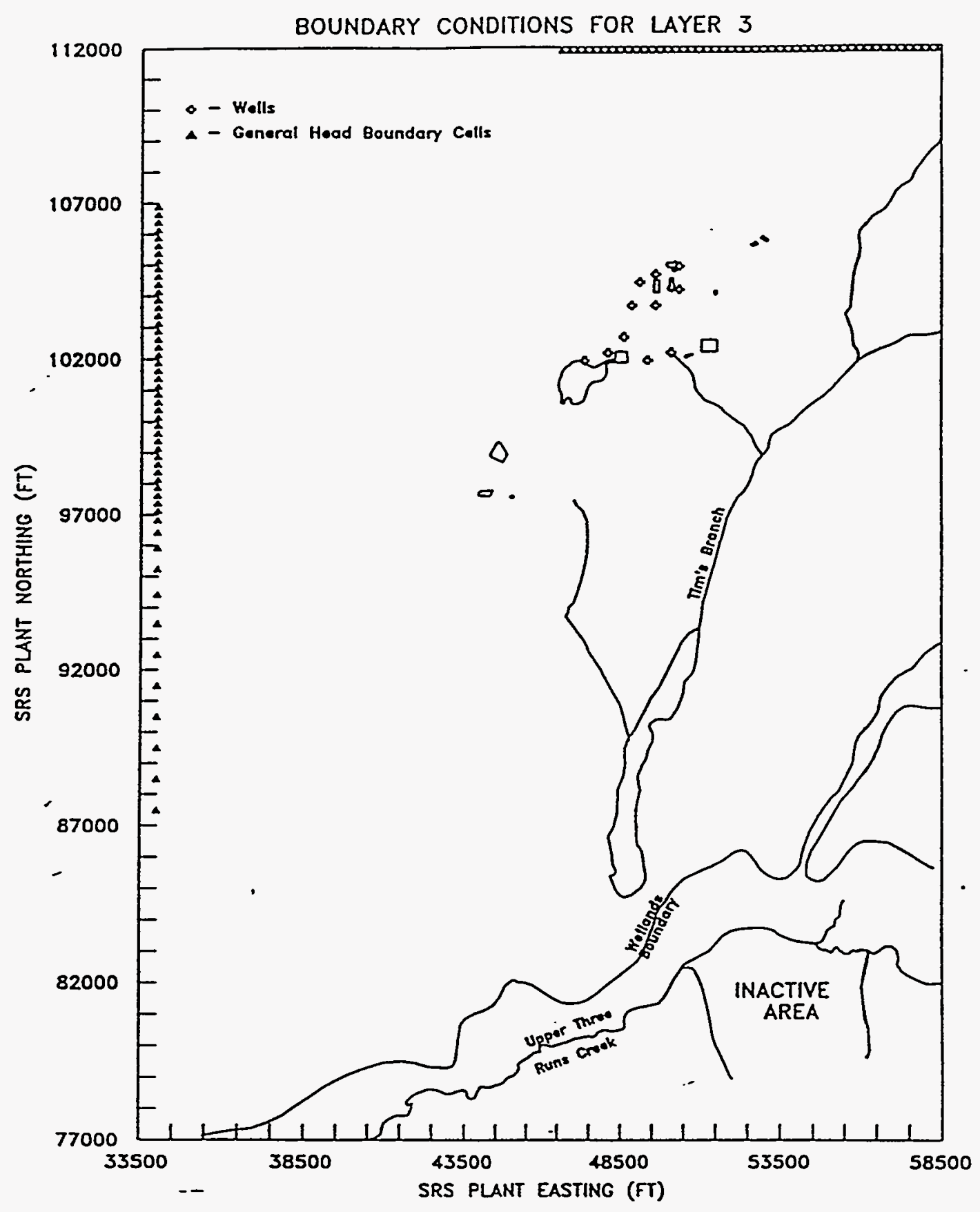

Fig. 14 Model boundary condition for Layer 3 


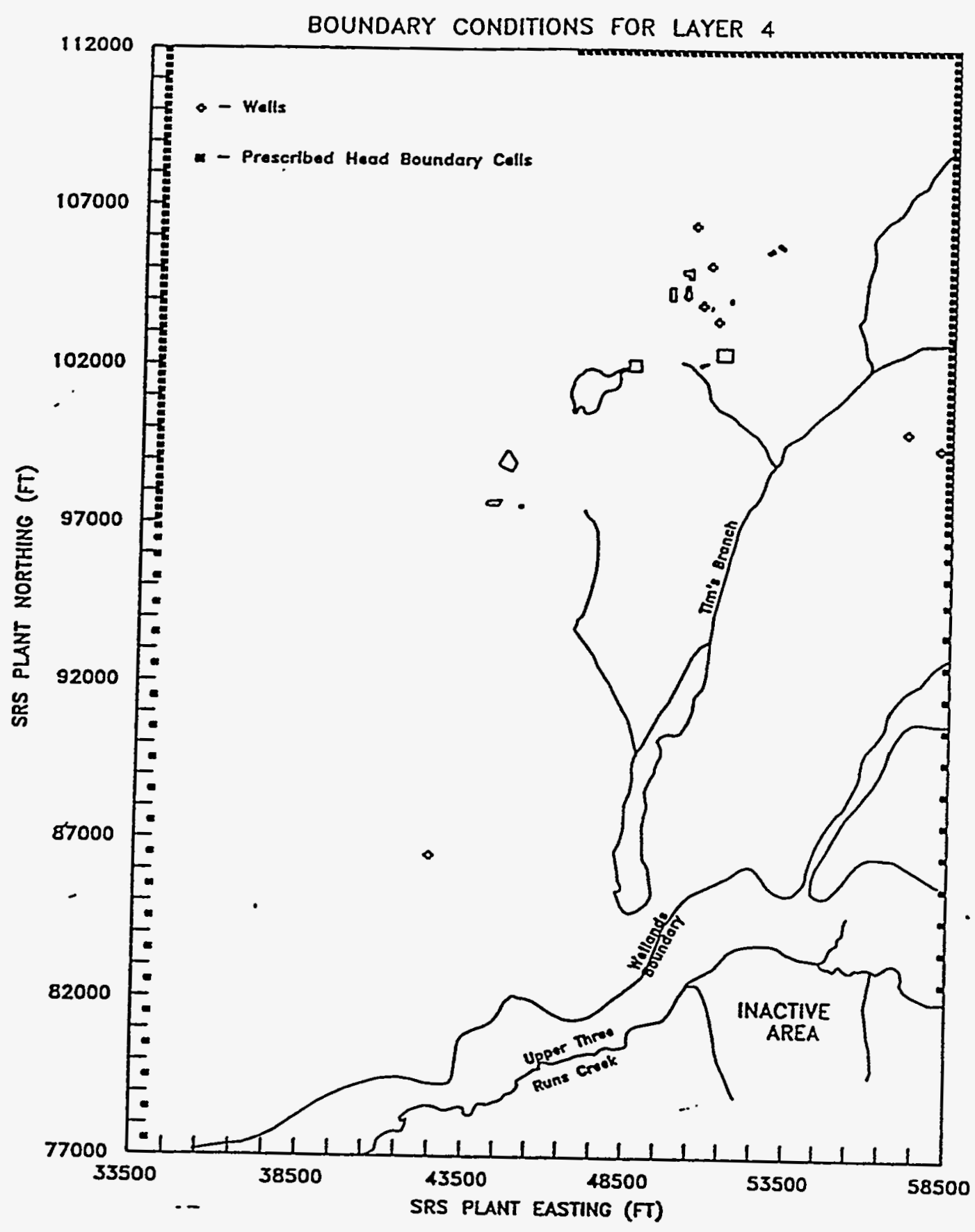

Fig. 15 Model boundary condition for Layer 4 
111111141199099980980009099990999099999999999999999999999999999990999909

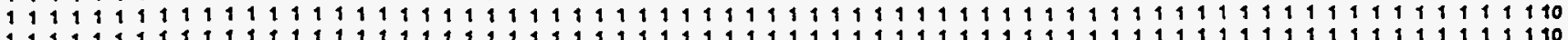

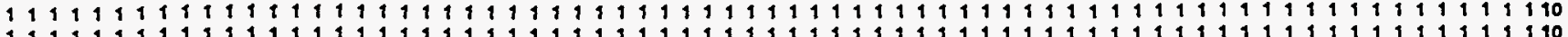

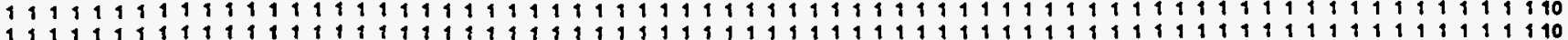

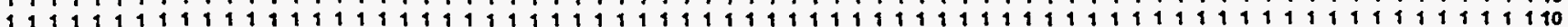

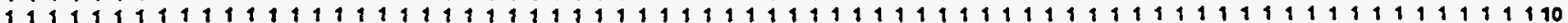

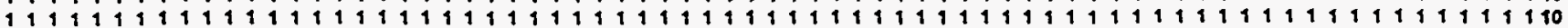

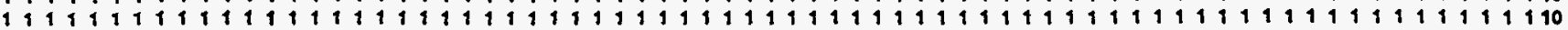

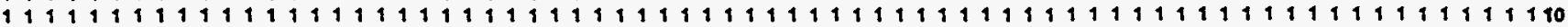

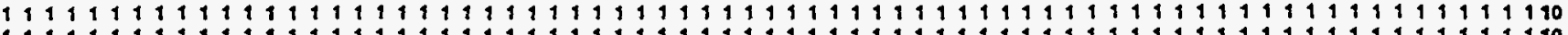

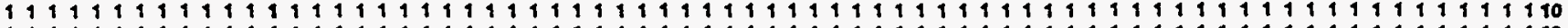

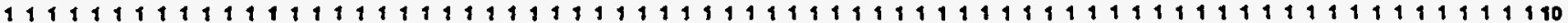

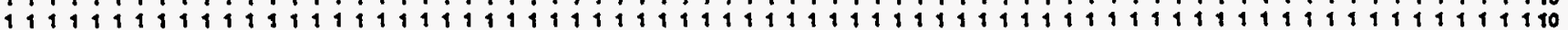

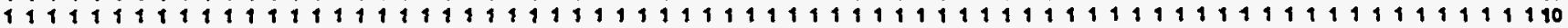

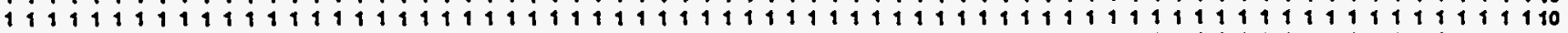

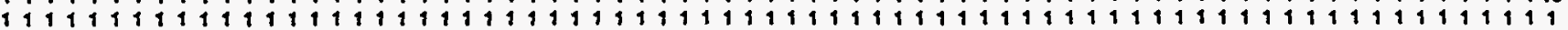

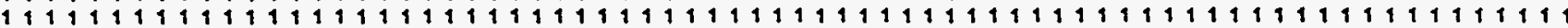

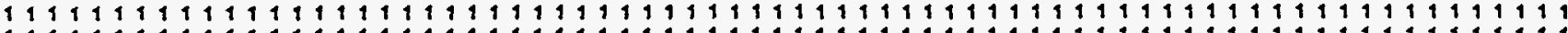

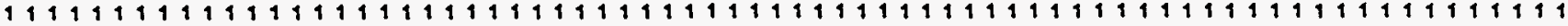

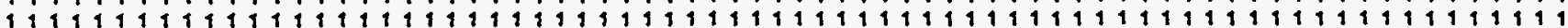

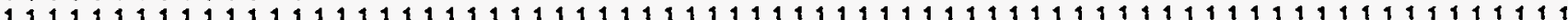

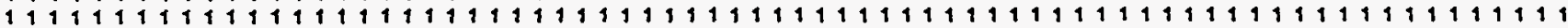

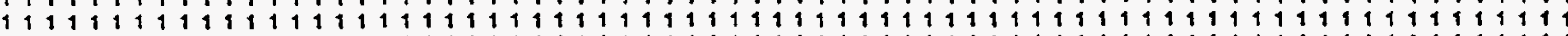

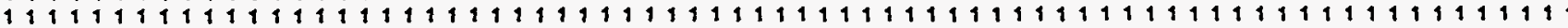

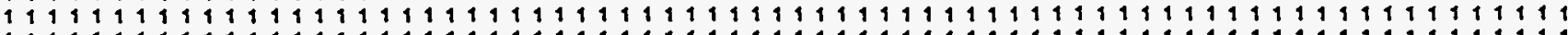

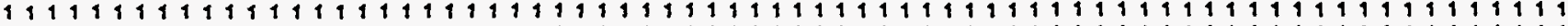

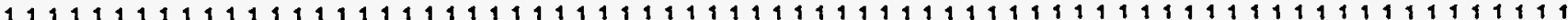

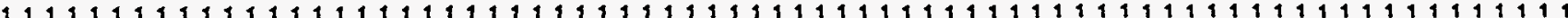

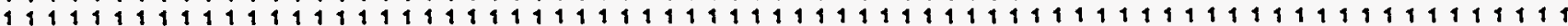

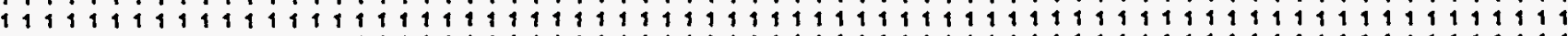

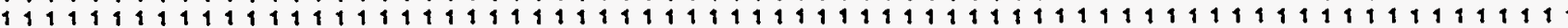

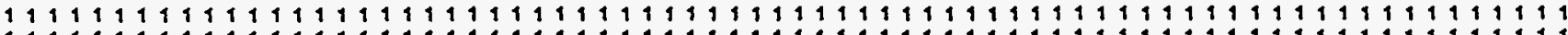

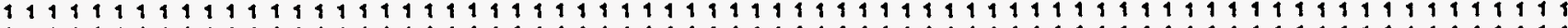

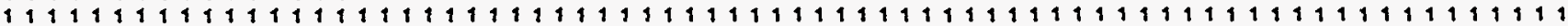

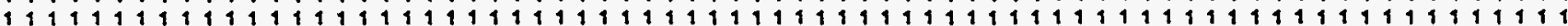

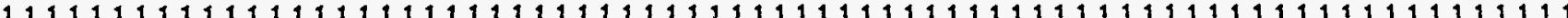

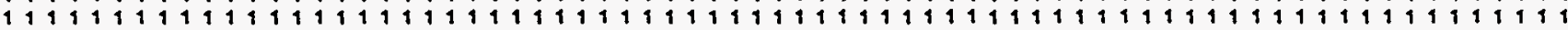

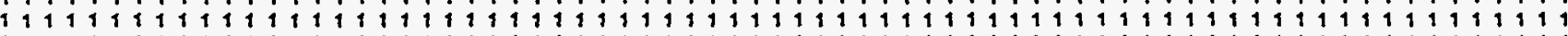

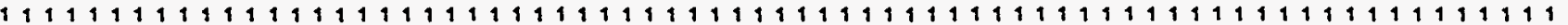

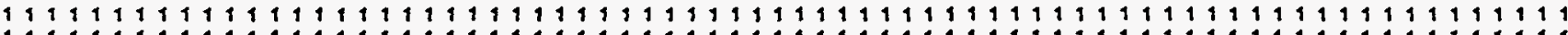

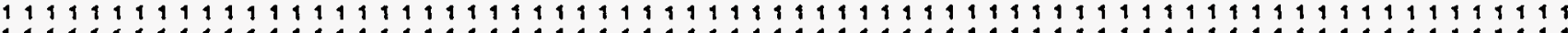

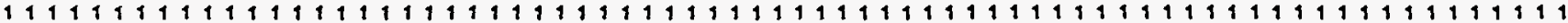

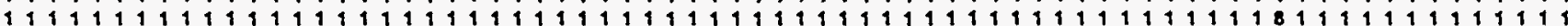

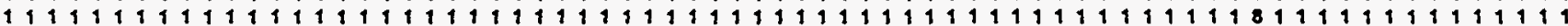

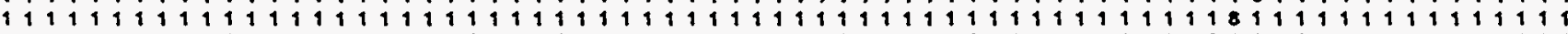

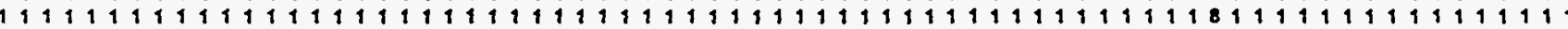

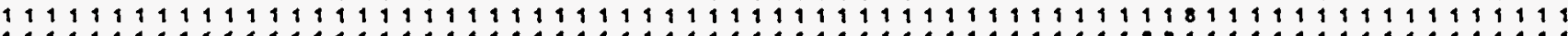

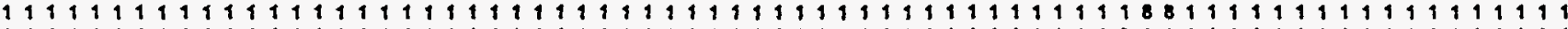

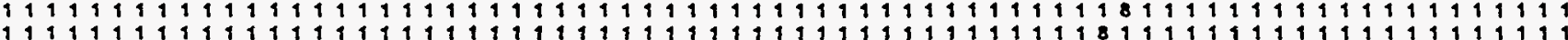

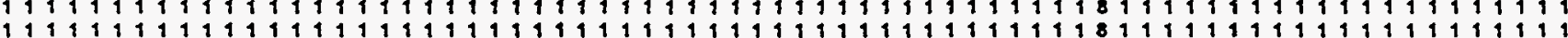

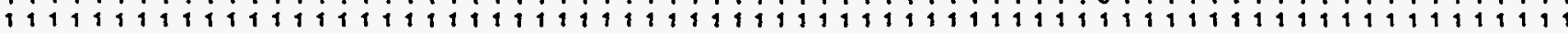

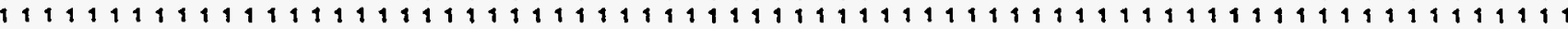

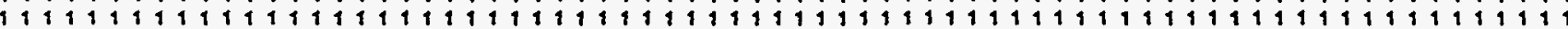

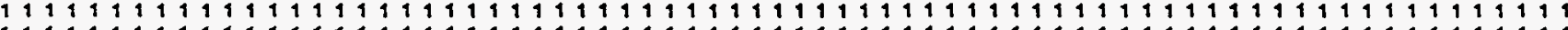

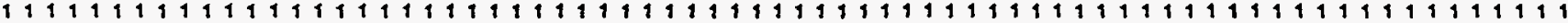

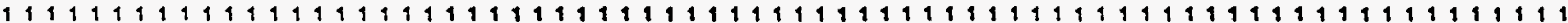

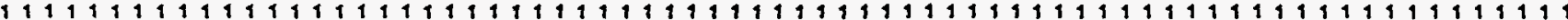

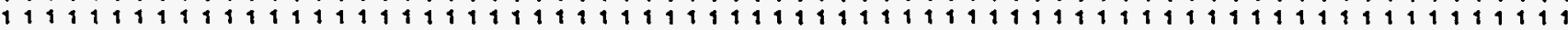

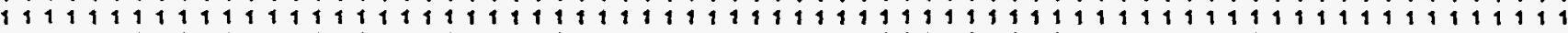

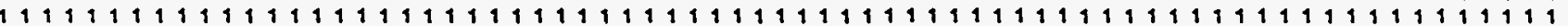

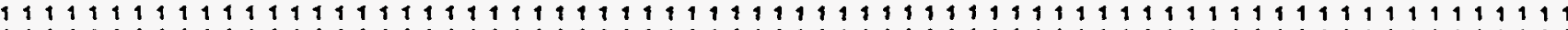

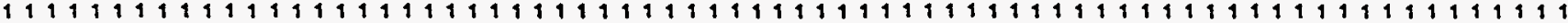

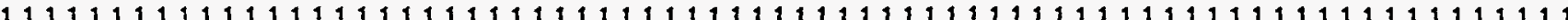

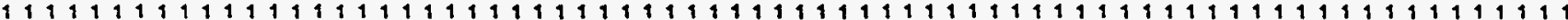

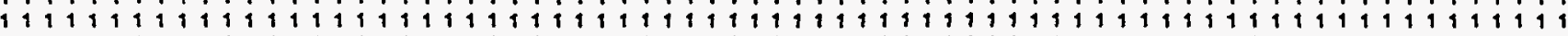

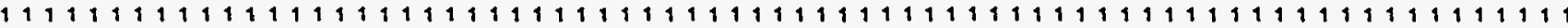

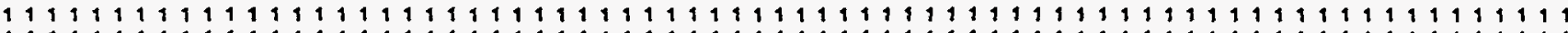

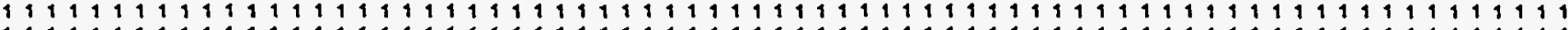

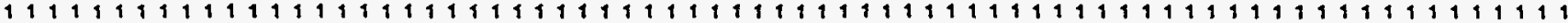

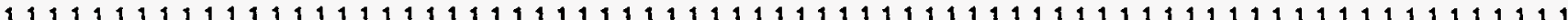

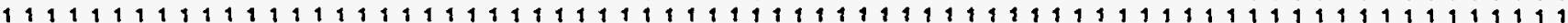

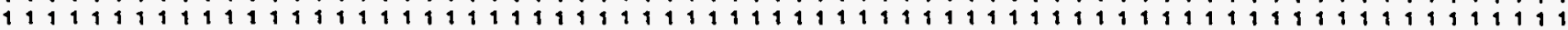

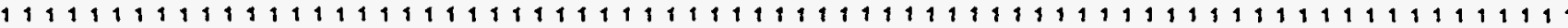

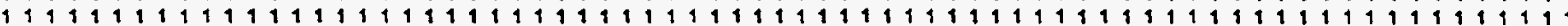

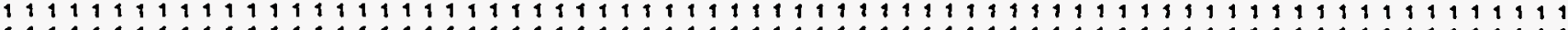

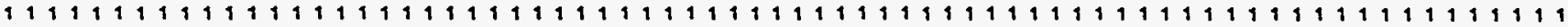

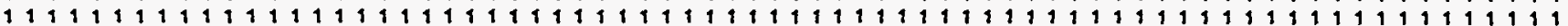

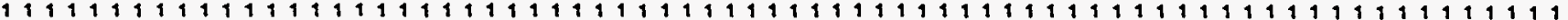

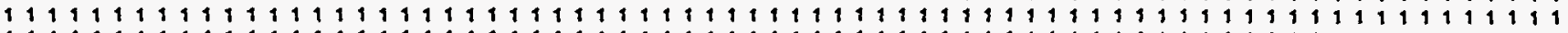

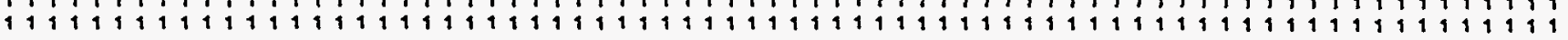

Figure 16. ZONEBUDGET node assignments for Layer 1 


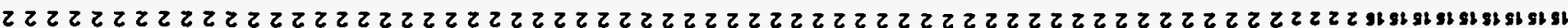

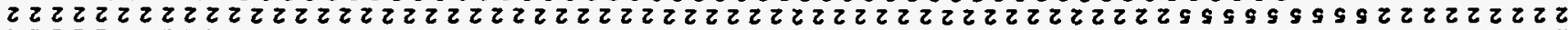

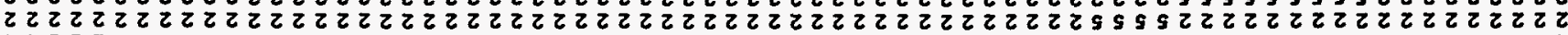

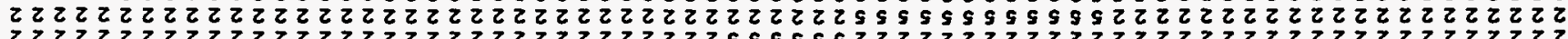
ssssss

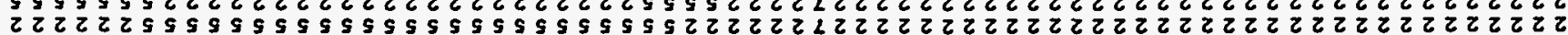

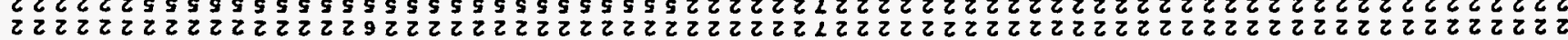

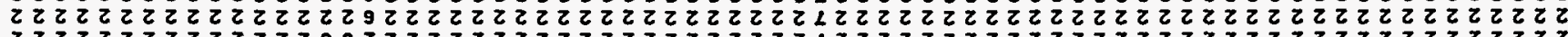

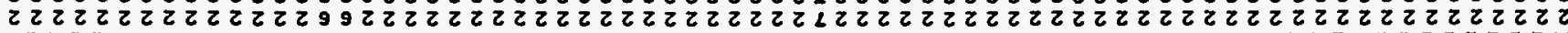

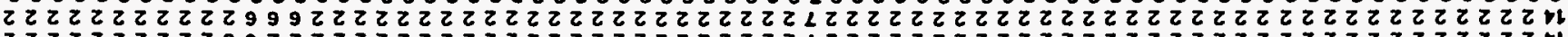

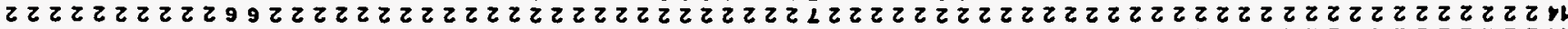

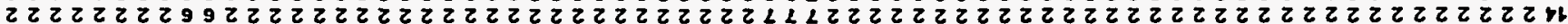

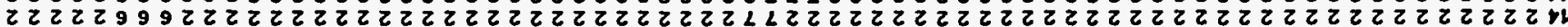

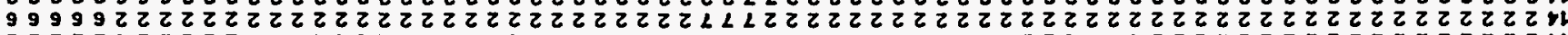

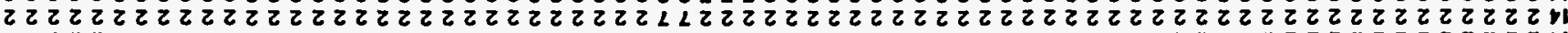

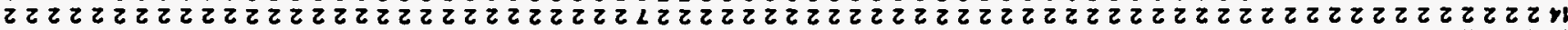

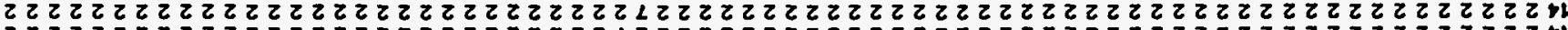

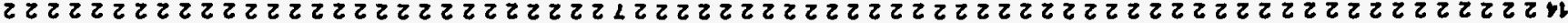

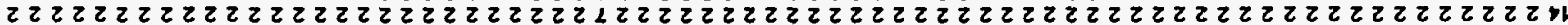

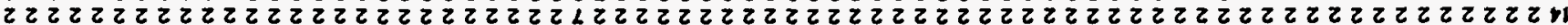

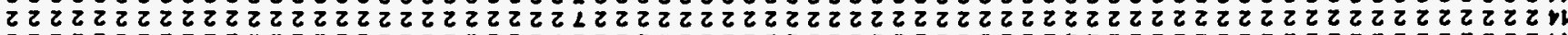

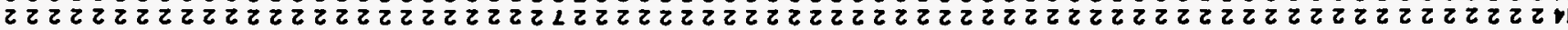

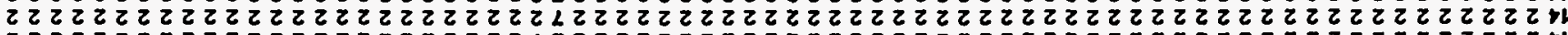

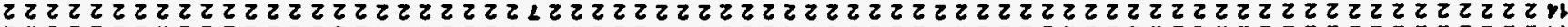

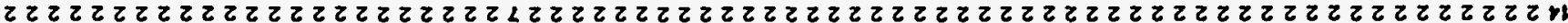

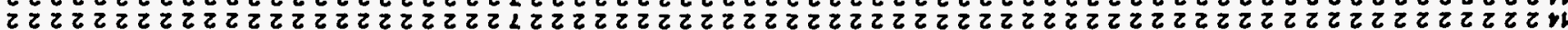

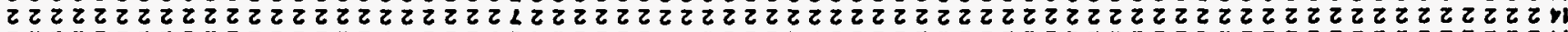

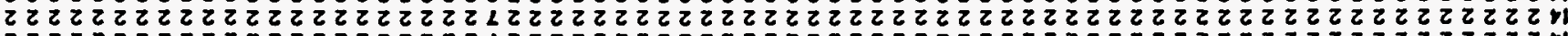

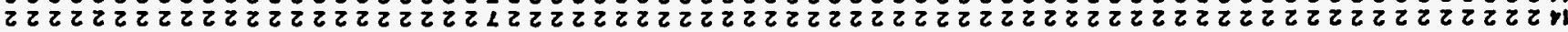

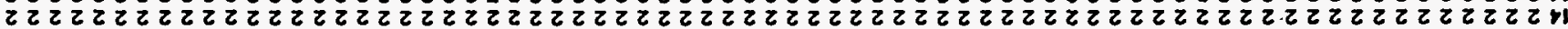
ててててててててててててててててててててててててててててててててててててててててててててててててててててててててててててててて山

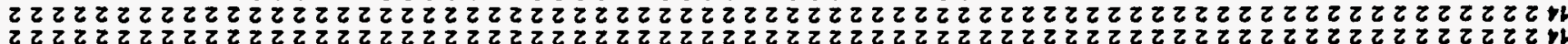

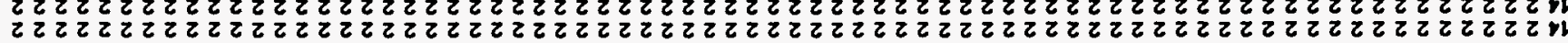

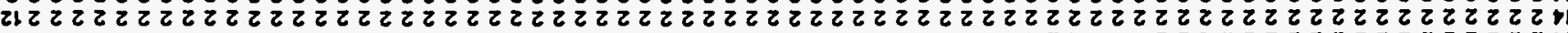

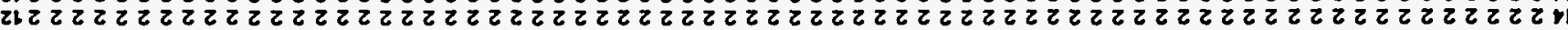

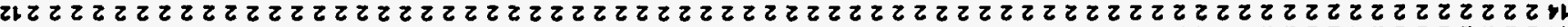

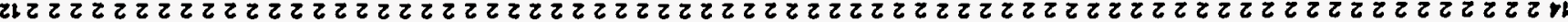

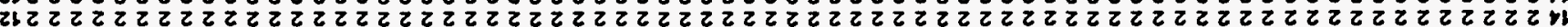

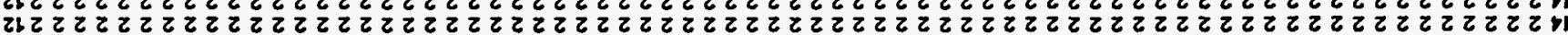

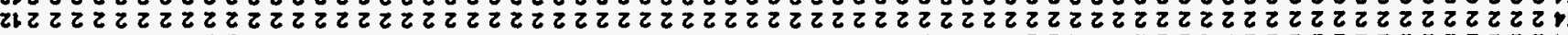

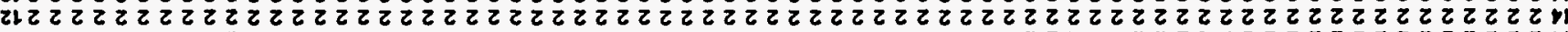

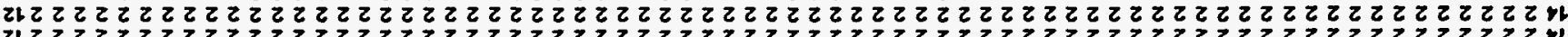

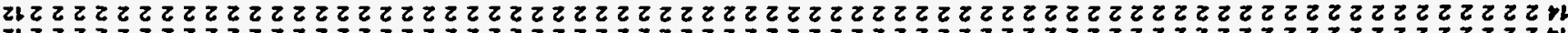

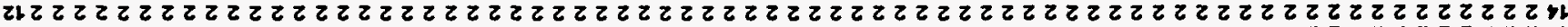

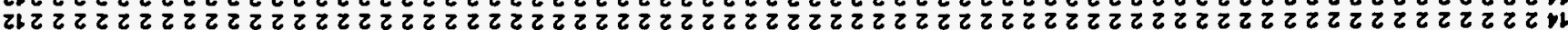

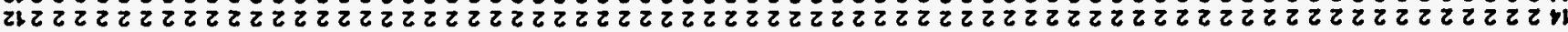

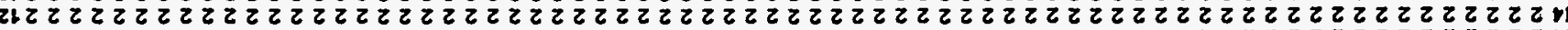

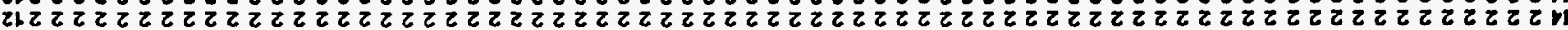

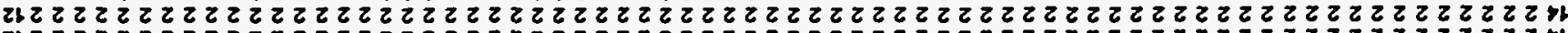

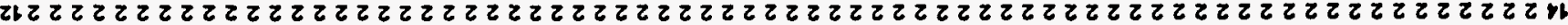

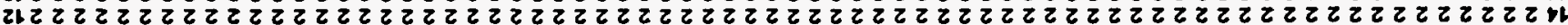

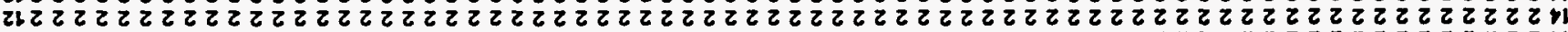

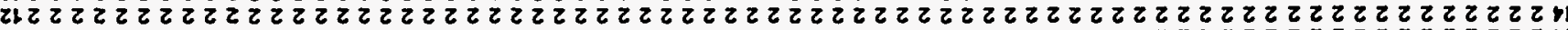

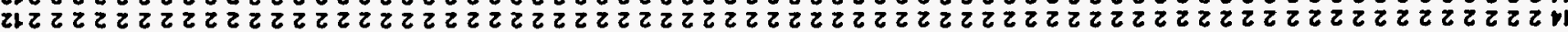

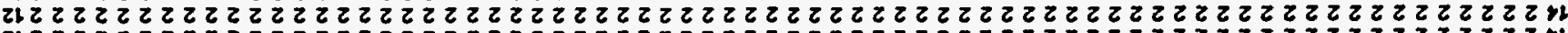

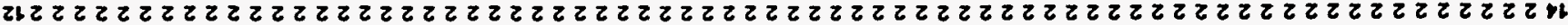

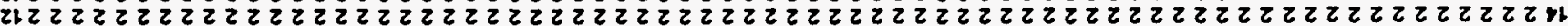

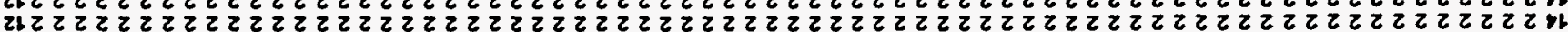

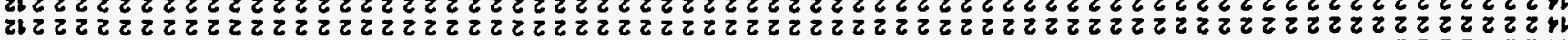

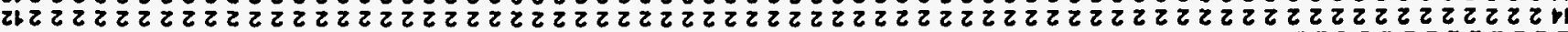

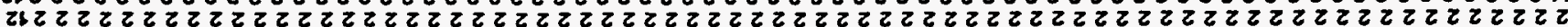

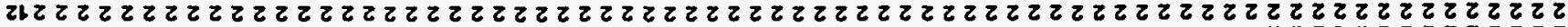

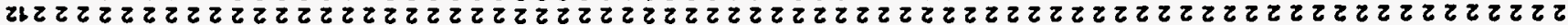

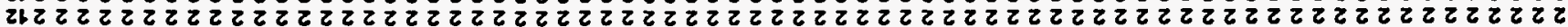

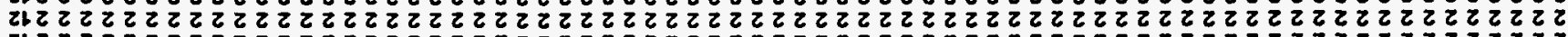

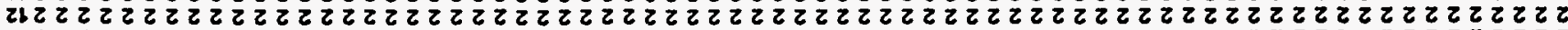

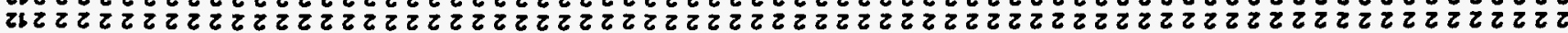

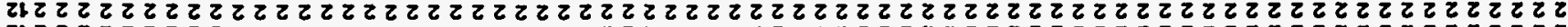

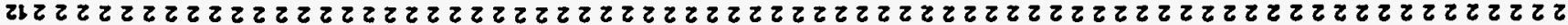

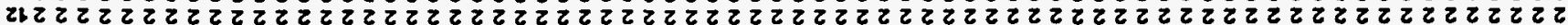

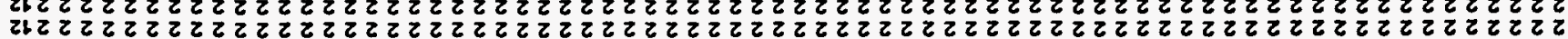

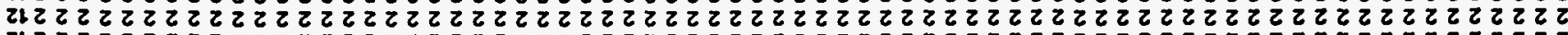

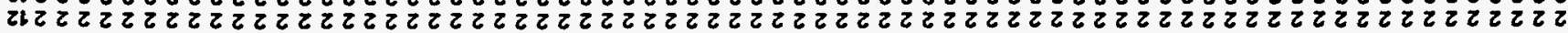

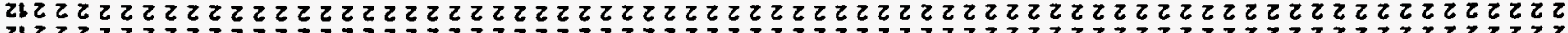

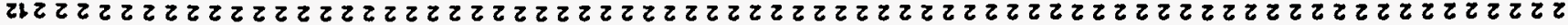

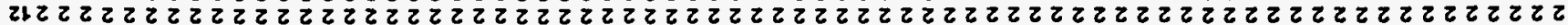

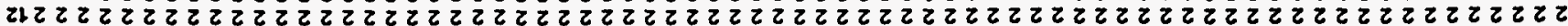

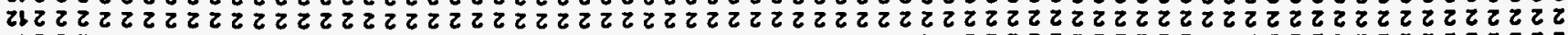

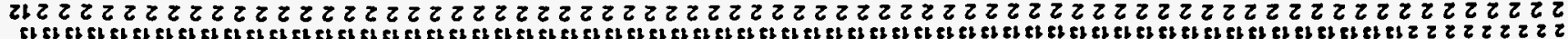




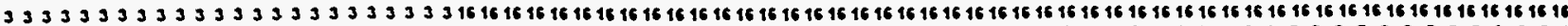

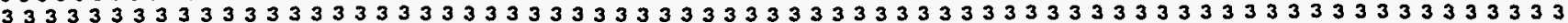

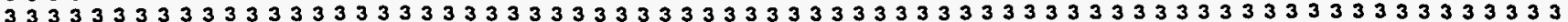

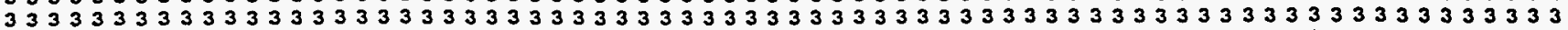

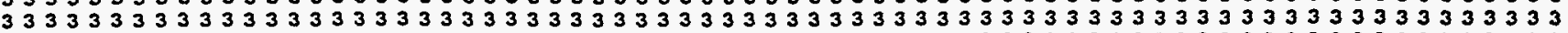

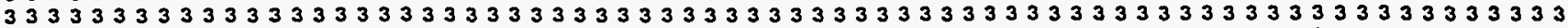

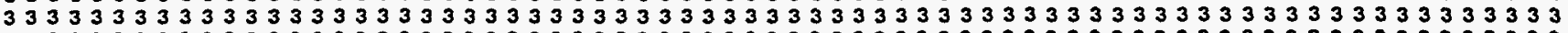

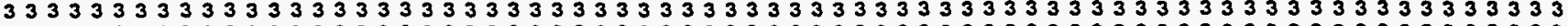

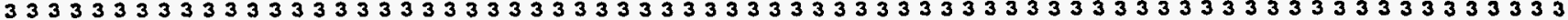

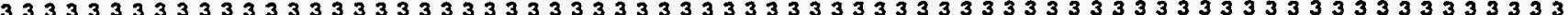

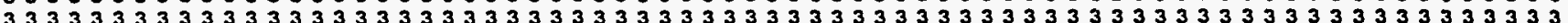

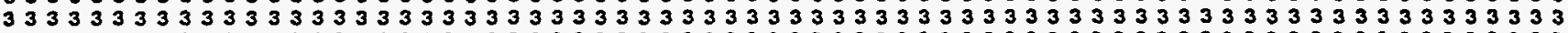

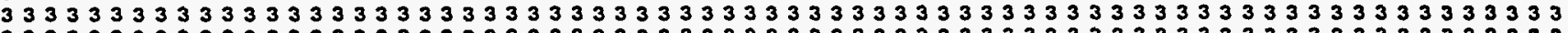

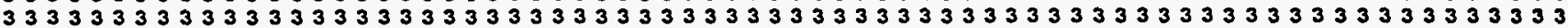

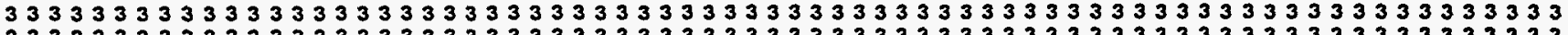

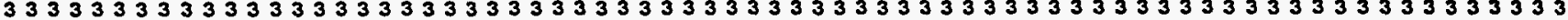

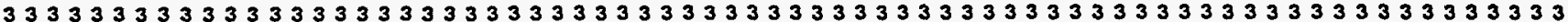

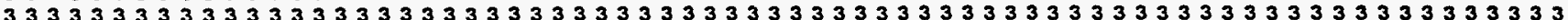

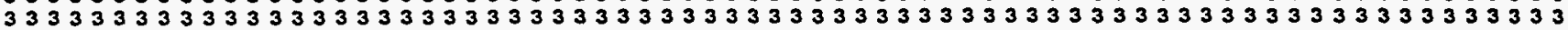

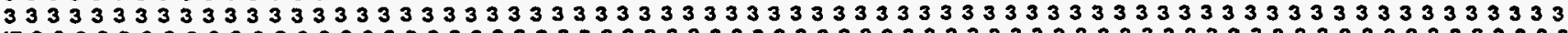

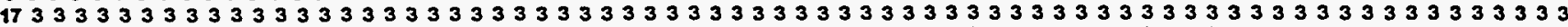

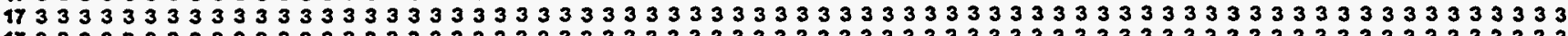

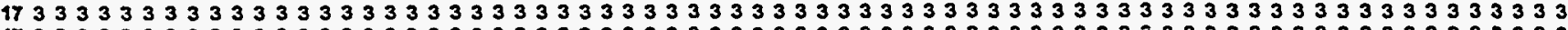

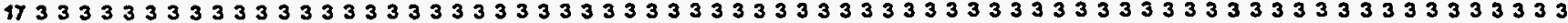

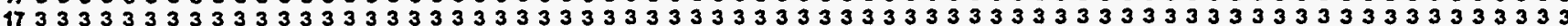

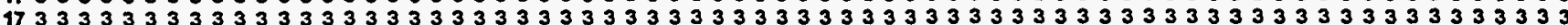

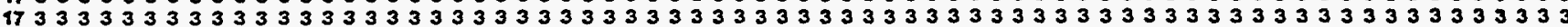

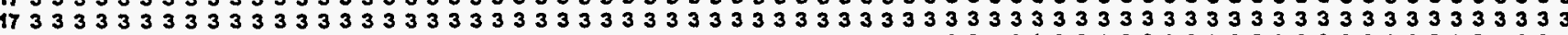

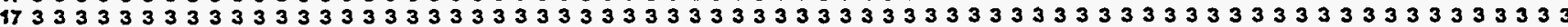

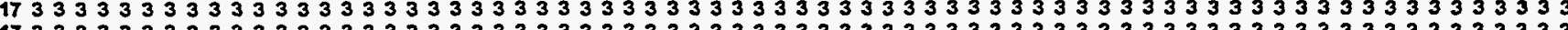

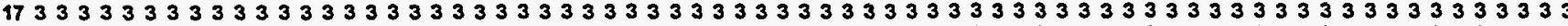
17333333333333333333333333333333333333333333333333333333333333333333333333

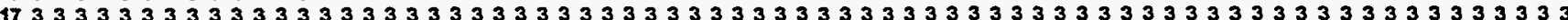

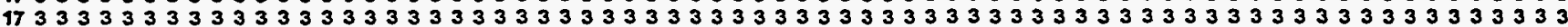

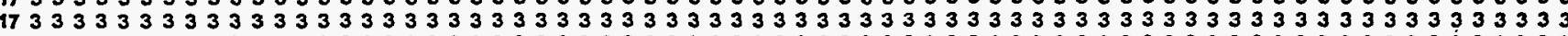

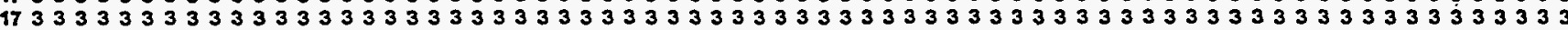

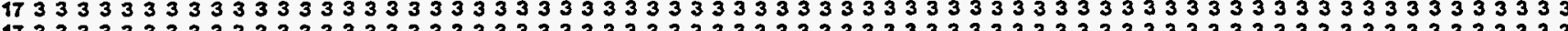

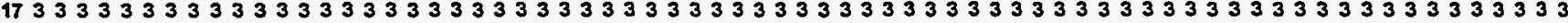

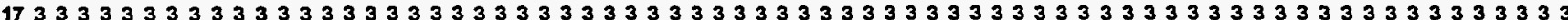

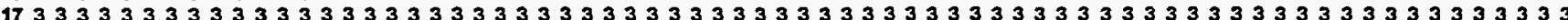

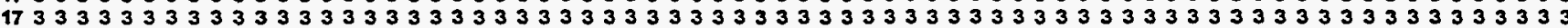

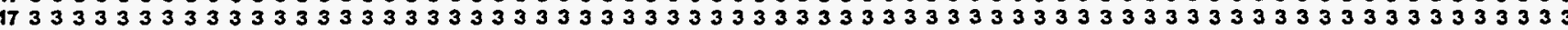

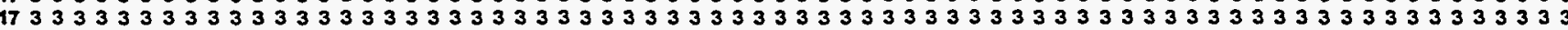

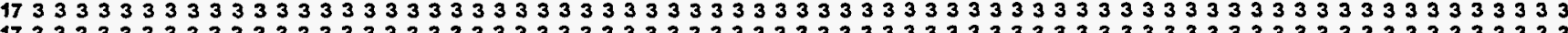

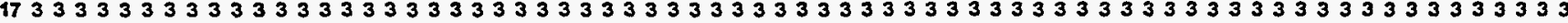

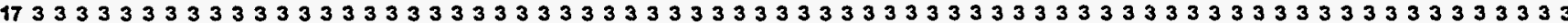

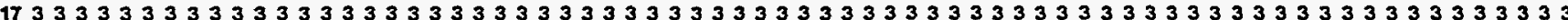

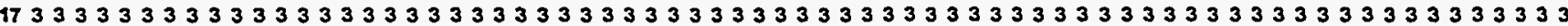

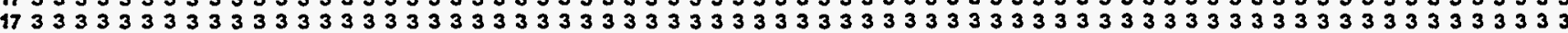

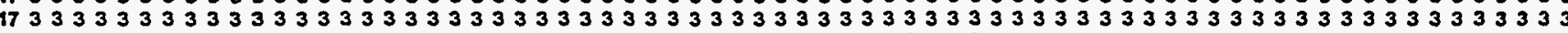

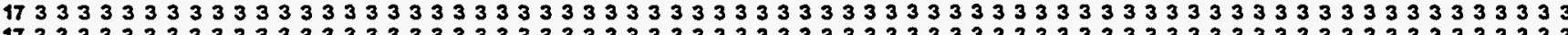

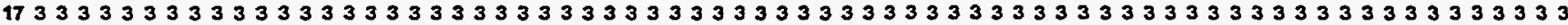
1733333333333333333333333333333333333333333333333333333333333333333333333333

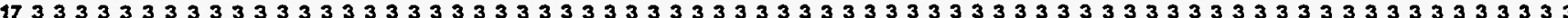

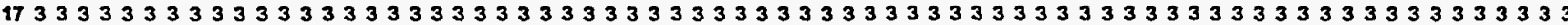

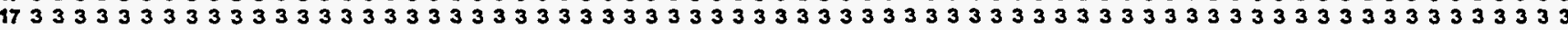

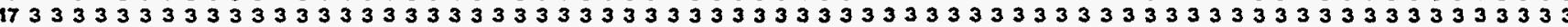

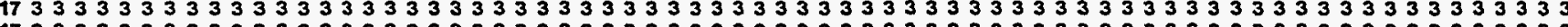

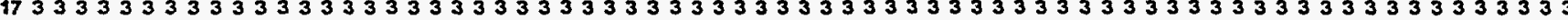

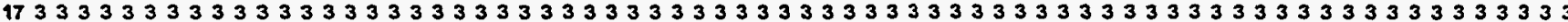

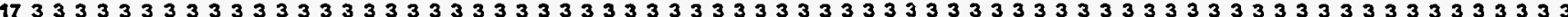

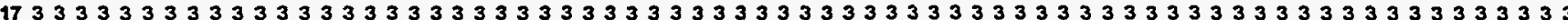

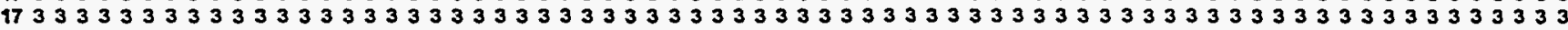

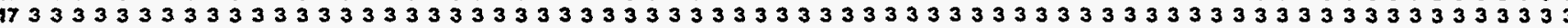

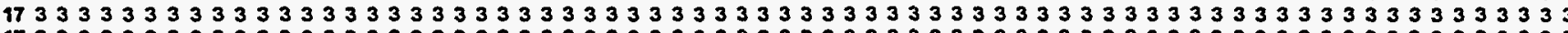

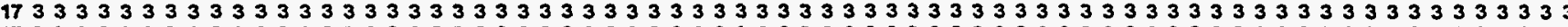

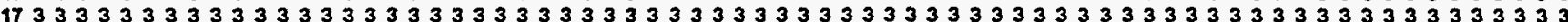

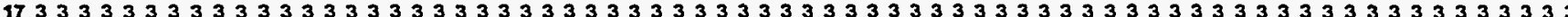

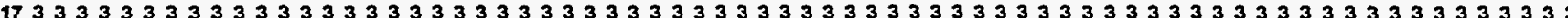

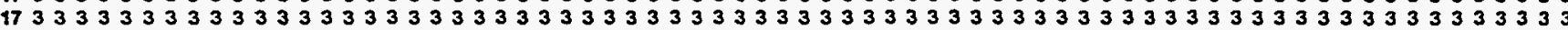

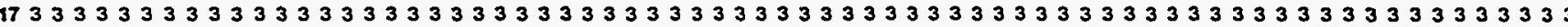

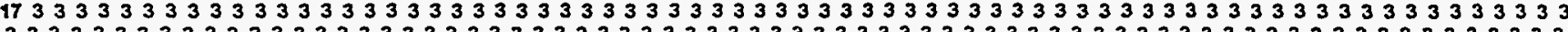

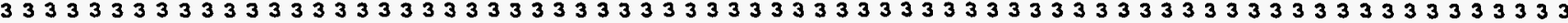

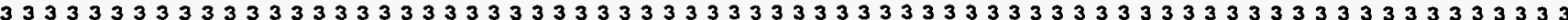

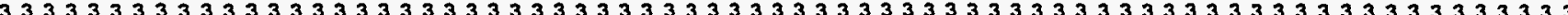

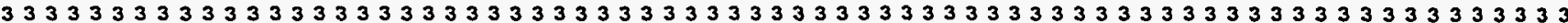

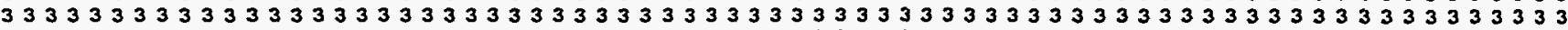

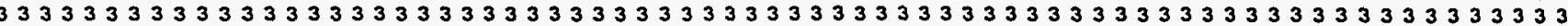

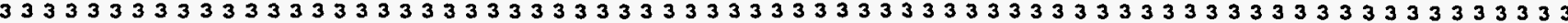

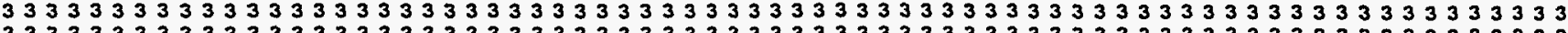

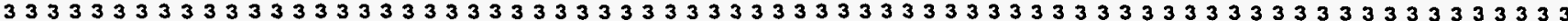

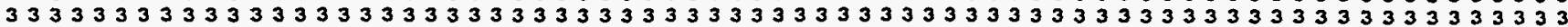

Figure 18. ZONEBUDGET node assignments for Layer 3 


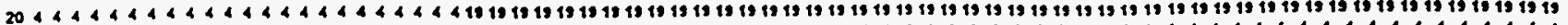
20444444444444444444444444444444444444444444444444444444444444444444444418 20444444444444444444444444414444444444444444444444444444444444444444444418 20444444444441444444414444444444444444444444444444444444441444444444444118

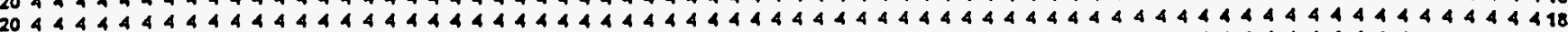

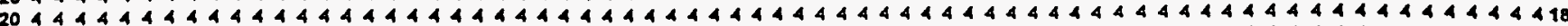

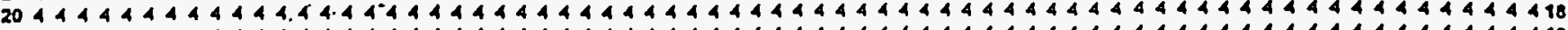

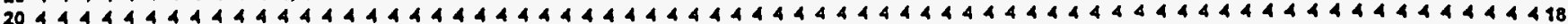

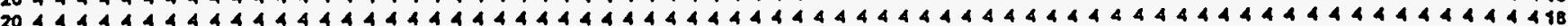

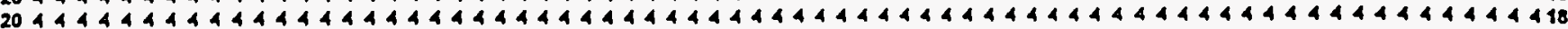

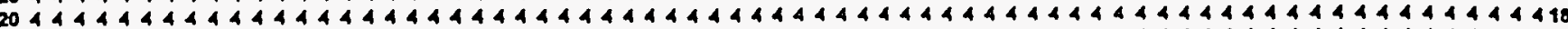

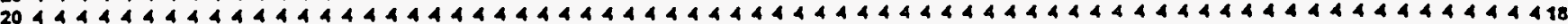

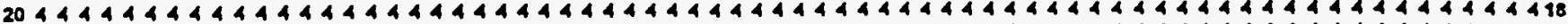

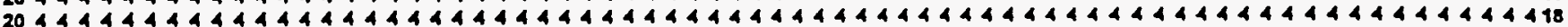

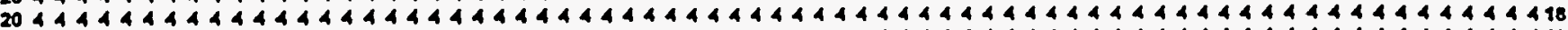

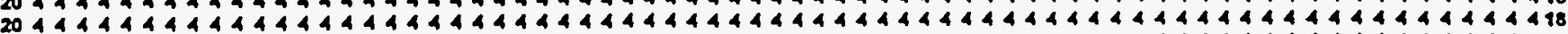

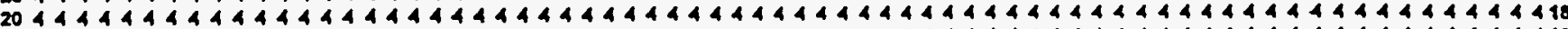

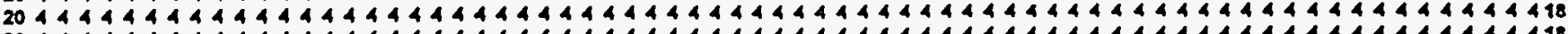

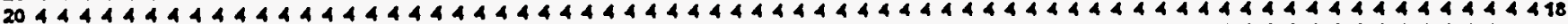

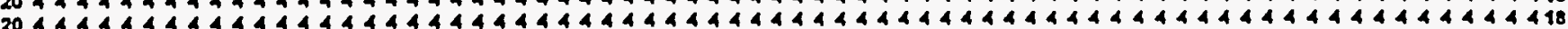

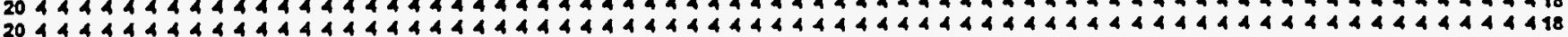

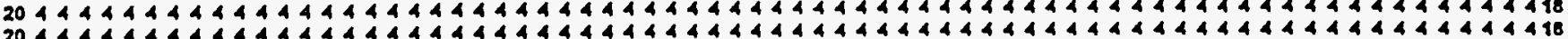

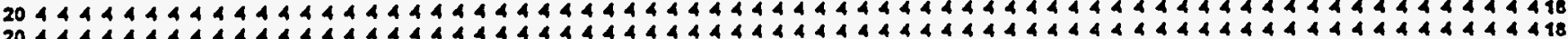

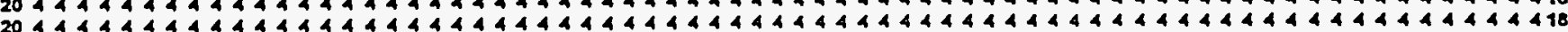

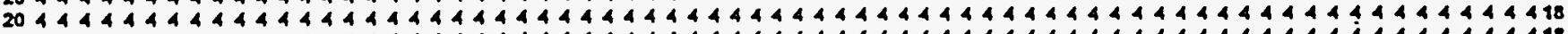

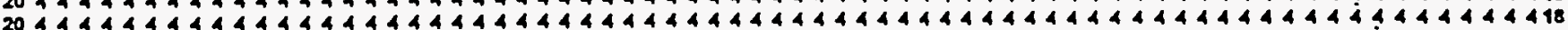

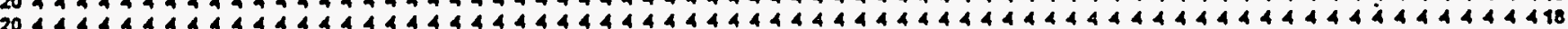

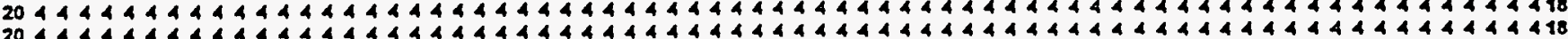

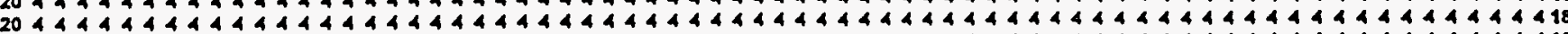

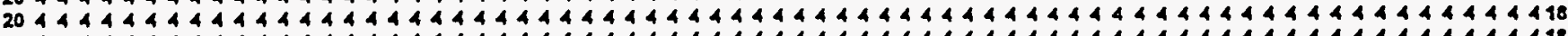

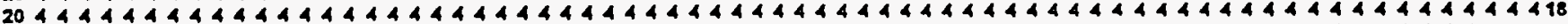

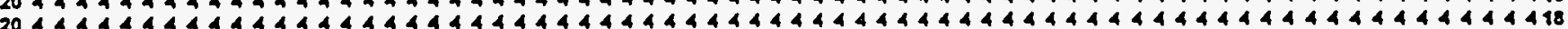

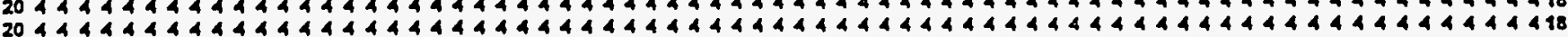

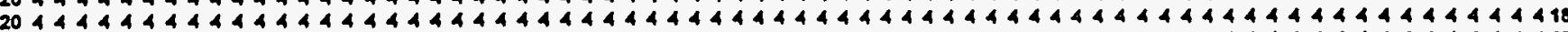

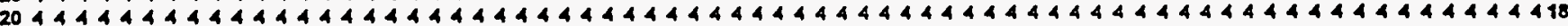

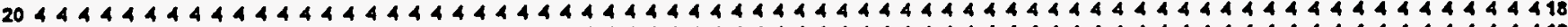

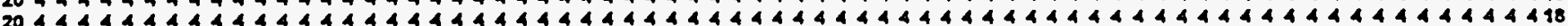
204a

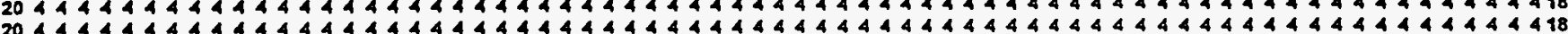

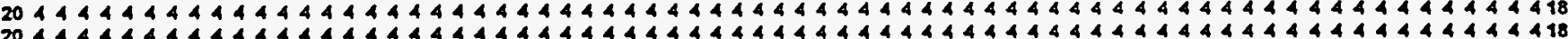

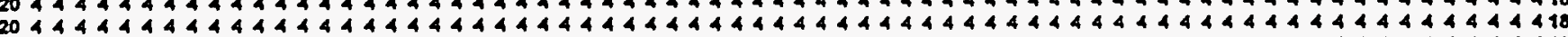

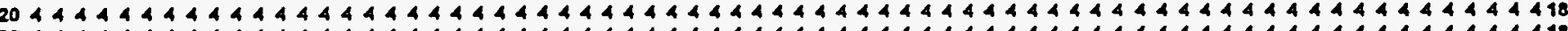
20444444444444444441444444444444444444444444444444444444444444444444444418 20444444444444444444444444444444444444444444444444444444444444444444444418

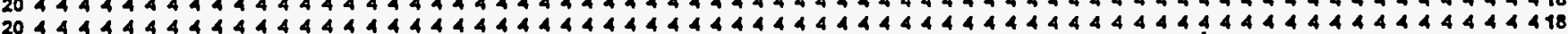

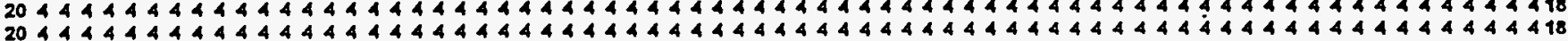
2044 444444444444444444441444444444444444444444444444444444444444444444418

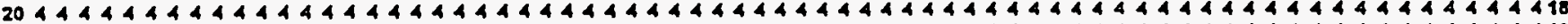

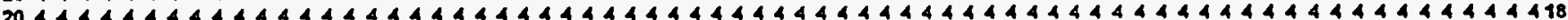
20444444444444444444444444444444444444444444444444444144444444444444444418

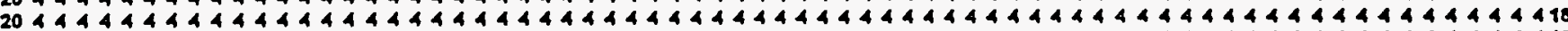

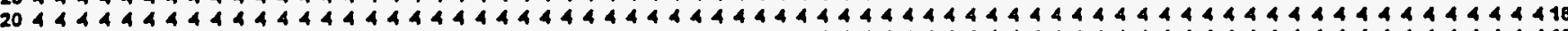

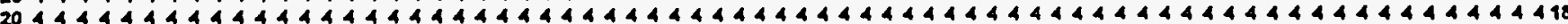

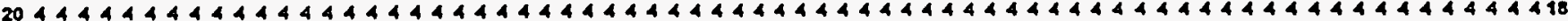

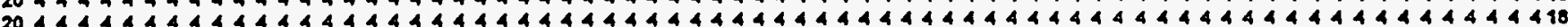
2014

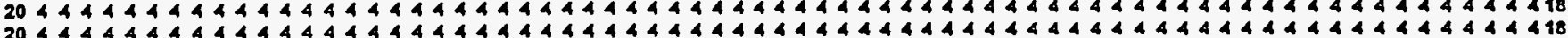

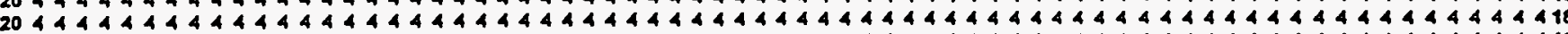

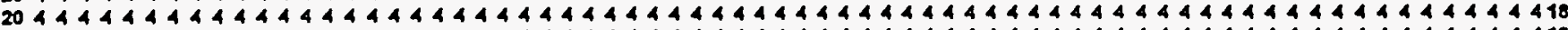

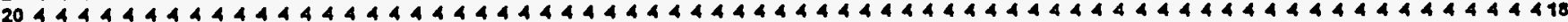

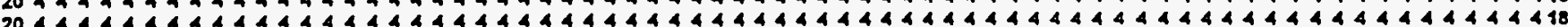

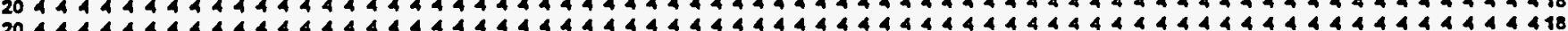

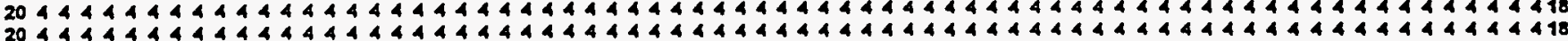

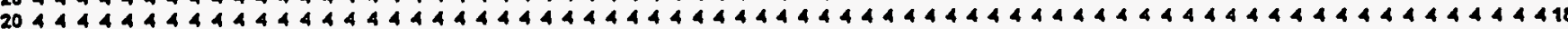

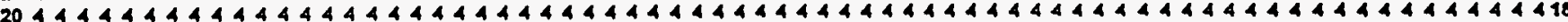

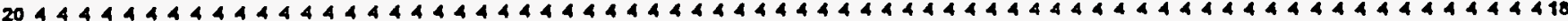

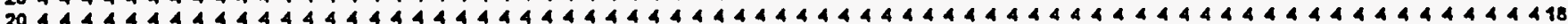

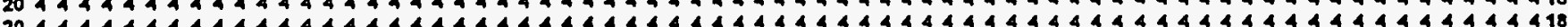

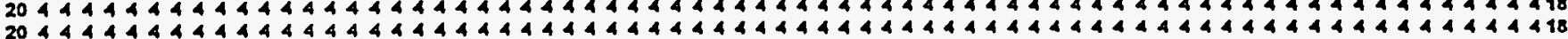

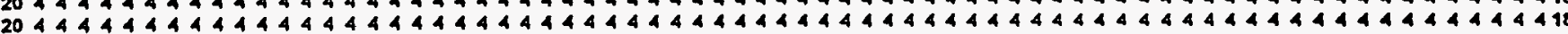
20444444444444444444444444444444444444444444444444444444444444444444444418 20444444444444444444444444444444444144444444444444444444444444444444444418 20444444444444444444444444444444444444444444444444444444444444444444444418 20144da

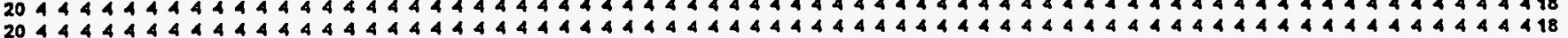
20444444444444444444444444444444444444444444444444444444444444444444444498 20444444444444444444444444444444444444444444444444444444444444444444444418 2044444444444444444444444444444444444444444444444444444444444444444444444 2044444444444444444444444444444444444444444444444444444444444444444444444 2041444444444444444444444444444441444444444444444444444444444444444444444

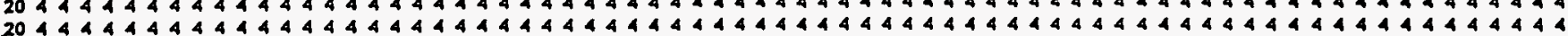
2044444444444444444,444444444444444444444444444444444444444444444444444444

Figure 19. ZONEBUDGET node assignments for Layer 4 


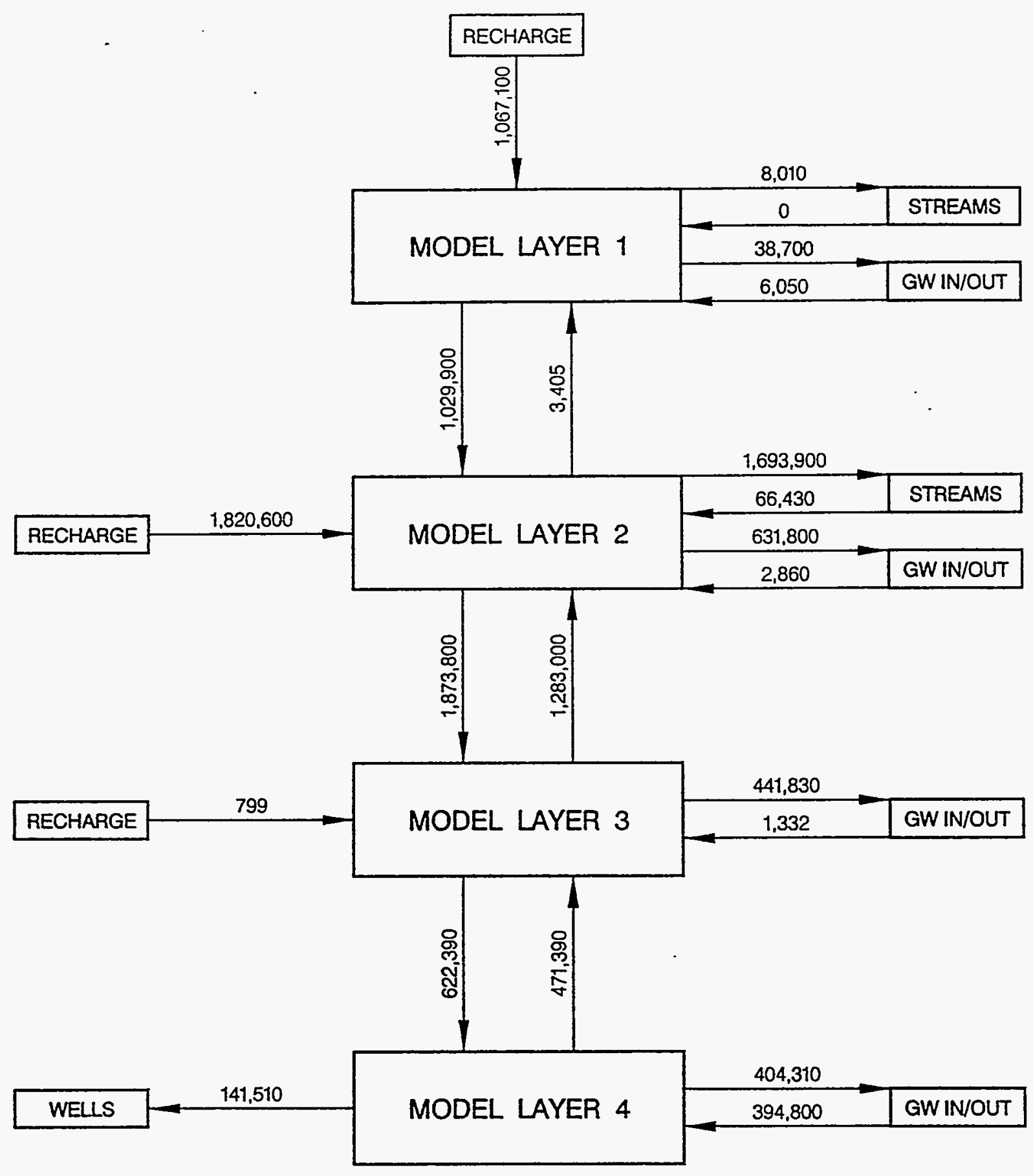

Fig. 20 Schematic diagram showing calculated fluxes ( $t^{3} /$ day) for the four model layers 


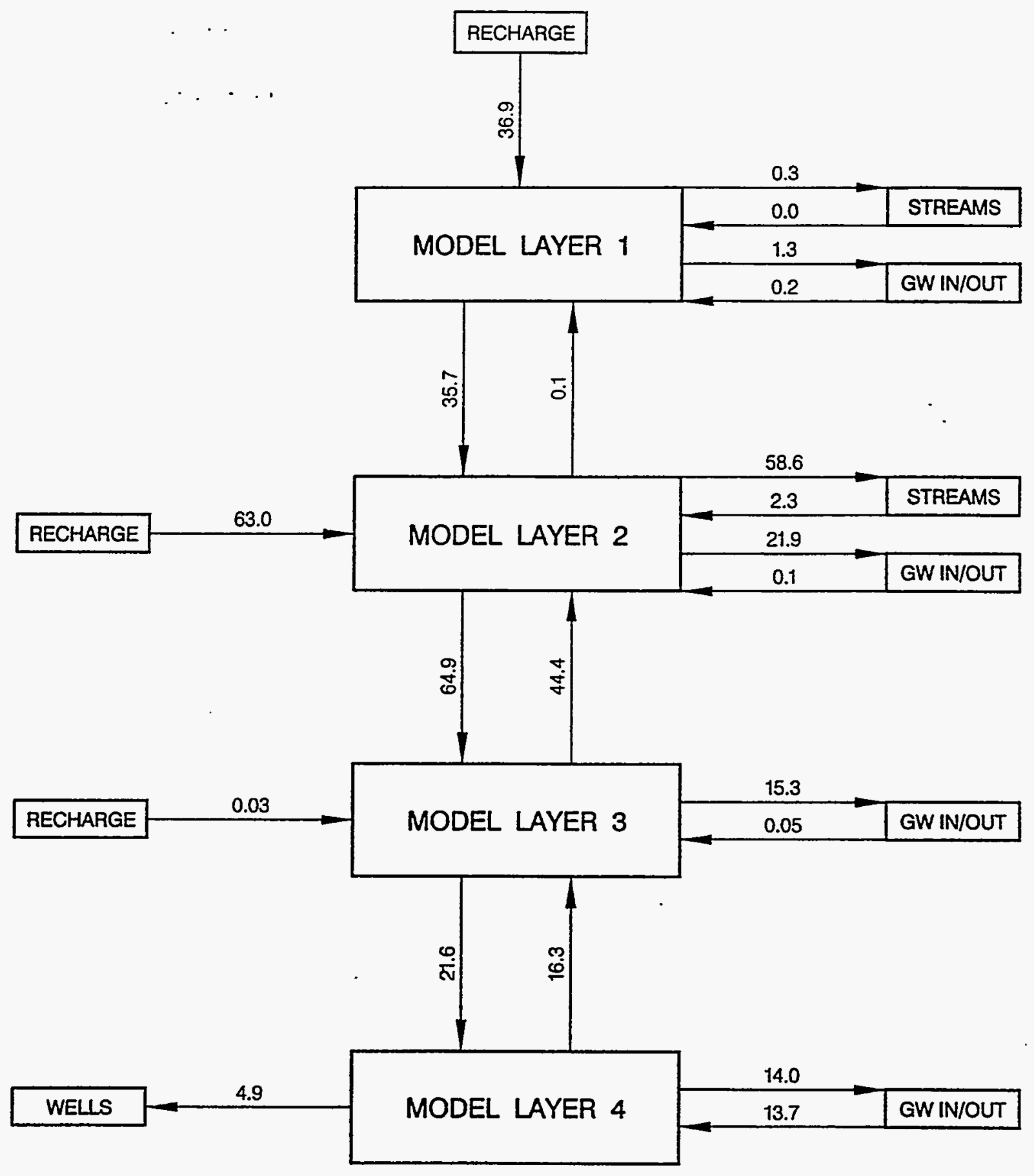

Fig. 21 Schematic diagram showing normalized fluxes for the four model layers 


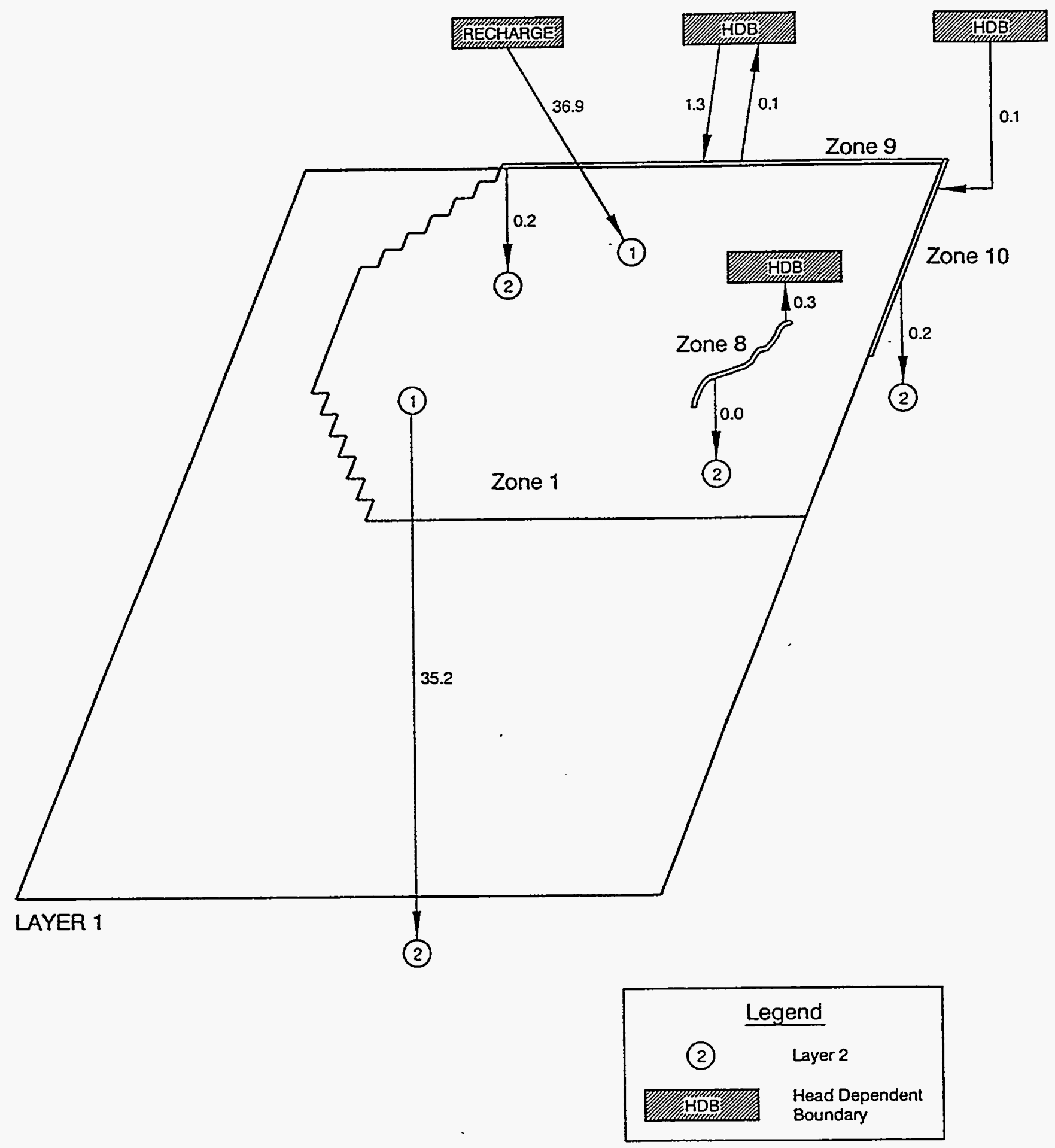

Fig. 22 Layer 1 subzone schematic showing normalized flow components 


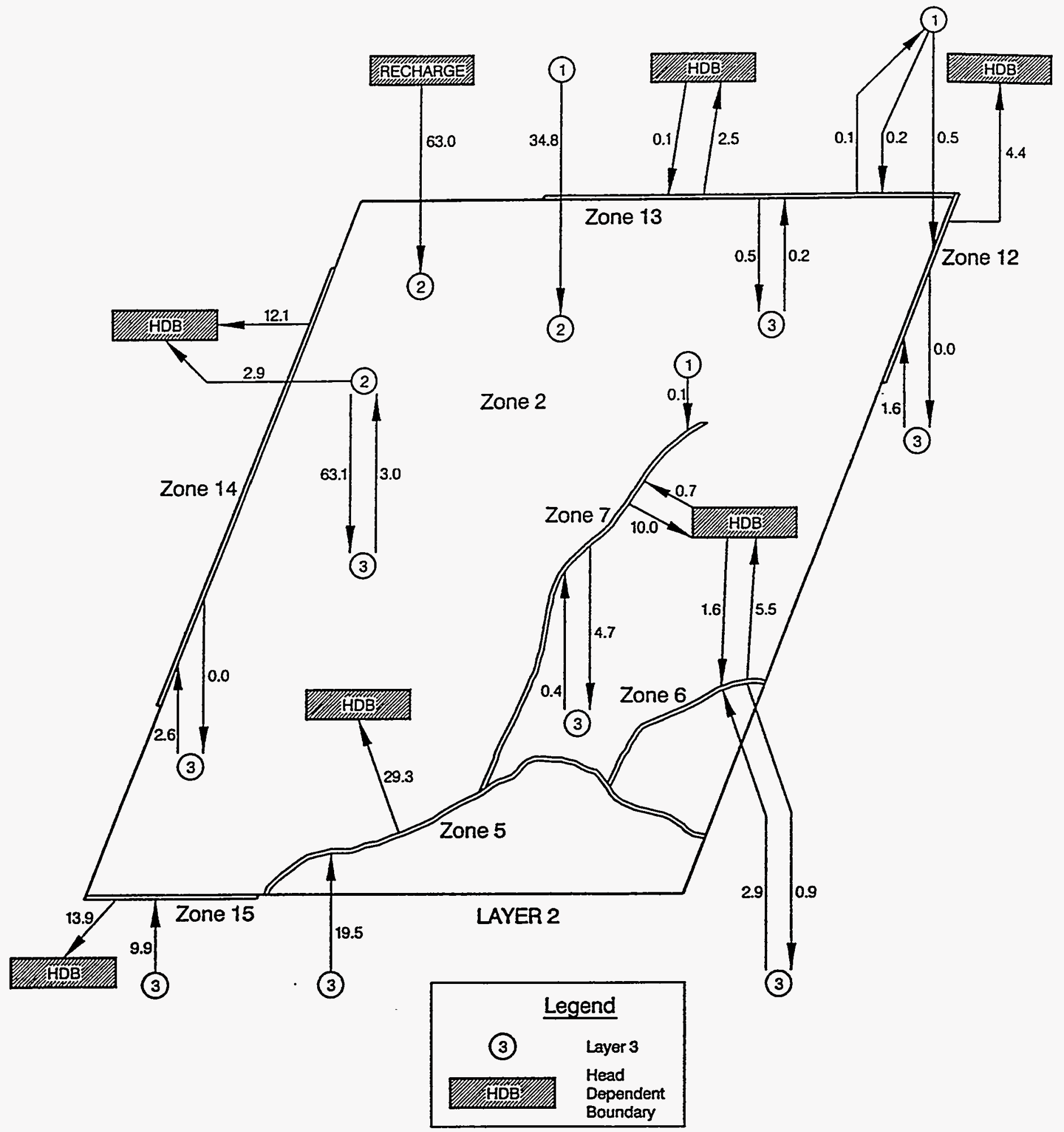

Fig. 23 Layer 2 subzone schematic showing normalized flow components 


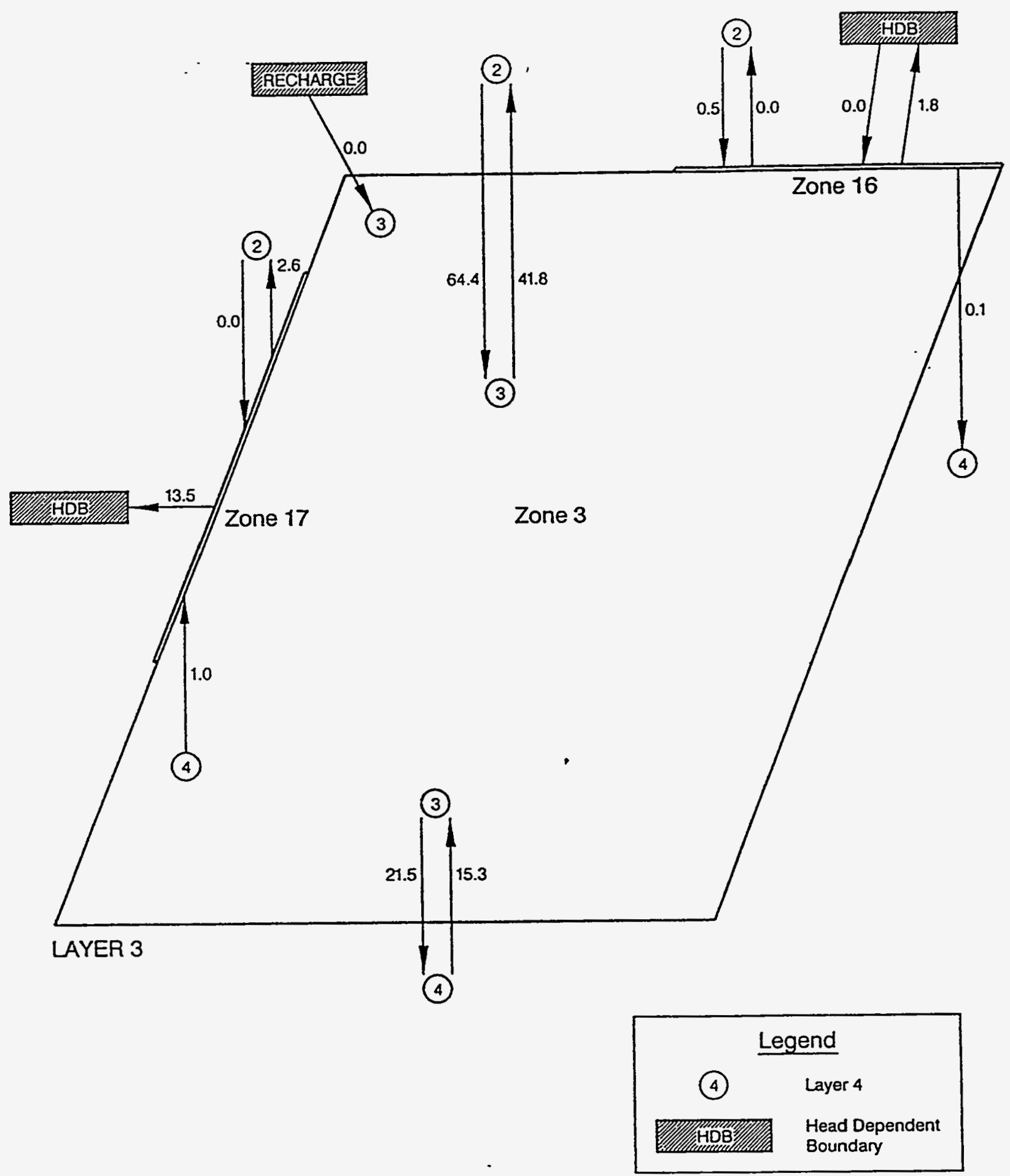

Fig. 24 Layer 3 subzone schematic showing normalized flow components 


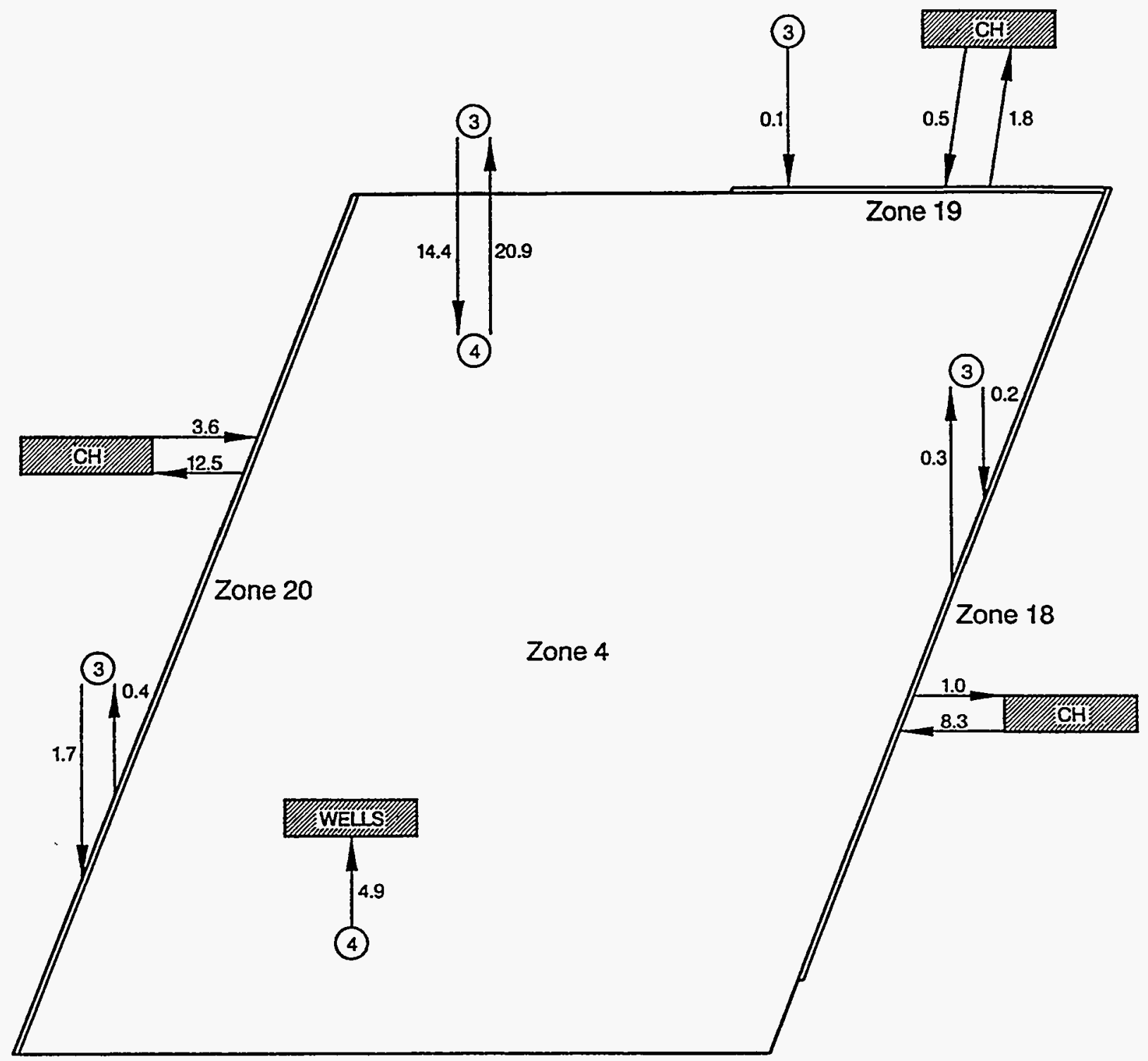

LAYER 4

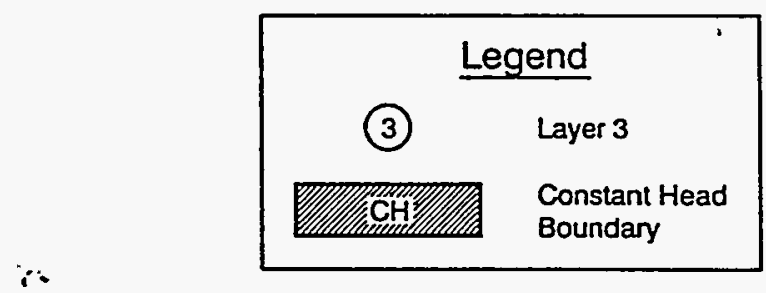

Fig. 25 Layer 4 subzone schematic showing normalized flow components 


\section{REFERENCES}

Bledsoe, H.W., 1988, Baseline Hydrogeologic Investigation-Phase III. U.S. DOE Report DPST-88-627, E.I. du Pont de Nemours \& Co. Savannah River Laboratory, Aiken, SC, $99 p, 8$ appendices

Geraghty and Miller, Inc., 1987. Aquifer Test of Well MSB-37TA, AVM Area, Prepared for E.l. du Pont de Nemours \& Co, Savannah River Plant, Aiken, SC.

Harbaugh, A.W., A Computer Program for Calculating Subregional Water Budgets Using Results from the U.S. Geological Survey Modular Three-Dimensional Finite-Difference Ground-Water Flow Model, U.S. Geological Survey Open-File Report 90-392.

Intera, Inc., 1993, A Transiently Calibrated Regional Groundwater Flow Model for the AM Area, Savannah River Site, Aiken, SC

Lewis, S.E., and R.K. Aadland, 1992, Hydrogeologic Setting of AM Area: Framework for Groundwater Transport (U). Westinghouse Savannah River Co., Savannah River Site, Aiken, SC, WSRC-TR-92-355.

McDonald, M.G., and A.W. Harbaugh, 1983, A Modular Three-Dimensional FiniteDifference Ground-Water Flow Model. U.S.Geological Survey Open-File Report 83-875.

Siple, G.E., 1967, Geology and Groundwater of the Savannah River Plant and Vicinity, South Carolina. U.S. Geological Survey Water-Supply Paper 1841, 113 p.

Sirrine, 1987, AM Area Phase IIB Monitoring Well Installation Report. Prepared for E.l. du Pont de Nemours \& Co, Savannah River Plant, Aiken, SC.

Sirrine, 1991, A/M Area Phase IV Monitoring and Recovery Well Installation Report. Prepared for Westinghouse Savannah River Co. Savannah River Site, Aiken, SC 
APPENDIX A 


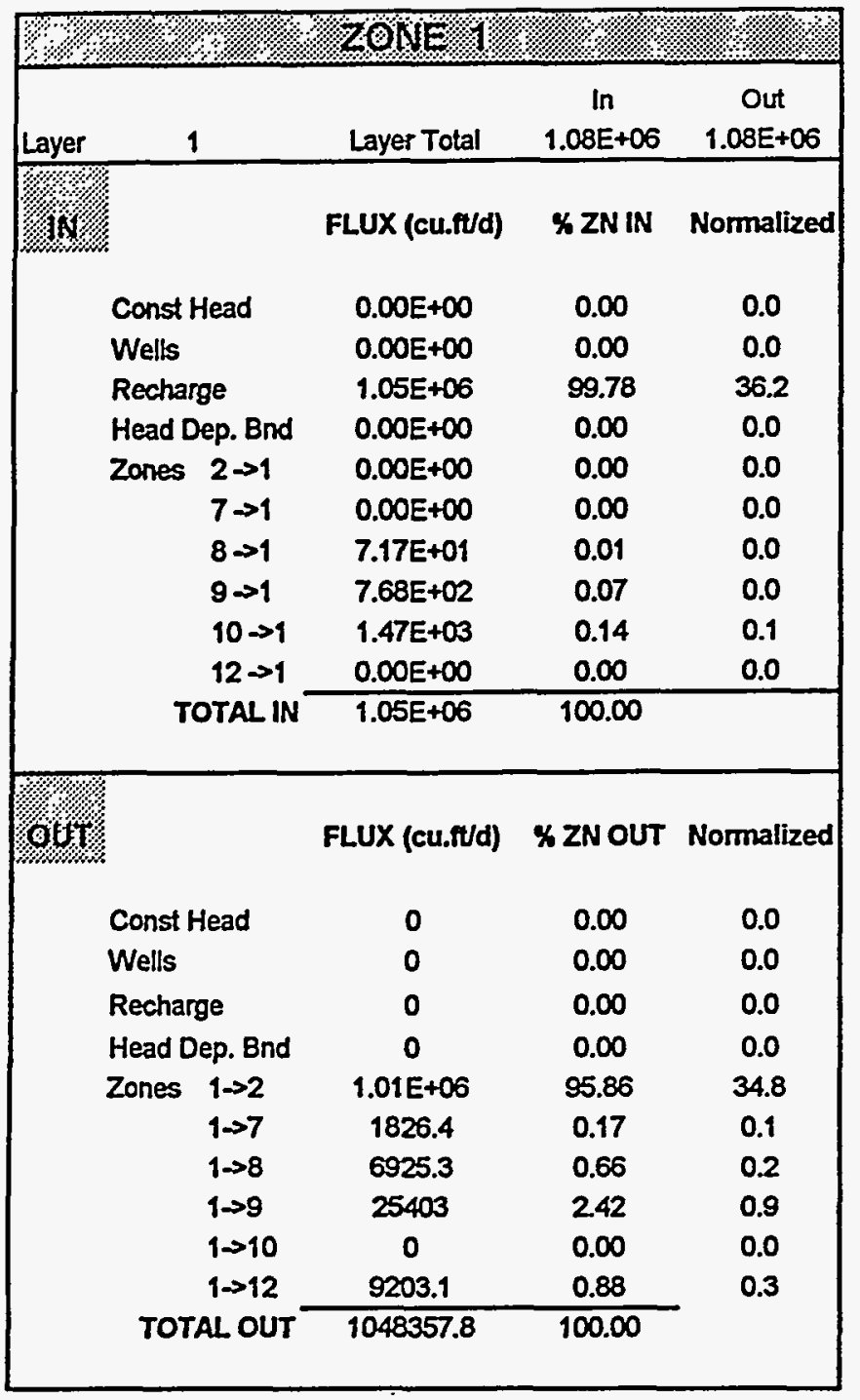

\begin{tabular}{|c|c|c|c|c|c|}
\hline ४ै & & ४ै & ZONE & & \\
\hline Layer & & & Layer Total & $\underset{4.20 E+06}{\ln }$ & $\begin{array}{c}\text { Out } \\
4.20 E+06\end{array}$ \\
\hline 搢 & & & FLUX (cu.ft/d) & $\%$ ZN IN & Normalized \\
\hline & Const & ead & $0.00 E+\infty$ & 0.00 & 0.0 \\
\hline & Wells & & $0.00 E+\infty$ & 0.00 & 0.0 \\
\hline & Recha & & $1.64 \mathrm{E}+06$ & 57.80 & 56.9 \\
\hline & Head $\mathrm{C}$ & p. Bnd & $0.00 E+\infty$ & 0.00 & 0.0 \\
\hline & Zones & $1 \rightarrow 2$ & $1.01 E+06$ & 35.35 & 34.8 \\
\hline & & $3 \rightarrow 2$ & $8.70 E+04$ & 3.06 & 3.0 \\
\hline & & $5 \rightarrow 2$ & $0.00 E+\infty$ & 0.00 & 0.0 \\
\hline & & $6 \rightarrow 2$ & $6.70 E+04$ & 2.36 & 2.3 \\
\hline & & $7 \rightarrow 2$ & $3.93 \mathrm{E}+04$ & 1.38 & 1.4 \\
\hline & & $8 \rightarrow 2$ & $1.41 E+03$ & 0.05 & 0.0 \\
\hline & & $12 \rightarrow 2$ & $0.00 E+00$ & 0.00 & 0.0 \\
\hline & & $13 \rightarrow 2$ & $0.00 E+\infty$ & 0.00 & 0.0 \\
\hline & & $14>2$ & $0.00 E+\infty$ & $0 . \infty$ & 0.0 \\
\hline & & $15>2$ & $0.00 \mathrm{E}+\infty 0$ & 0.00 & 0.0 \\
\hline & & DTAL IN & $2.84 E+06$ & 100.00 & \\
\hline 018 & & & FLUX (cu.ft/d) & \% ZN OUT & Normalized \\
\hline & Const & ead & $0.00 E+\infty$ & 0.00 & 0.0 \\
\hline & Wells & & $0.00 E+\infty$ & 0.00 & 0.0 \\
\hline & Recha: & & $0.00 E+\infty$ & 0.00 & 0.0 \\
\hline & Head $\mathrm{C}$ & p. Bnd & $8.40 E+04$ & 2.95 & 2.9 \\
\hline & Zones & $2 \rightarrow 1$ & $0.00 E+\infty$ & 0.00 & 0.0 \\
\hline & & $2 \rightarrow 3$ & $1.82 E+06$ & 64.09 & 63.1 \\
\hline & & $2 \rightarrow 5$ & 2.25E+05 & 7.99 & 7.8 \\
\hline & & $2->6$ & $1.07 E+05$ & 3.77 & 3.7 \\
\hline & & $2 \rightarrow 7$ & $1.68 E+05$ & 5.90 & 5.8 \\
\hline & & $2>8$ & $0.00 E+\infty$ & 0.00 & 0.0 \\
\hline & & $2 \rightarrow 12$ & $6.54 E+04$ & 2.30 & 2.3 \\
\hline & & $2 \rightarrow 13$ & $7.48 E+04$ & 2.63 & 2.6 \\
\hline & & $2 \rightarrow 14$ & $2.10 E+05$ & 7.40 & 7.3 \\
\hline & & $2 \rightarrow 15$ & $8.67 E+04$ & 3.05 & 3.0 \\
\hline & TO & AL OUT & $2.84 E+06$ & 100.00 & \\
\hline
\end{tabular}




\begin{tabular}{|c|c|c|c|c|c|}
\hline & & & HOUE & & \\
\hline Layer & 3 & & Layer Total & $\begin{array}{c}\text { In } \\
2.35 E+06\end{array}$ & $\begin{array}{c}\text { Out } \\
2.35 E+06\end{array}$ \\
\hline , x & & & FLUX (cu.tt/d) & $\% \mathrm{ZN}$ IN & Normalized \\
\hline & Const & lead & $0.00 E+\infty 0$ & 0.00 & 0.0 \\
\hline & Wells & & $0.00 E+\infty$ & 0.00 & 0.0 \\
\hline & Recha: & & $7.99 E+02$ & 0.03 & 0.0 \\
\hline & Head $\mathrm{C}$ & ep. Bnd & $0.00 E+\infty 0$ & 0.00 & 0.0 \\
\hline & Zones & $2 \rightarrow 3$ & $1.82 E+06$ & 79.10 & 63.1 \\
\hline & & $4>3$ & $4.15 E+05$ & 18.03 & 14.4 \\
\hline & & $5 \rightarrow 3$ & $0.00 E+\infty$ & 0.00 & 0.0 \\
\hline & & $6 \rightarrow 3$ & 2.63E+04 & 1.14 & 0.9 \\
\hline & & $7 \rightarrow 3$ & $1.12 E+04$ & 0.49 & 0.4 \\
\hline & & $12 \rightarrow 3$ & $1.03 E+02$ & 0.00 & 0.0 \\
\hline & & $13 \rightarrow 3$ & $0.00 E+\infty 0$ & 0.00 & 0.0 \\
\hline & & $15>3$ & $0.00 E+\infty$ & 0.00 & 0.0 \\
\hline & & $16-3$ & $9.98 E+02$ & 0.04 & 0.0 \\
\hline & & $17 \rightarrow 3$ & $0.00 E+\infty$ & 0.00 & 0.0 \\
\hline & & $18>3$ & $7.55 E+03$ & 0.33 & 0.3 \\
\hline & & $20 \rightarrow 3$ & $1.93 E+04$ & 0.84 & 0.7 \\
\hline & & DTAL IN & $2.30 \mathrm{E}+06$ & 100.00 & \\
\hline 8,13 & & & FLUX (cu.ft/d) & \% ZN OUT & Normalized \\
\hline & Const 1 & lead & $0.00 E+00$ & 0.00 & 0.0 \\
\hline & Wells & & $0.00 E+00$ & 0.00 & 0.0 \\
\hline & Rechar & & $0.00 E+\infty 0$ & 0.00 & 0.0 \\
\hline & Head $\mathrm{C}$ & ep. Bnd & $0.00 E+00$ & 0.00 & 0.0 \\
\hline & Zones & $3 \rightarrow 2$ & 8.70E+04 & 3.78 & 3.0 \\
\hline & & $3 \rightarrow>4$ & $6.04 E+05$ & 26.21 & 20.9 \\
\hline & & $3 \rightarrow 5$ & $5.62 E+05$ & 24.41 & 19.5 \\
\hline & & $3 \rightarrow 6$ & $8.44 E+04$ & 3.67 & 2.9 \\
\hline & & $3 \rightarrow 7$ & $1.36 E+05$ & 5.92 & 4.7 \\
\hline & & $3 \rightarrow 12$ & $4.70 E+04$ & 2.04 & 1.6 \\
\hline & & $3 \rightarrow 13$ & $3.51 E+03$ & 0.15 & 0.1 \\
\hline & & $3 \rightarrow 15$ & $2.86 E+05$ & 12.43 & 9.9 \\
\hline & & $3 \rightarrow 16$ & 4.14E+04 & 1.80 & 1.4 \\
\hline & & $3 \rightarrow 17$ & $4.35 E+05$ & 18.88 & 15.1 \\
\hline & & $3 \rightarrow 18$ & $4.82 E+03$ & 0.21 & 0.2 \\
\hline & & $3 \rightarrow 20$ & $1.16 \mathrm{E}+04$ & 0.50 & 0.4 \\
\hline & TOT & AL OUT & $2.30 E+06$ & 100.00 & \\
\hline
\end{tabular}

\begin{tabular}{|c|c|c|c|c|c|}
\hline & & & $\angle O U \mathrm{UL} / \%$ & & \% \\
\hline Layer & \multicolumn{2}{|c|}{4} & Layer Total & $\begin{array}{c}\ln \\
1.02 E+06 \\
\end{array}$ & $\begin{array}{c}\text { Out } \\
1.02 E+06\end{array}$ \\
\hline \multirow[t]{10}{*}{ 祭 } & & FLUX (cu.ftud) & $\%$ ZN IN & Normalized \\
\hline & \multicolumn{2}{|c|}{ Const Head } & $0.00 E+\infty 0$ & $0 . \infty$ & 0.0 \\
\hline & \multicolumn{2}{|c|}{ Wells } & $0.00 E+\infty$ & 0.00 & 0.0 \\
\hline & \multicolumn{2}{|c|}{ Recharge } & $0.00 E+\infty$ & 0.00 & 0.0 \\
\hline & \multicolumn{2}{|c|}{ Head Dep. Bnd } & $0.00 E+\infty$ & 0.00 & 0.0 \\
\hline & \multirow[t]{5}{*}{ Zones } & $3>4$ & $6.04 E+05$ & 64.07 & 20.9 \\
\hline & & $18 \rightarrow 4$ & $2.32 E+05$ & 24.65 & 8.0 \\
\hline & & $19>4$ & $5.08 E+04$ & 5.39 & 1.8 \\
\hline & & $20-4$ & $5.55 E+04$ & 5.89 & 1.9 \\
\hline & & DTAL IN & $9.42 E+05$ & 100.00 & \\
\hline \multirow[t]{10}{*}{ sour } & & & FLUX (cu.ft/d) & \% ZN OUT & Normalized \\
\hline & \multicolumn{2}{|c|}{ Const Head } & $0.00 E+\infty$ & 0.00 & 0.0 \\
\hline & \multicolumn{2}{|c|}{ Wells } & $1.42 E+05$ & 15.02 & 4.9 \\
\hline & \multicolumn{2}{|c|}{ Recharge } & $0.00 E+\infty 0$ & 0.00 & 0.0 \\
\hline & \multicolumn{2}{|c|}{ Head Dep. Bnd } & $0.00 E+\infty$ & 0.00 & 0.0 \\
\hline & \multirow[t]{5}{*}{ Zones } & $4>3$ & 4.15E+05 & 44.06 & 14.4 \\
\hline & & $4>18$ & $2.42 E+04$ & 2.56 & 0.8 \\
\hline & & $4>19$ & $1.27 E+04$ & 1.35 & 0.4 \\
\hline & & $4>20$ & $3.49 E+05$ & 37.01 & 12.1 \\
\hline & & AL OUT & $9.42 \mathrm{E}+05$ & 100.00 & \\
\hline
\end{tabular}




\begin{tabular}{|c|c|c|c|c|c|}
\hline \% & 8 & \% & Zoul & & ॥. \\
\hline Layer & 2 & & Layer Total & $\begin{array}{c}\ln \\
4.20 E+06\end{array}$ & $\begin{array}{c}\text { Out } \\
4.20 E+06\end{array}$ \\
\hline s/ & & & FLUX (cu.ft/d) & $\%$ ZN IN & Normalized \\
\hline & Const I & lead & $0.00 E+\infty$ & 0.00 & 0.0 \\
\hline & Wells & & $0.00 E+\infty 0$ & 0.00 & 0.0 \\
\hline & Rechar & & $5.38 E+04$ & 6.36 & 1.9 \\
\hline & Head D & ep. Bnd & $0.00 E+\infty 0$ & 0.00 & 0.0 \\
\hline & Zones & $2 \rightarrow 5$ & 2.25E+05 & 26.60 & 7.8 \\
\hline & & $3>5$ & $5.62 E+05$ & 66.49 & 19.5 \\
\hline & & $6 \rightarrow 5$ & $2.60 E+03$ & 0.31 & 0.1 \\
\hline & & $7 \rightarrow 5$ & $2.03 E+03$ & 0.24 & 0.1 \\
\hline & & TTAL IN & $8.46 E+05$ & 100.00 & \\
\hline$\%$ & & & FLUX (cu.ft/d) & \% ZN OUT & Normalized \\
\hline & Const 1 & lead & $0.00 E+\infty 0$ & 0.00 & 0.0 \\
\hline & Wells & & $0.00 E+\infty$ & 0.00 & 0.0 \\
\hline & Rechar & & $0.00 E+\infty 0$ & 0.00 & 0.0 \\
\hline & Head D & ep. Bnd & $8.46 E+05$ & 100.00 & 29.3 \\
\hline & Zones & $5 \rightarrow 2$ & $0.00 E+\infty 0$ & 0.00 & 0.0 \\
\hline & & $5 \rightarrow 3$ & $0.00 E+\infty$ & 0.00 & 0.0 \\
\hline & & $5>6$ & $0.00 E+\infty 0$ & 0.00 & 0.0 \\
\hline & & $5->7$ & $0.00 E+\infty$ & 0.00 & 0.0 \\
\hline & TOT & AL OUT & $8.46 E+05$ & 100.00 & \\
\hline
\end{tabular}

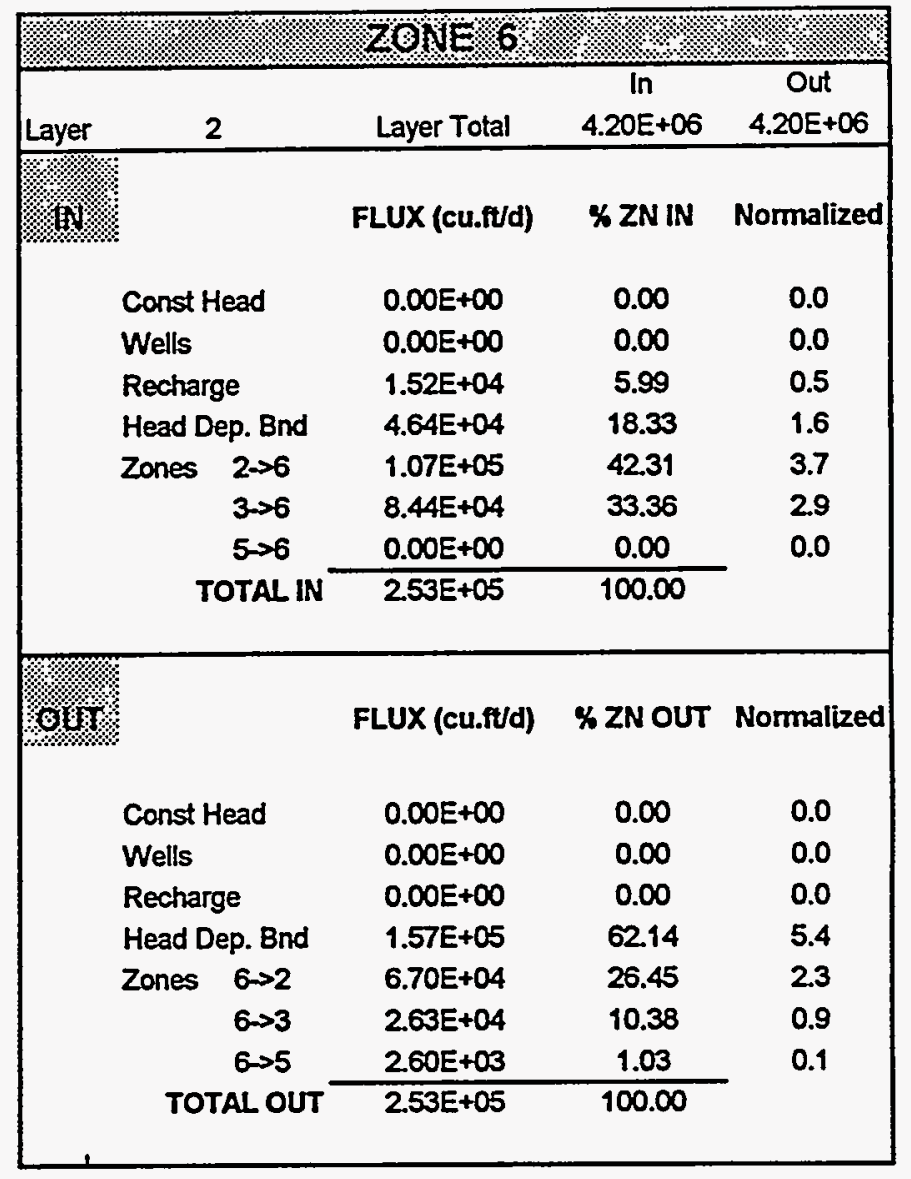




\begin{tabular}{|c|c|c|c|c|c|}
\hline \% & \% & & $4014=1$ & & \\
\hline Layer & ? & & Layer Total & $\begin{array}{c}\text { In } \\
4.20 E+05 \\
\end{array}$ & $\begin{array}{c}\text { Out } \\
4.20 E+06\end{array}$ \\
\hline \% & & & FLUX (cu.ft/d) & K ZN IN & Normalized \\
\hline & Const & Head & $0.00 E+\infty$ & 0.00 & 0.0 \\
\hline & Wells & & $0.00 E+\infty$ & 0.00 & 0.0 \\
\hline & Recha & & $1.70 E+04$ & 4.95 & 0.6 \\
\hline & Head I & ep. Bnd & $200 E+04$ & 5.84 & 0.7 \\
\hline & Zones & $1 \rightarrow 7$ & $1.83 E+03$ & 0.53 & 0.1 \\
\hline & & $2 \rightarrow 7$ & $1.68 E+05$ & 48.88 & 5.8 \\
\hline & & $3 \rightarrow 7$ & 1.36E+05 & 39.80 & 4.7 \\
\hline & & $5 \rightarrow 7$ & $0.00 \mathrm{E}+\infty$ & 0.00 & 0.0 \\
\hline & & OTAL IN & $3.43 E+05$ & 100.00 & \\
\hline 8 & & & FLUX (cu.ft/d) & K ZN OUT & Normalized \\
\hline & Const & lead & $0.00 E+\infty$ & 0.00 & 0.0 \\
\hline & Wells & & $0.00 E+\infty$ & 0.00 & 0.0 \\
\hline & Rechar & & $0.00 E+\infty$ & 0.00 & 0.0 \\
\hline & Head D & ep. Bnd & $2.90 E+05$ & 84.67 & 10.0 \\
\hline & Zones & $7 \rightarrow 1$ & $0.00 E+\infty$ & 0.00 & 0.0 \\
\hline & & $7 \rightarrow 2$ & $3.93 E+04$ & 11.47 & 1.4 \\
\hline & & $7 \rightarrow 3$ & $1.12 E+04$ & 3.26 & 0.4 \\
\hline & & $7 \rightarrow 5$ & $2.03 E+03$ & 0.59 & 0.1 \\
\hline & TOT & AL OUT & $3.43 E+05$ & 100.00 & \\
\hline
\end{tabular}

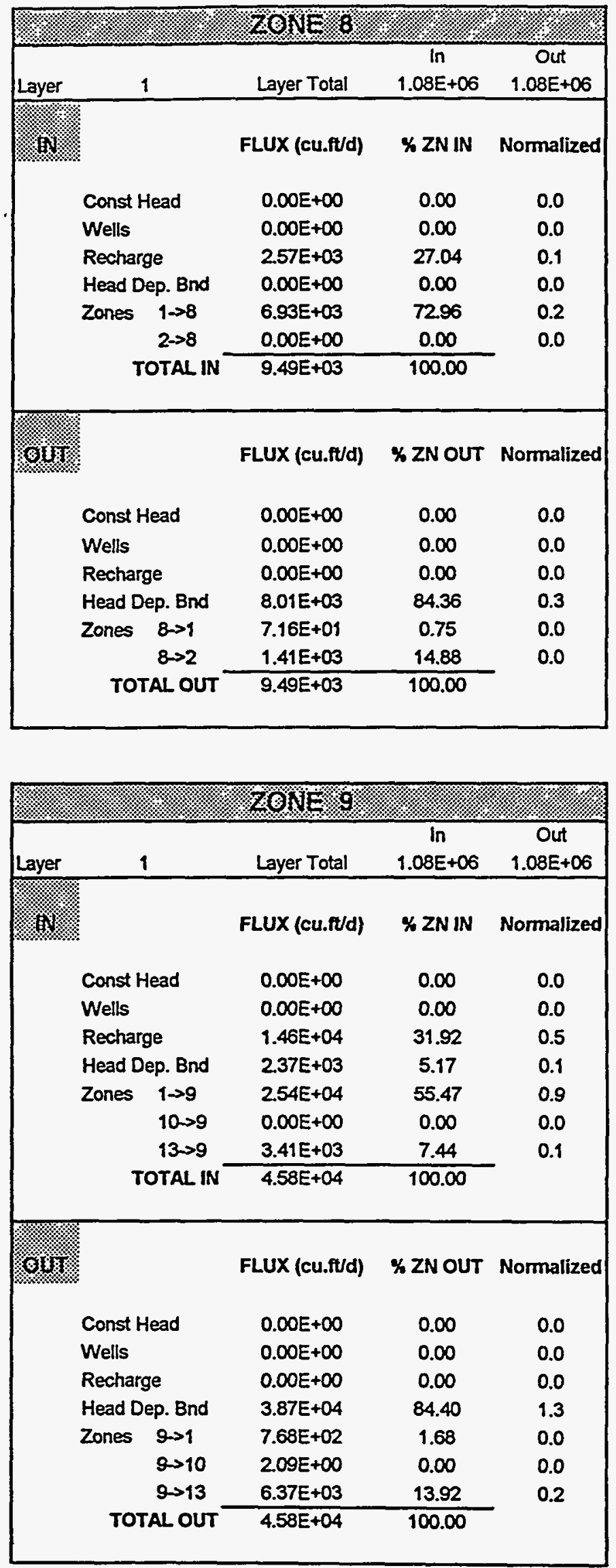




\begin{tabular}{|c|c|c|c|c|c|}
\hline \multirow[b]{2}{*}{ Layer } & \multicolumn{3}{|r|}{$2 O \mu 1=10$} & \multirow[b]{2}{*}{$\begin{array}{c}\text { In } \\
1.08 E+06\end{array}$} & \multirow[b]{2}{*}{$\begin{array}{c}\text { Out } \\
1.08 E+06\end{array}$} \\
\hline & \multicolumn{2}{|c|}{1} & Layer Total & & \\
\hline \multirow[t]{9}{*}{${ }^{\prime \prime k}$} & & FLUX (cu.ft/d) & $\%$ ZN IN & Normalized \\
\hline & \multicolumn{2}{|c|}{ Const Head } & $0.00 E+\infty$ & 0.00 & 0.0 \\
\hline & \multicolumn{2}{|c|}{ Wells } & $0.00 E+\infty$ & 0.00 & 0.0 \\
\hline & \multicolumn{2}{|c|}{ Recharge } & $3.85 E+03$ & 51.09 & 0.1 \\
\hline & \multicolumn{2}{|c|}{ Head Dep. Bnd } & $3.68 E+03$ & 48.69 & 0.1 \\
\hline & \multirow[t]{4}{*}{ Zones } & $i>10$ & $0.00 E+\infty$ & 0.00 & 0.0 \\
\hline & & $9>10$ & $2.09 E+\infty$ & 0.03 & 0.0 \\
\hline & & $12>10$ & $0.00 E+\infty$ & 0.00 & 0.0 \\
\hline & & TOTAL IN & $7.54 E+03$ & 100.00 & \\
\hline \multirow{10}{*}{ ofy } & & & & & \\
\hline & & & FLUX (cu.ft/d) & \% ZN OUT & Normalized \\
\hline & \multicolumn{2}{|c|}{ Const Head } & $0.00 E+\infty$ & 0.00 & 0.0 \\
\hline & \multicolumn{2}{|c|}{ Wells } & $0.00 E+\infty 0$ & 0.00 & 0.0 \\
\hline & \multicolumn{2}{|c|}{ Recharge } & $0.00 E+\infty 0$ & 0.00 & 0.0 \\
\hline & \multicolumn{2}{|c|}{ Head Dep. Bnd } & $0.00 E+\infty$ & 0.00 & 0.0 \\
\hline & \multirow[t]{4}{*}{ Zones } & $10>1$ & $1.47 E+03$ & 19.51 & 0.1 \\
\hline & & $10>9$ & $0.00 E+\infty 0$ & 0.00 & 0.0 \\
\hline & & $10>12$ & $6.07 E+03$ & 80.49 & 0.2 \\
\hline & & AL OUT & $7.54 E+03$ & 100.00 & \\
\hline
\end{tabular}

\begin{tabular}{|c|c|c|c|c|c|}
\hline 14 & & 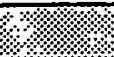 & $\angle O H E$ & & 8 \\
\hline Layer & & & Layer Total & $\begin{array}{c}\ln \\
4.20 E+06\end{array}$ & $\begin{array}{c}\text { Out } \\
4.20 E+06\end{array}$ \\
\hline אy & & & FLUX (cu.ft/d) & $\%$ ZN IN & Normalized \\
\hline & Const & lead & $0.00 E+\infty$ & 0.00 & 0.0 \\
\hline & Wells & & $0.00 E+\infty$ & 0.00 & 0.0 \\
\hline & Rechar & & $0.00 E+\infty$ & 0.00 & 0.0 \\
\hline & Head D & ep. Bnd & $0.00 E+\infty 0$ & 0.00 & 0.0 \\
\hline & Zones & $1 \rightarrow 12$ & $9.20 \mathrm{E}+03$ & 7.21 & 0.3 \\
\hline & & $2>12$ & $6.54 E+04$ & 51.26 & 2.3 \\
\hline & & $3 \rightarrow 12$ & $4.70 E+04$ & 36.78 & 1.6 \\
\hline & & $10>12$ & $6.07 E+03$ & 4.75 & 0.2 \\
\hline & & $13>12$ & $0.00 E+00$ & 0.00 & 0.0 \\
\hline & & OTAL IN & $1.28 E+05$ & 100.00 & \\
\hline \% & & & FLUX (cu.ft/d) & \% ZN OUT & Normalized \\
\hline & Const I & lead & $0.00 E+\infty$ & 0.00 & 0.0 \\
\hline & Wells & & $0.00 E+\infty$ & 0.00 & 0.0 \\
\hline & Rechar & & $0.00 E+\infty$ & 0.00 & 0.0 \\
\hline & Head D & ep. Bnd & $1.27 E+05$ & 99.80 & 4.4 \\
\hline & Zones & $12>1$ & $0.00 E+\infty 0$ & 0.00 & 0.0 \\
\hline & & $12 \rightarrow 2$ & $0.00 E+\infty 0$ & 0.00 & 0.0 \\
\hline & & $12 \rightarrow 3$ & $1.03 E+02$ & 0.08 & 0.0 \\
\hline & & $12>10$ & $0.00 E+\infty 0$ & 0.00 & 0.0 \\
\hline & & $12 \rightarrow 13$ & $1.52 E+02$ & 0.12 & 0.0 \\
\hline & TO & AL OUT & $1.28 E+05$ & 100.00 & \\
\hline
\end{tabular}




\begin{tabular}{|c|c|c|c|c|c|}
\hline & & & $\angle \& N=13$ & & \% \\
\hline & & & & $\ln$ & Out \\
\hline Layer & & 2 & Layer Total & $4.20 E+06$ & $4.20 E+06$ \\
\hline 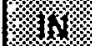 & & & FLUX (cu.tt/d) & K ZN IN & Normalized \\
\hline & Const & Head & $0.00 E+\infty 0$ & 0.00 & 0.0 \\
\hline & Wells & & $0.00 E+\infty 0$ & 0.00 & 0.0 \\
\hline & Recha & & $0.00 E+\infty 0$ & 0.00 & 0.0 \\
\hline & Head I & ep. Bnd & $2.86 E+03$ & 3.23 & 0.1 \\
\hline & Zones & $2 \rightarrow 13$ & $7.48 E+04$ & 84.54 & 2.6 \\
\hline & & $3 \rightarrow 13$ & $3.51 E+03$ & 3.96 & 0.1 \\
\hline & & $9>13$ & $6.37 E+03$ & 7.20 & 0.2 \\
\hline & & $12>13$ & $1.51 E+02$ & 0.17 & 0.0 \\
\hline & & $16 \rightarrow 13$ & $7.87 E+02$ & 0.89 & 0.0 \\
\hline & & OTAL IN & $8.85 E+04$ & 100.00 & \\
\hline $80 \%$ & & & FLUX (cu.ft/d) & \% ZN OUT & Normalized \\
\hline & Const & Head & $0.00 E+\infty 0$ & 0.00 & 0.0 \\
\hline & Wells & & $0.00 E+\infty$ & 0.00 & 0.0 \\
\hline & Recha & & $0.00 E+\infty 0$ & 0.00 & 0.0 \\
\hline & Head I & ep. Bnd & $7.11 E+04$ & 80.30 & 25 \\
\hline & Zones & $13>2$ & $0.00 E+\infty 0$ & 0.00 & 0.0 \\
\hline & & $13 \rightarrow 3$ & $0.00 E+\infty 0$ & 0.00 & 0.0 \\
\hline & & $13 \rightarrow 9$ & $3.41 E+03$ & 3.85 & 0.1 \\
\hline & & $13>12$ & $0.00 E+\infty 0$ & 0.00 & 0.0 \\
\hline & & $13>16$ & $1.40 E+04$ & 15.86 & 0.5 \\
\hline & TOT & ALL OUT & $8.85 E+04$ & 100.00 & \\
\hline
\end{tabular}

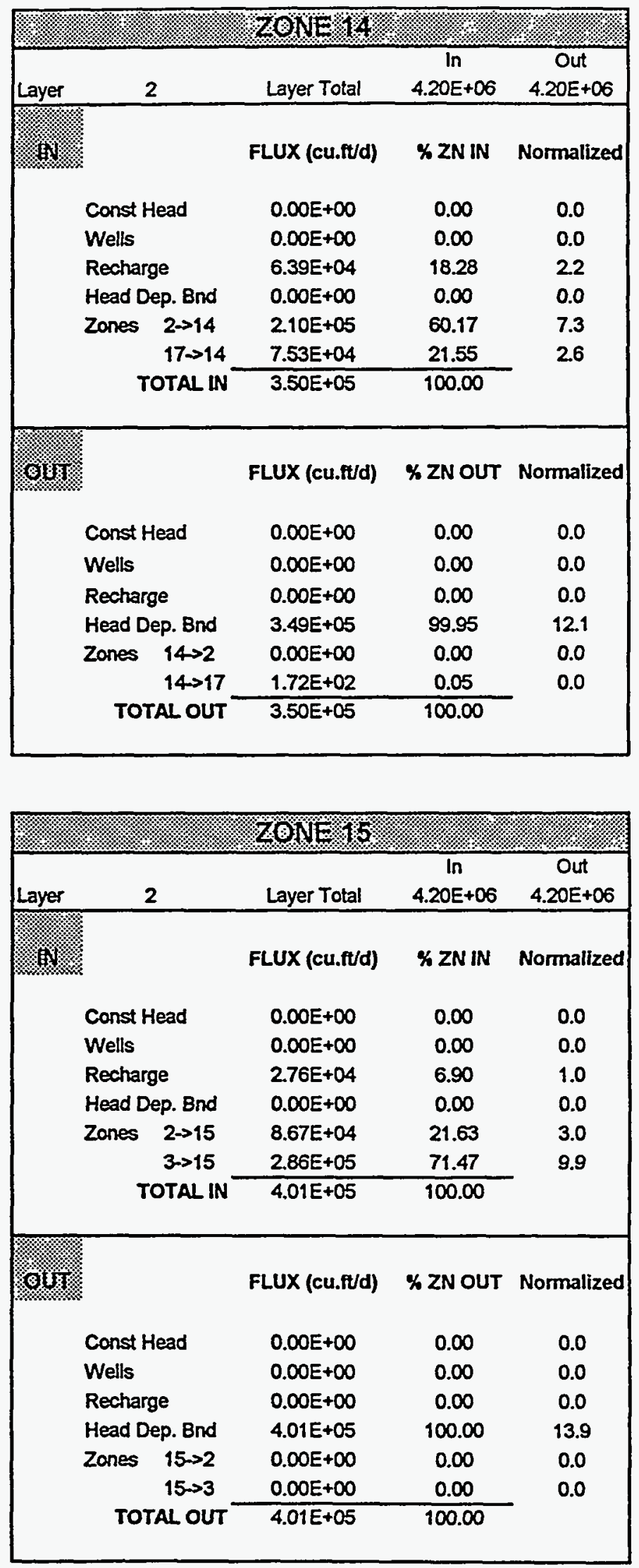




\begin{tabular}{|c|c|c|c|c|c|}
\hline \multicolumn{6}{|c|}{ 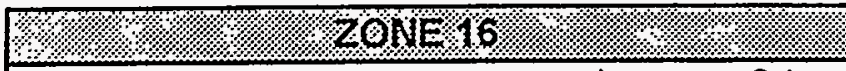 } \\
\hline Layer & \multicolumn{2}{|c|}{ תחמשת } & Layer Total & $\ln _{2.35 E+\infty 6}^{\ln }$ & $\begin{array}{c}\text { Out } \\
2.35 E+06\end{array}$ \\
\hline \multirow[t]{9}{*}{ 絸 } & & FLUX (cu.ft/d) & \% ZN IN & Nomalized \\
\hline & \multicolumn{2}{|c|}{ Const Head } & $0.00 E+\infty$ & 0.00 & 0.0 \\
\hline & \multicolumn{2}{|c|}{ Wells } & $0.00 E+\infty$ & 0.00 & 0.0 \\
\hline & \multicolumn{2}{|c|}{ Recharge } & $0.00 E+00$ & 0.00 & 0.0 \\
\hline & \multicolumn{2}{|c|}{ Head Dep. Bnd } & 1.33E+03 & 2.35 & 0.0 \\
\hline & \multirow[t]{4}{*}{ Zones } & $3 \rightarrow 16$ & 4.14E+04 & 72.92 & 1.4 \\
\hline & & $13>16$ & $1.40 E+04$ & 24.73 & 0.5 \\
\hline & & $19 \rightarrow 16$ & $0.00 E+00$ & 0.00 & 0.0 \\
\hline & & OTAL IN & $5.67 E+04$ & 100.00 & \\
\hline \multirow[t]{9}{*}{$\%$} & & & FLUX (cu.ft/d) & \% ZN OUT & Normalized \\
\hline & \multicolumn{2}{|c|}{ Const Head } & $0.00 E+\infty 0$ & 0.00 & 0.0 \\
\hline & \multicolumn{2}{|c|}{ Wells } & $0.00 E+\infty$ & 0.00 & 0.0 \\
\hline & \multicolumn{2}{|c|}{ Recharge } & $0.00 E+\infty$ & 0.00 & 0.0 \\
\hline & \multicolumn{2}{|c|}{ Head Dep. Bnd } & $5.26 E+04$ & 92.79 & 1.8 \\
\hline & \multirow[t]{3}{*}{ Zones } & $16>3$ & $9.98 E+02$ & 1.76 & 0.0 \\
\hline & & $16->13$ & $7.87 E+02$ & 1.39 & 0.0 \\
\hline & & $16>19$ & 2.31E+03 & 4.06 & 0.1 \\
\hline & Tor & AL OUT & 5.67E+04 & 100.00 & \\
\hline
\end{tabular}

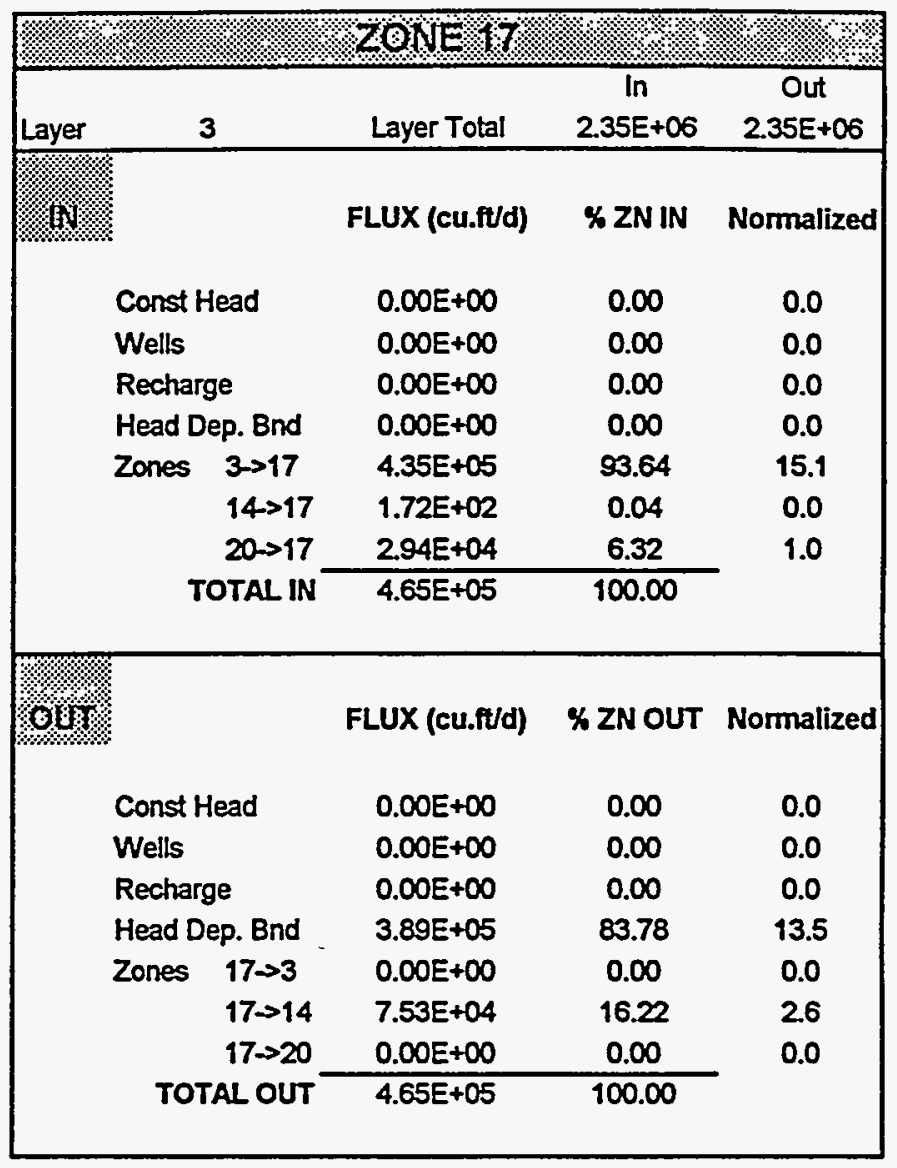

\begin{tabular}{|c|c|c|c|c|}
\hline \%) & א\%א\%" & $40 \mathrm{HE} / 8$ & & \\
\hline Layer & 4 & Layer Total & $\begin{array}{c}\ln \\
1.02 E+06 \\
\end{array}$ & $\begin{array}{c}\text { Out } \\
1.02 E+06 \\
\end{array}$ \\
\hline \multirow[t]{8}{*}{ \% } & & FLUX (cu.ft/d) & $\%$ ZN IN & Normalized \\
\hline & Const Head & $2.40 E+05$ & 89.22 & 8.3 \\
\hline & Wells & $0.00 E+\infty 0$ & 0.00 & 0.0 \\
\hline & Recharge & $0.00 E+\infty$ & 0.00 & 0.0 \\
\hline & Head Dep. Bnd & $0.00 E+\infty$ & 0.00 & 0.0 \\
\hline & Zones $3 \rightarrow 18$ & $4.82 E+03$ & 1.79 & 0.2 \\
\hline & $4>18$ & $2.42 E+04$ & 8.99 & 0.8 \\
\hline & TOTAL IN & $2.69 E+05$ & 100.00 & \\
\hline \multirow[t]{8}{*}{ \%ol\% } & & FLUX (cu.ft/d) & \% ZN OUT & Normalized \\
\hline & Const Head & $2.90 E+04$ & 10.78 & 1.0 \\
\hline & Wells & $0.00 E+\infty$ & 0.00 & 0.0 \\
\hline & Recharge & $0.00 E+\infty$ & 0.00 & 0.0 \\
\hline & Head Dep. Bnd & $0.00 E+\infty 0$ & 0.00 & 0.0 \\
\hline & Zones $18 \rightarrow 3$ & $7.55 E+03$ & 2.81 & 0.3 \\
\hline & $18 \rightarrow 4$ & $2.32 E+05$ & 86.41 & 8.0 \\
\hline & TOTAL OUT & $2.69 E+05$ & 100.00 & \\
\hline
\end{tabular}

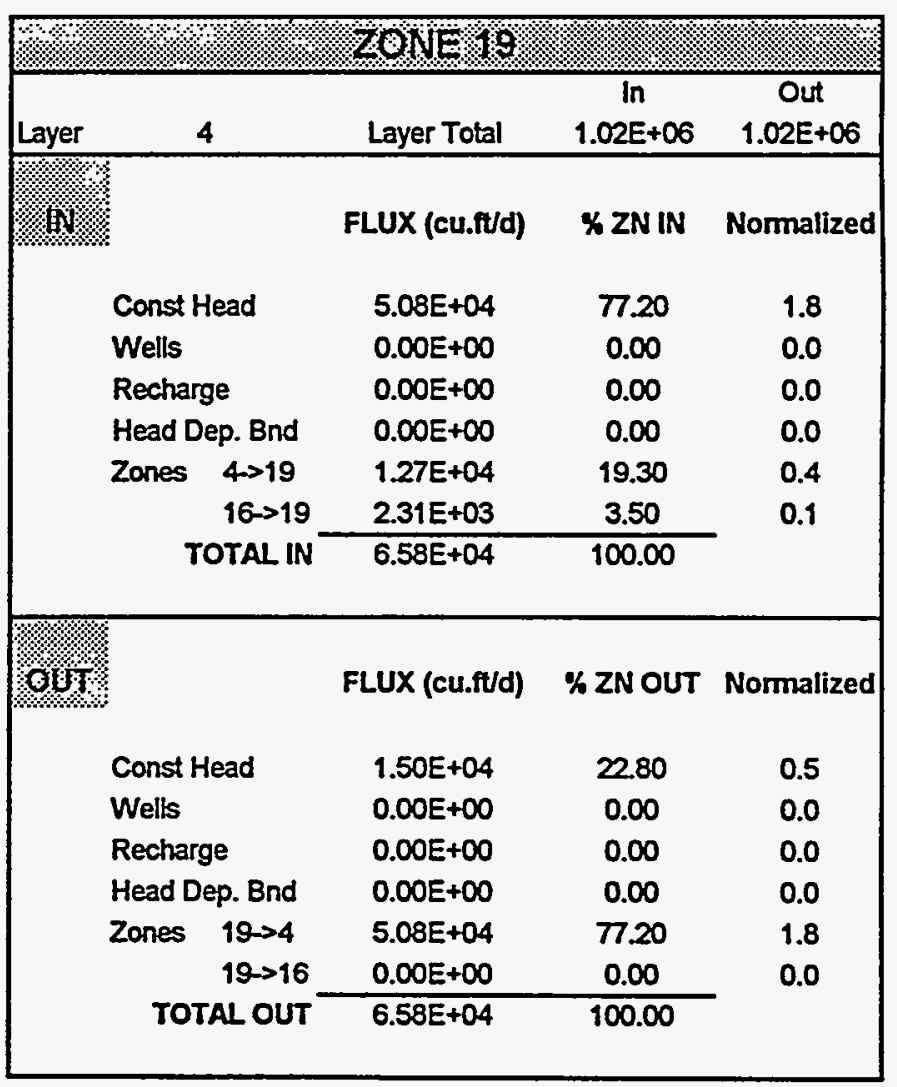




\begin{tabular}{|c|c|c|c|c|c|}
\hline & & & $781)=20$ & & \\
\hline Layer & 2 & & Layer Total & $\ln _{1.02 E+06}^{\ln }$ & $\begin{array}{c}\text { Out } \\
1.02 E+06\end{array}$ \\
\hline \% & & & FLUX (cu.ft/d) & K ZN IN & Normalized \\
\hline & Const I & lead & $1.04 E+05$ & 22.43 & 3.6 \\
\hline & Wells & & $0.00 E+\infty$ & 0.00 & 0.0 \\
\hline & Rechar & & $0.00 E+\infty 0$ & 0.00 & 0.0 \\
\hline & Head D & ep. Bnd & $0.00 E+00$ & 0.00 & 0.0 \\
\hline & Zones & $3 \rightarrow 20$ & $1.16 E+04$ & 2.49 & 0.4 \\
\hline & & $4 \rightarrow 20$ & $3.49 E+05$ & 75.08 & 12.1 \\
\hline & & $17 \rightarrow 20$ & $0.00 E+00$ & 0.00 & 0.0 \\
\hline & & DTAL IN & $4.64 E+05$ & 100.00 & \\
\hline 6 & & & FLUX (cu.ftd) & * ZN OUT & Normalized \\
\hline & Const & lead & $3.60 \mathrm{E}+0.5$ & 77.57 & 12.5 \\
\hline & Wells & & $0.00 E+\infty$ & 0.00 & 0.0 \\
\hline & Rechar & & $0.00 E+\infty$ & 0.00 & 0.0 \\
\hline & Head $\mathrm{C}$ & ep. Bnd & $0.00 E+\infty$ & 0.00 & 0.0 \\
\hline & Zones & $20 \rightarrow 3$ & $1.93 E+04$ & 4.15 & 0.7 \\
\hline & & $20->4$ & $5.55 E+04$ & 11.95 & 1.9 \\
\hline & & $20 \rightarrow 17$ & $2.94 E+04$ & 6.32 & 1.0 \\
\hline & TOT & AL OUT & $4.64 E+05$ & 100.00 & \\
\hline
\end{tabular}

